Review

\title{
Organic-Inorganic Hybrid Polymers as Adsorbents for Removal of Heavy Metal Ions from Solutions: A Review
}

\author{
Babak Samiey ${ }^{1, *, \dagger}$, Chil-Hung Cheng ${ }^{2, *, \dagger}$ and Jiangning Wu ${ }^{2, *, \dagger}$
}

1 Department of Chemistry, Faculty of Science, Lorestan University, Khoramabad 68137-17133, Iran

2 Department of Chemical Engineering, Ryerson University, Toronto, ON M5B 2K3, Canada

$\dagger$ These authors contributed equally to this work.

* Authors to whom correspondence should be addressed; E-Mails: babsamiey@yahoo.com (B.S.); chilhung.cheng@ryerson.ca (C.-H.C.); j3wu@ryerson.ca (J.W.); Tel.: +98-0661-2202782 (B.S.); +1-416-979-5000 (ext. 2131) (C.-H.C.); +1-416-979-5000 (ext. 6549) (J.W.).

Received: 25 November 2013; in revised form: 6 January 2014 / Accepted: 10 January 2014 /

Published: 27 January 2014

\begin{abstract}
Over the past decades, organic-inorganic hybrid polymers have been applied in different fields, including the adsorption of pollutants from wastewater and solid-state separations. In this review, firstly, these compounds are classified. These compounds are prepared by sol-gel method, self-assembly process (mesopores), assembling of nanobuilding blocks (e.g., layered or core-shell compounds) and as interpenetrating networks and hierarchically structures. Lastly, the adsorption characteristics of heavy metals of these materials, including different kinds of functional groups, selectivity of them for heavy metals, effect of $\mathrm{pH}$ and synthesis conditions on adsorption capacity, are studied.
\end{abstract}

Keywords: organic-inorganic hybrid polymer; heavy metal ion; wastewater treatment; adsorption; sol-gel method; self-assembly process; nanobuilding blocks; interpenetrating networks

\section{Introduction}

A wide variety of toxic inorganic and organic chemicals are discharged into the environment as industrial wastes, causing serious water, air, and soil pollution. Water pollution caused by toxic heavy metal ions has become a serious environmental problem. Heavy metals (such as $\mathrm{Pt}, \mathrm{Pd}, \mathrm{Ag}, \mathrm{Cu}, \mathrm{Cd}$, 
$\mathrm{Pb}, \mathrm{Hg}, \mathrm{Ni}, \mathrm{Co}, \mathrm{Zn}$, etc.) are natural constituents of the earth crust and present in the environment as a result of weathering and erosion of parent rocks [1]. In addition to natural sources, they are introduced in ecosystems through wastewaters originating from anthropogenic sources such as chemical manufacturing, metal finishing, welding, alloys manufacturing, painting, mining, extractive metallurgy, plating, tannery and battery industry and using metal-containing fertilizers and pesticides [2].

These toxic metal ions, even at low concentrations, have deteriorated water resources and drinking water and easily accumulated in the human body throughout the food chain, causing a variety of diseases and disorders [3]. So, it is necessary to remove these metal ions from industrial effluents for their subsequent safe disposal.

The removal of heavy metal ions from wastewaters has been a subject of extensive industrial research. At the same time, some of them (e.g., Pt and Au) are precious and can be recycled and reused for extensive applications [4,5]. The recovery of heavy or valuable metals from water or wastewaters can often result in considerable cost savings and have both ecological and economic benefits.

Different methods, such as precipitation [6], solvent extraction [7] chemical and electrochemical techniques [8], ion-exchange methods [9] ultrafiltration [10] and reverse osmosis [11,12], flotation [13] and coagulation [14] have been developed for the removal of toxic metal ions from industrial effluents and wastewaters. However, most of these processes are unacceptable, owing to the disposal of sludge, their high cost, low efficiency and inapplicability to a wide range of pollutants [15].

Adsorption is a well-known separation method and recognized as one of efficient and economic methods for water decontamination applications. In addition, owing to the reversible nature of most adsorption processes, the adsorbents can be regenerated by suitable desorption processes for multiple uses [16], and many desorption processes are of low maintenance cost, high efficiency, and ease of operation [17].

However, the major problem in this field is to select novel types of adsorbents. A number of adsorbents such as activated carbon [18], zeolites [19,20], clays [21,22] and agricultural residues [23-25] have been used for the removal of heavy metal ions. However, the major disadvantages of these adsorbents are their low adsorption capacities, their relatively weak interactions with metallic ions and difficulties of separation and regeneration of some of them from water. Ion-exchange resins can remove metal ions substantially; however, they have low selectivities and show a high degree of swelling combined with poor mechanical stability [26].

To overcome these limitations, more recently, promising organic-inorganic hybrid polymers have been used for the removal of toxic species from wastewater [27-35]. In these compounds, the functional variation of organic materials is combined with advantages of a thermally stable and robust inorganic substrate, resulting in strong binding affinities toward selected metal ions and relatively high metal ion adsorption capacities. Functionalized hybrid polymeric materials as adsorbent are regarded as one of the most effective techniques because metal ions can be chemically bonded by the organic-inorganic polymer hybrids. These kinds of materials often present the best properties of each of its components in a synergic way and have high performances of physical, chemical and mechanical properties [36].

Organic-inorganic hybrid polymeric materials are currently intensely studied [37] for their efficient applications. The intrinsic multifunctional character of these materials makes them potentially useful in multiple fields. Different forms of organic-inorganic hybrids have been intensively studied due to their 
interesting properties resulting in a number of applications such as electroanalytical applications [38], their extensive applications as membranes for ultra-and nanofiltration [39,40], superhydrophobic surfaces [41,42], highly transparent films [43,44], $\mathrm{pH}$ sensitive composites [45], solar cells [46,47], electrolyte [48], molecular shuttles [49], semiconductors [50], gas separation [51,52], catalysts [53], biosensors [54], drug delivery systems [55], coatings for corrosion protection [56], adsorbents of toxic compounds [27-35], Fire retardant polymers [57], biomaterials for osteo-reconstructive surgery [58], materials for telecommunications or information displays [59], etc.

This review describes classifications and synthesis methods of organic-inorganic hybrid polymers and particular attention will be focused on application of them for the adsorption of heavy metals from water as well as their performances and mechanisms.

\section{Classification and Synthesis of Organic-Inorganic Hybrid Polymers}

Organic-inorganic hybrid polymers are classes of materials whose structure includes both organic and inorganic units that interact with each other at the molecular level. These materials are divided into two classes on the basis of interaction between organic and inorganic components. In class I, organic and inorganic are embedded and there are weak interactions, such as hydrogen bonding, van der Waals, $\pi-\pi$ or weak electrostatic interactions between them and in class II, these two components are bonded together through strong covalent or coordinative bonds [37]. Organic-inorganic hybrid polymers are obtained through (1) sol-gel process; (2) self-assembly process; (3) assembling or dispersion of nanobuilding blocks; (4) hierarchical structures [37] and interpenetrating networks [60].

\subsection{Sol-Gel Process}

In 1846, Ebelmanl and Graham reported that the hydrolysis of tetraethylorthosilicate (TEOS), under acidic conditions produced $\mathrm{SiO}_{2}$ in the form of fibres [61,62]. In 1950s, Brady et al. [63] produced a number of phenylsilsesquioxane-alkylsilsesquioxane copolymers that were the first successful commercial organic-inorganic hybrid polymers. The sol-gel process is a cheap and low-temperature method for producing transparent and homogenous solid materials with high purity from small molecules and for controlling the chemical composition of products. Compounds produced by the sol-gel process have many applications in superhydrophobic surfaces [41] (shown in Scheme 1), electrolyte [48], biosensors [54], corrosion protection [56], etc.

This process is carried out in water and organic solvents and its precursors are usually metal halides [64] (in organic solvents) and metal alkoxides such as $\mathrm{Si}(\mathrm{OR})_{4}, \mathrm{SiR}^{\prime}(\mathrm{OR})_{3}, \mathrm{Ti}(\mathrm{OR})_{4}$, etc. [41,65-67] (Scheme 1). As seen in Scheme 2 [68], these materials are subject to a series of hydrolysis (or non-hydrolytic process in organic solvents) and condensation reactions that through nucleophilic substitution mechanisms result in sol formation. Sol is a colloidal solution in which individual particles interact weakly with each other and due to cross-linking reactions, converts into an integrated network (wet gel). This structure with further drying processes converts to gel.

In spite of silicon alkoxides, hydrolysis reactions of other metal alkoxides in water are too fast. The hydrolysis reaction of silicon alkoxides, is typically acid- or base-catalyzed [69]. As reported [70], silica networks formed under acid-catalyzed conditions are dense and those of formed in the presence of base are porous and loose. 
Scheme 1. Schematic superhydrophobic surfaces prepared through the sol-gel derived organic-inorganic hybrid emulsion. Reprinted with permission from [41]. Copyright 2011 Elsevier.

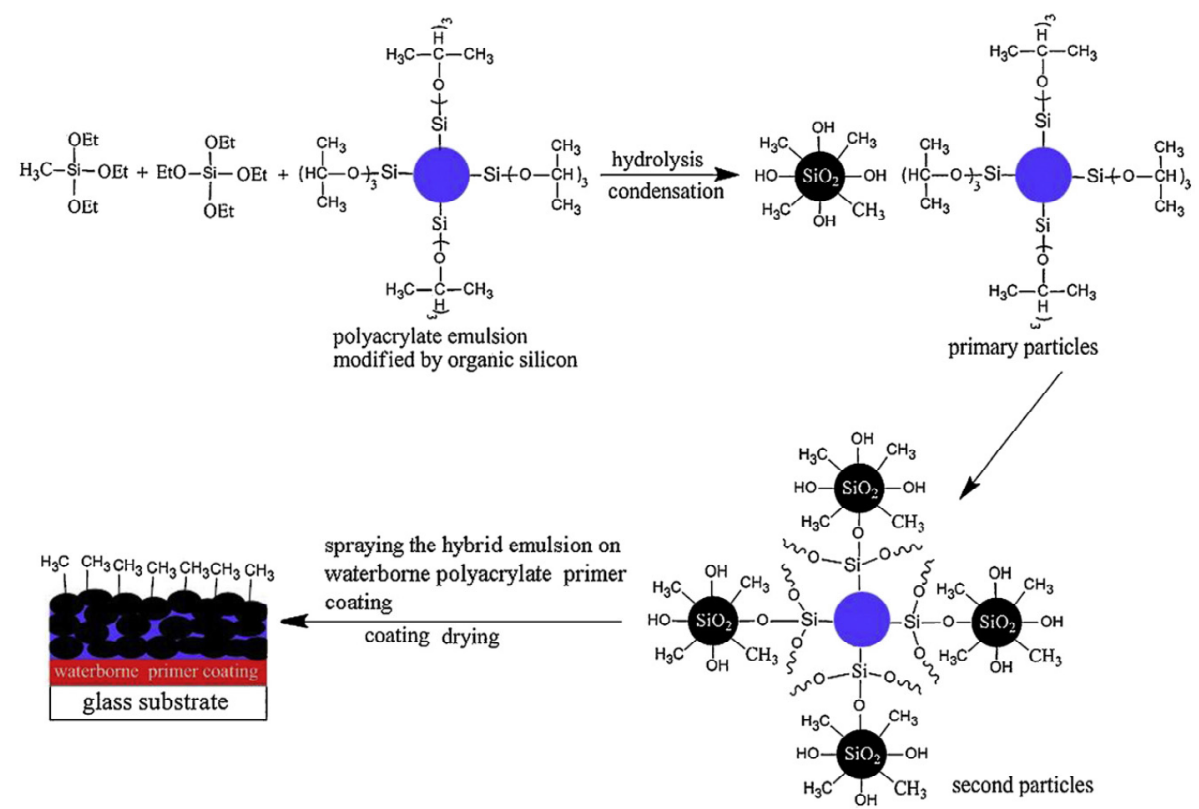

Scheme 2. Description of technologies and products of the sol-gel process [68].

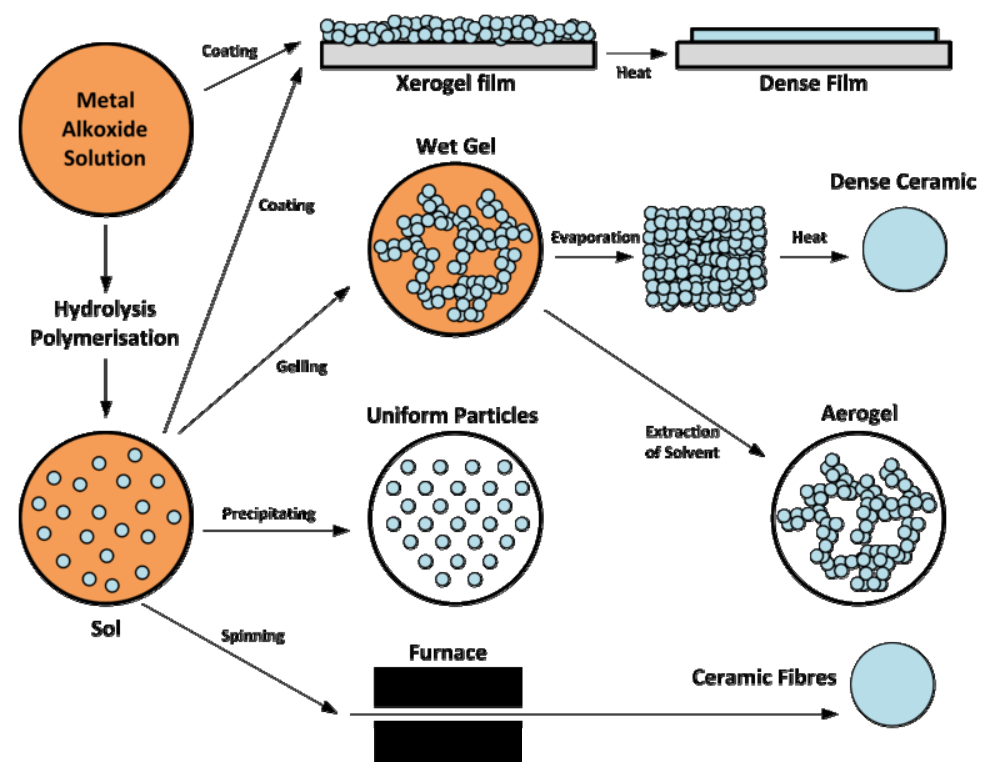

A suitable way for modifications of properties of materials obtained from this method is the introduction of organic groups (R) into their structure [71]. For example, the $\mathrm{Si}-\mathrm{C}$ bond does not hydrolyze in most sol-gel processes and organic groups can be incorporated covalently into the network of inorganic gel using silsesquioxanes $\left[\left(\mathrm{R}-\mathrm{SiO}_{1.5}\right)_{n}(n=\right.$ even number $\left.)\right]$, such as $\mathrm{R}^{\prime}(\mathrm{OR})_{2} \mathrm{Si}-\mathrm{R}-\mathrm{Si}(\mathrm{OR})_{3}$ compounds or derivatives of tetrafunctional silicon alkoxide [organically modified silicates (ORMOSILs)], such as TEOS, $\mathrm{R}^{\prime} \mathrm{Si}(\mathrm{OR})_{3}$, etc. [71]. If an organic group remains stable and does not hydrolyze during sol-gel processes (e.g., alkyl groups) it is defined as a network modifier. On the other hand, if it can react with another monomers or with itself (e.g., $\left.-\mathrm{CH}=\mathrm{CH}_{2}\right)$ it is named as a network builder. Moreover, if it is a reactive functional group, such as $-\mathrm{NH}_{2}$, it is specified 
as a network functionalizer [72] (Scheme 3). These materials belong to class II interactions of organic-inorganic hybrid polymers.

Scheme 3. Organically functionalized trialkoxysilanes, $\mathrm{R}^{\prime} \mathrm{Si}(\mathrm{OR})_{3}$, used as (a) modifier; (b) builder and (c) functionalizer of silica-based network through the sol-gel process. Reproduced with permission from [72]. Copyright 2006 WILEY-VCH Verlag GmbH.

a) Network Modifier:

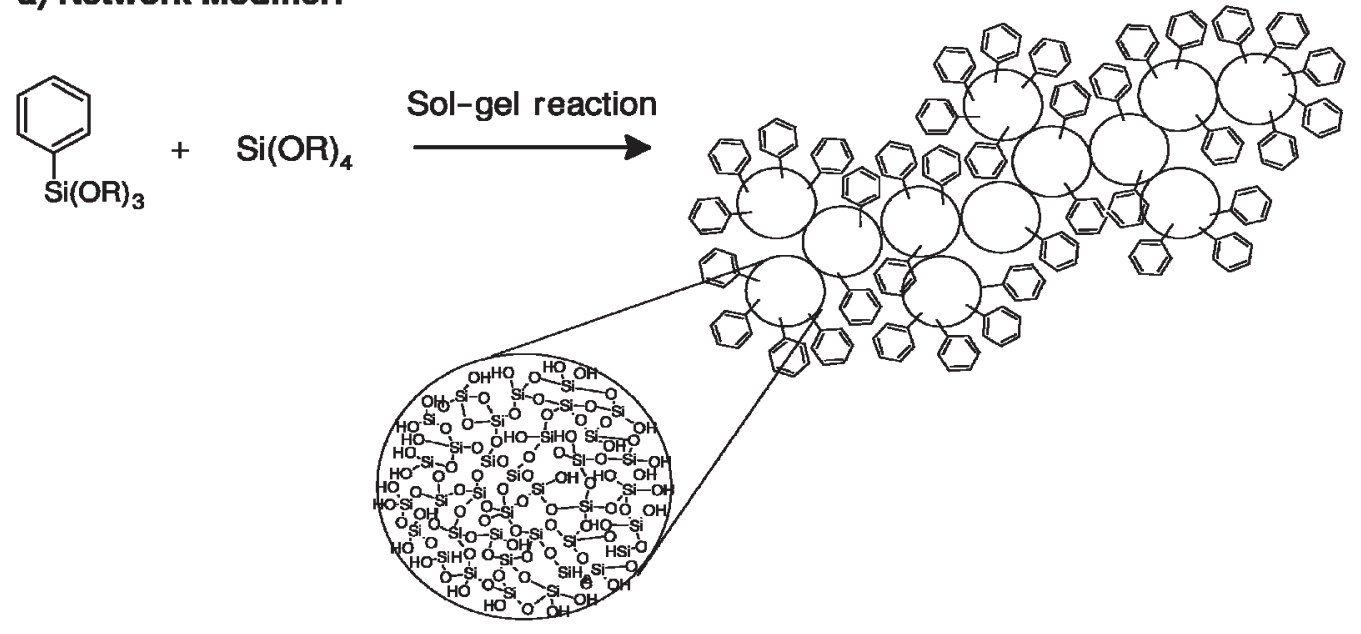

b) Network Builder:
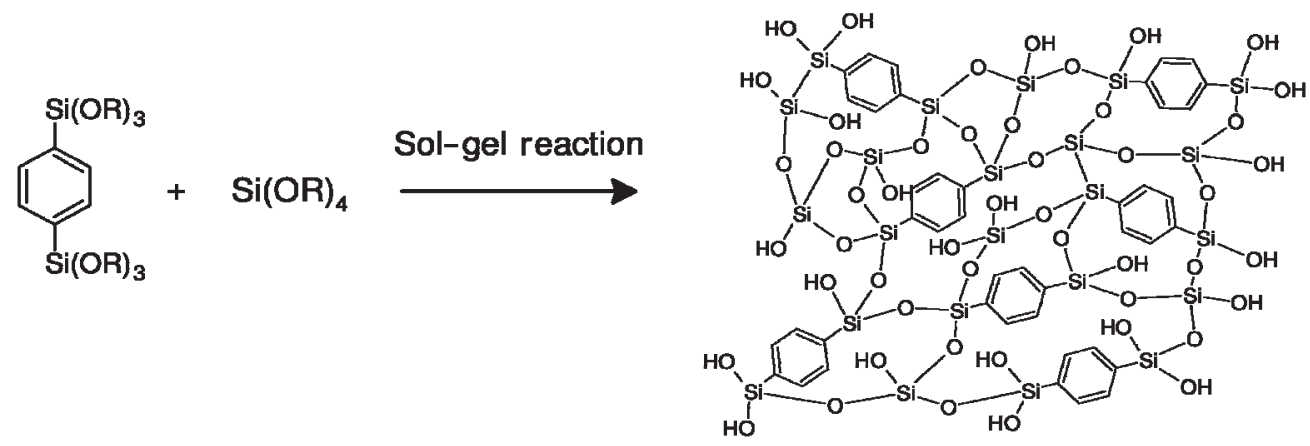

c) Network Functionalizer:

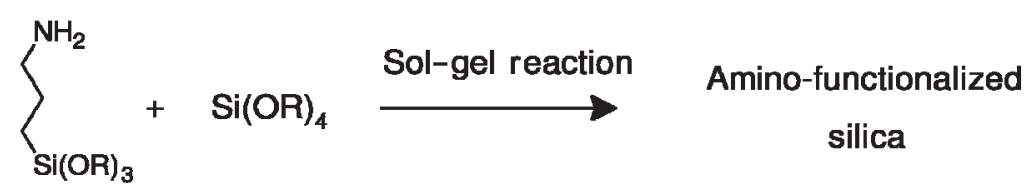

Another example of using sol-gel processes is the synthesis of microporous zeolites (or molecular sieves). These materials are framework aluminosilicate and have a three-dimensional structure with high internal surface area and an ordered crystalline structure [73]. Zeolites with high silica contents are synthesized in the presence of bulky organic alkylammonium cations known as structure-directing agents or templates [74].

Synthetic zeolites are microporous (diameter of their pores $<2 \mathrm{~nm}$ ) and have many applications such as membranes, catalysts, catalyst supports, gas storage, etc. [73]. In recent years, great efforts have been made on the direct preparation of hybrid organic-inorganic zeolites [75,76]. The incorporation of organic moieties within the pores or in the framework of microporous zeolites has developed their catalytic activity [77], molecular sieving property [78] and adsorption capacity [79]. 


\subsection{Self-Assembly Process}

In 1992, researchers of Mobil Oil Company discovered a new type of mesoporous silicas, so-called M41S [80,81]. M41S family includes hexagonal MCM-41, cubic MCM-48, and lamellar MCM-50 [82] (Figure 1). MCM is an abbreviation of "Mobil Crystalline Materials".

Notwithstanding their amorphorous pore walls, these organic-inorganic hybrid compounds exhibit a long-range ordered array of uniform and controllable mesopores with sizes ranging between 2-10 nm [82]. Mesostructure compounds have high specific surface areas (greater than $1000 \mathrm{~m}^{2} / \mathrm{g}$ ) [82] and the pore size of these materials enables them to adsorb much larger molecules than is possible for zeolites. These compounds are used for catalysis [83], gas adsorption [84], etc. M41S type compounds were synthesized using a silica source (e.g., TEOS) in the presence of long-chain alkyltrimethylammonium halide surfactants as templates or structure-directing agents [80]. These compounds formed through a base-catalysed hydrolytic sol-gel process. Mesostructures can be synthesized using different ionic or non-ionic surfactants or water-soluble polymers as templates $[85,86]$. Other types of ordered mesoporous silicas are Santa Barbara Amorphous (SBA) (e.g., SBA-15 [87]), Michigan State University (MSU) (e.g., MSU-2 [88]), folded sheets mechanism (FSM) (e.g., FSM-16 [89]), etc., respectively.

Figure 1. Representation of mesoporous M41S compounds including (a) MCM-41; (b) MCM-48 and (c) MCM-50. Reproduced with permission from [82]. Copyright 1999 WILEY-VCH Verlag GmbH.

a)

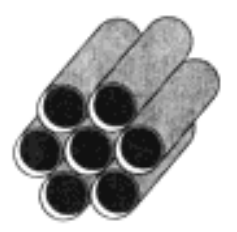

b)

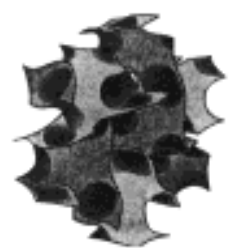

c)

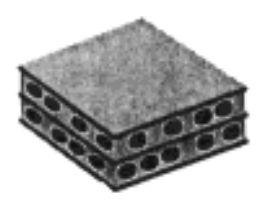

In recent years, attempts of scientists resulted in syntheses of non-silica mesoporous metal oxides such as $\mathrm{TiO}_{2}, \mathrm{ZrO}_{2}, \mathrm{Al}_{2} \mathrm{O}_{3}, \mathrm{Nb}_{2} \mathrm{O}_{5}, \mathrm{SnO}_{2}$, mixed oxides such as $\mathrm{SiAlO}_{3.5}, \mathrm{SiTiO}_{4}$, carbon nanocage, mesoporous carbon nitride, etc. [90]. The formation of mesoporous materials is depicted schematically in Figure 2, based on "liquid crystal templating" mechanism [91]. Through route (a) at surfactant concentrations above its critical micelle concentration (CMC), the self-assembly of precursor molecules on the space between micellar rods of lyotropic liquid crystal phase and creates walls between them. Through route (b) at surfactant concentrations below CMC, the mesostructure is formed as a cooperative self-assembly of the precursor and surfactant molecules [82,91].

To prevent phase separation, there should be attractive interactions between inorganic precursors and template molecules. Depending on reaction conditions, such as $\mathrm{pH}$ and chemicals, e.g., inorganic precursors and templates, six routes have been suggested for syntheses of ordered mesoporous compounds [92]. These routes include (a) $\mathrm{S}^{+} \mathrm{I}^{-}$; (b) $\mathrm{S}^{+} \mathrm{X}^{-} \mathrm{I}^{+}$; (c) $\mathrm{S}^{-} \mathrm{M}^{+} \mathrm{I}^{-}$; (d) $\mathrm{S}^{-} \mathrm{I}^{+}$; (e) $\mathrm{S}^{0} \mathrm{I}^{0}$ or $\mathrm{N}^{0} \mathrm{I}^{0}$ and (f) $\mathrm{S}^{0}(\mathrm{XI})^{0}$ where $\mathrm{S}$ is the surfactant, I is the inorganic phase and $\mathrm{X}^{-}$is a mediator anionic species (usually a halide), $\mathrm{M}^{+}$is a mediator cation, $\mathrm{S}^{0}$ is a neutral amine and $\mathrm{N}^{0}$ is a long-chain non-ionic template. Interactions between the charged inorganic phase and the head group of surfactants in 
routes $(\mathrm{a}-\mathrm{d})$ are mainly electrostatic forces; while those between neutral inorganic species and non-electrolyte template molecules are hydrogen bonds in routes (e) and (f) [92,93] (Figure 3). It is necessary to say that the inorganic precursor is neutral at its isoelectric point (e.g., at $\mathrm{pH} \sim 2$ for silica [94]) and has negative and positive electric charge at $\mathrm{pH}$ above and below this point, respectively.

Figure 2. Synthesis of mesoporous compounds in the presence of template through (A) liquid-crystal template or (B) cooperative liquid-crystal mechanisms. Reprinted with permission from [91]. Copyright 2002 American Chemical Society.

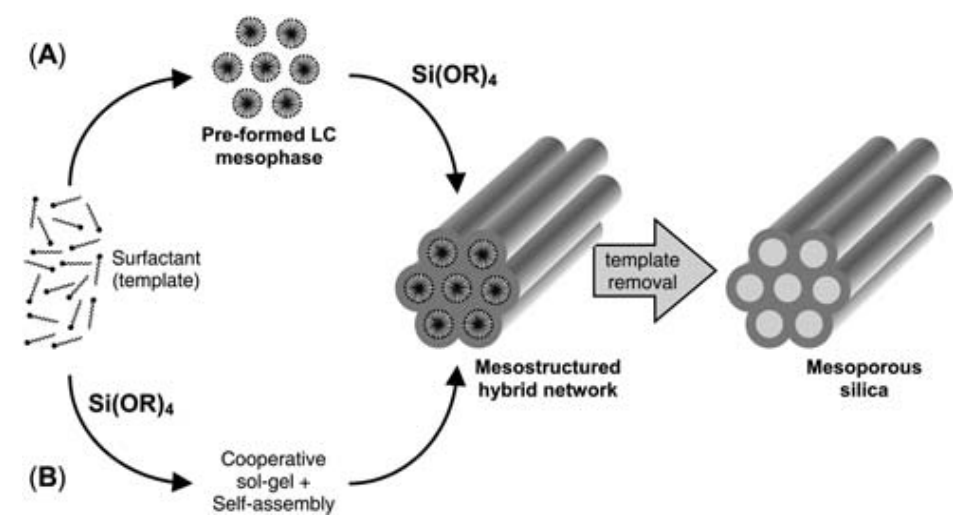

Figure 3. Different kinds of interactions between inorganic species and surfactant head groups through electrostatic interactions in (a) and (c) basic, (b) acidic and (d) neutral media or via hydrogen bonds between (e) unchared species or (f) ion pairs. Reproduced with permission from [93]. Copyright 2006 WILEY-VCH Verlag GmbH.
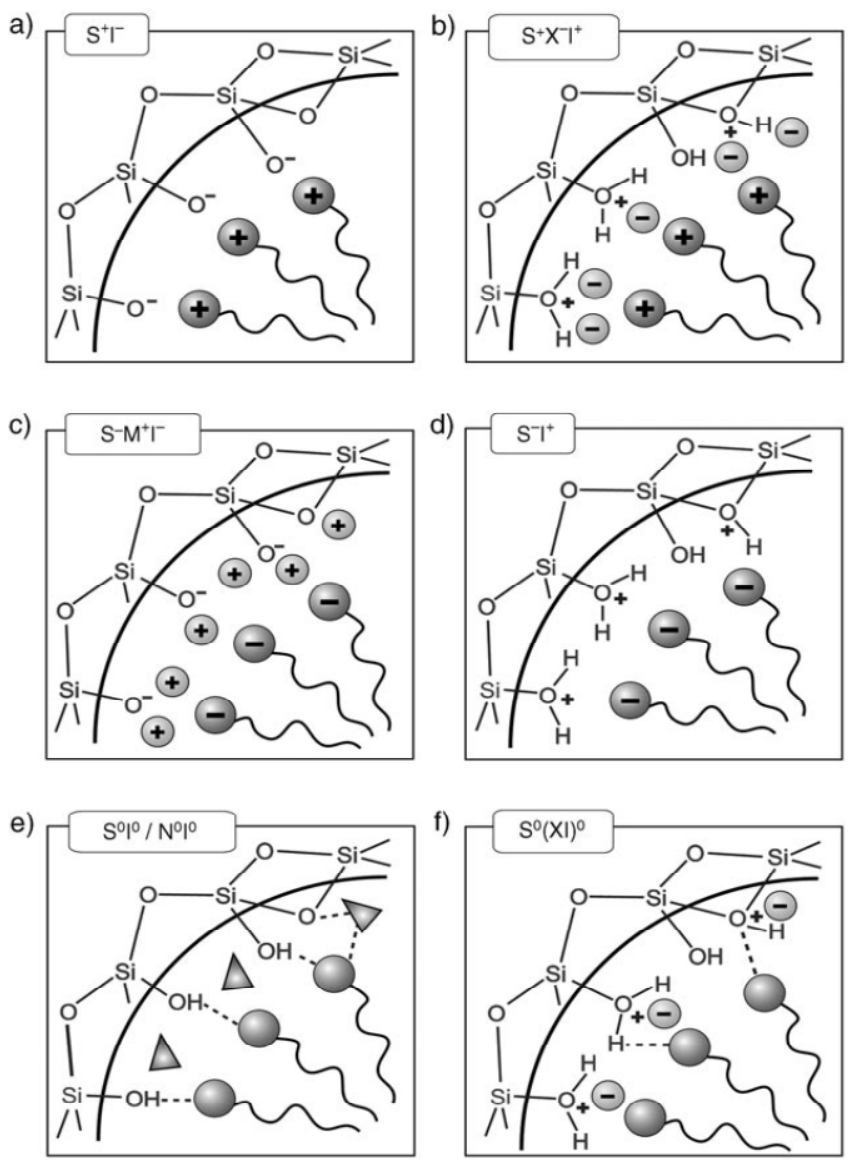
In recent years, mesoporous silicas have been used as supports for preparations of organic-inorganic hybrid polymers and have many applications in lasers [95], drug delivery [96], pollutant adsorption [36], etc. In these compounds, different organic functional groups are located on the robust, thermally stable and porous inorganic substrate.

As illustrated in Figure 4, these organosilica compounds are prepared through (a) grafting or post-synthetic functionalisation; (b) co-condensation or one-pot synthesis and (c) synthesis of periodic mesoporous organosilicas (PMOs) [93,97,98]. In grafting processes, an organosilica is synthesized through condensation reaction between $\mathrm{Si}-\mathrm{OH}$ groups of the pore walls of mesoporous silica and appropriate reagents such as, chlorosilanes (e.g., $\left.\mathrm{ClSiR}_{3}\right)$, alkoxyorganosilanes [e.g., $\mathrm{RSi}\left(\mathrm{OR}^{\prime}\right)_{3}$ ] etc. In the co-condensation method, an organosilica compound is prepared in one step through co-condensation reactions of tetraalkoxysilanes (e.g., TEOS) and an appropriate reagent (e.g., terminal trialkoxyorganosilanes) in the presence of a template. Syntheses of PMOs are carried out through the hydrolysis and condensation of bridged organosilane precursors of the type $\left(\mathrm{R}^{\prime} \mathrm{O}\right)_{3} \mathrm{Si}-\mathrm{R}-\mathrm{Si}(\mathrm{OR})_{3}$ in the presence of a structure-directing agent. In this method, $\mathrm{R}$ organic group are incorporated uniformly and periodically in the pore walls of resulted organosilica $[93,98]$.

Figure 4. Different methods for the synthesis of organic-inorganic hybrid mesoporous silica: 1. Grafting, 2. Co-condensation or in situ grafting and 3. Periodic mesoporous silica. Reproduced wity permissiom from [93]. Copyright 2006 WILEY-VCH Verlag GmbH.

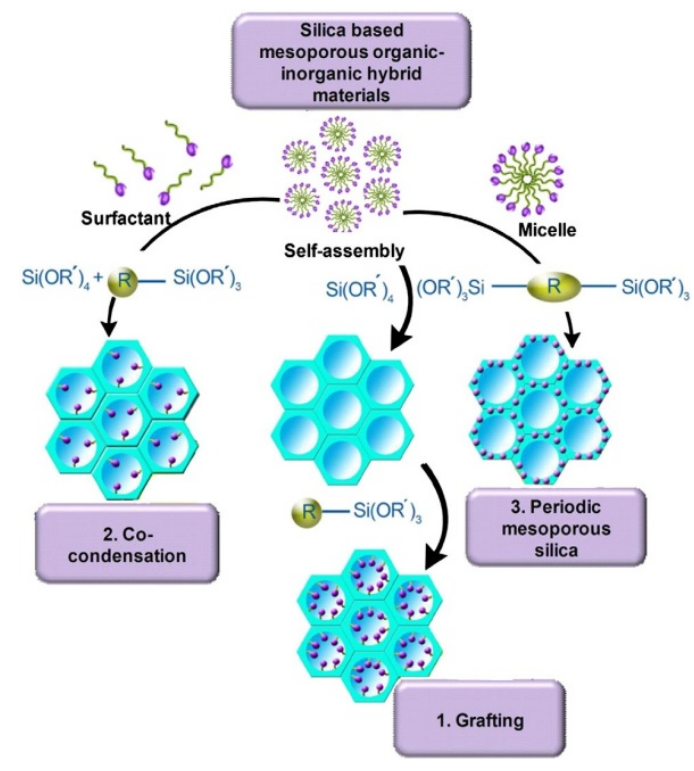

\subsection{Assembling or Dispersion of Nanobuilding Blocks (NBBs)}

The interest in nanoscale materials originates from this fact that their properties are a function of their size, composition, and structural order. Here, a series of compounds called as nanobuilding blocks (NBBs) are used for preparing organic-inorganic hybrid polymers. NBBs are capped with polymerizable ligands or connected through organic spacers, e.g., telechelic molecules or functional dendrimers [37]. These compounds maintain their integrity and fulfill certain (chemical or physical) functions in the final material. NBBs are classified as (1) clusters; (2) organically in situ- or post-functionalized nanoparticles; (3) layered compounds and (4) core-shell nanocompounds [37,99]. 


\subsubsection{Clusters}

Metallic clusters (e.g., polyoxometalates) are an ensemble of bound atoms and contain a group of two or more metal atoms that bind together by direct Metal-Metal bonding. Clusters are connected either (1) by the polymerization of their ligands (e.g., allyl) and are called cross-linked clusters or (2) by coordinative bonds between coordinating groups of organic ligands (called as a linker or spacer) to each metal center (called as a connector) of clusters [100,101]. In the latter case, a linker is a bi-, trior tetradentate organic ligand (e.g., 1,4-benzenedicarboxylate) with an organic spacer between coordinating groups [102]. For example, a one-dimensional polymer is built when a metal cluster links to just one coordinating group of two bidentate organic linkers and through them links to other metal clusters. Coordination of more than two coordinating groups to each metal center, optionally through tri- or tetradentate linkers, results in two- or three-dimensional polymers [100]. The three-dimensional polymers are called metal-organic frameworks (MOFs) and their metal centers are bridged in three dimensions (Supporting information Figure S1). MOFs along with cross-linked clusters are major types of cluster-based organic-inorganic hybrid polymers [103,104].

\subsubsection{Organically in Situ- or Post-Functionalized Nanoparticles}

In this method reactive organic groups are bound to the surface of inorganic moiety by strong ionic or covalent interactions. These organic groups are either grafted to preformed nanoparticles (called as post-functionalization) [105] or are incorporated during the synthesis of nanoparticles (called as in-situ-functionalization) [106]. This method is used for metal oxides (e.g., $\mathrm{TiO}_{2}$ [107]), chalcogenides (e.g., CdSe [108]), metallic nanoparticles (e.g., $\mathrm{Au}$ [109]) and polyoxometalates (e.g., $\left.\gamma-\left[\mathrm{SiW}_{10} \mathrm{O}_{36}\right]^{8-}[110]\right)$, etc.

\subsubsection{Layered Compounds}

To improve the physical properties of polymers, inorganic compounds physically are dispersed in them (as fillers) in various forms such as platelets, spheres, fibers, etc. If the size of discrete inorganic components is in the range of $1-100 \mathrm{~nm}$, the resulted organic-inorganic compound is called a nanocomposite [111]. Organic-inorganic hybrid nanocomposites are either as interpenetrating networks which will be explained in Section 2.4 [99] or layered inorganic components embedded into the organic matrix.

Layered compounds are regular stacks of two-dimensional inorganic constituent. These compounds such as clay, are used as fillers in organic-inorganic hybrid composites. Some examples of nanocomposites are polyaniline-montmorillonite [112], polyaniline- $\mathrm{V}_{2} \mathrm{O}_{5}$ [113], polyvinyl alcohol-layered double hydroxide (LDH) [114], poly-N-vinyl carbazole-graphene oxide [115], etc. These compounds are incorporated in organic polymers as (a) a phase-separated structure in which the polymer can not intercalate within the inorganic layers and the inorganic component is dispersed as aggregates or particles within the polymer matrix; (b) an intercalated structure in which one or more polymer chains are inserted into the galleries (space between layers) of inorganic components and subsequently increase the interlayer spacing and (c) an exfoliated structure in which the insertion of polymer chains between inorganic sheets delaminates the layered compound [116] (Figure 5). 
Polymers can be intercalated to layered compounds by (1) solution; (2) melting polymers and (3) in situ polymerization of intercalated monomers [99]. However, some compounds (e.g., EDTA and malate) intercalate layer compounds $[117,118]$ are purly nanocomposites and not organic-inorganic hybrid polymers.

Figure 5. Schematic representation of different kinds of composites produced from interaction of layer compound with polymers: (a) phase separated; (b) intercalated and (c) exfoliated structures. Reprinted with permission from [116]. Copyright 2000 Elsevier.

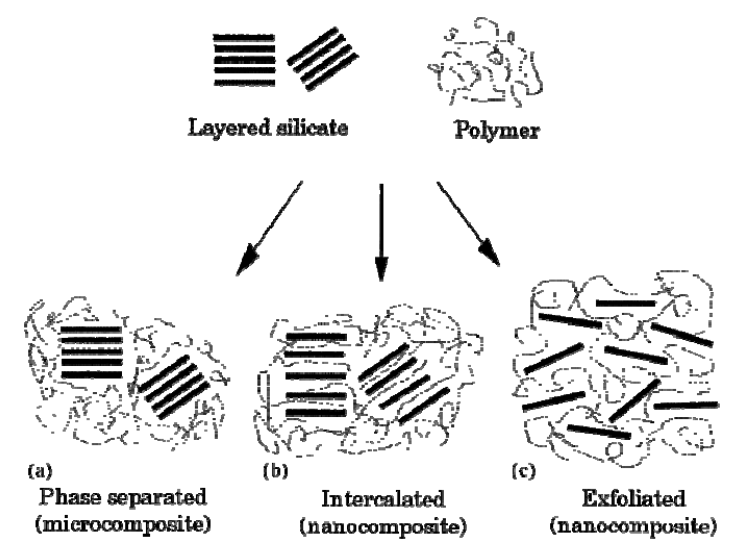

\subsubsection{Core-Shell Nanocomposites}

Core-shell nanocomposites (CSNs) consist of a core region covered by a shell domain (Figure 6). A series of CSNs are polymer-coated inorganic compounds [119-121]. The encapsulation of an inorganic particles in a polymer shell are carried out through (1) the adsorption of monomers on the surface of inorganic moiety followed by their polymerization in the adsorbed layer [122,123] and (2) interaction of inorganic particle with preformed polymer as in situ growing inorganic components in a polymer matrix [124]. CSNs are also shown as core@shell. Some kinds of CSNs are completely inorganic in nature (e.g., $\left.\mathrm{CdS} @ \mathrm{TiO}_{2}[125]\right)$.

Figure 6. TEM of polystyrene-coated $\mathrm{Fe}_{2} \mathrm{O}_{3}$ particles. The polymer coatings are seen as a shell around the $\mathrm{Fe}_{2} \mathrm{O}_{3}$ cores. Reprinted with permission from [122]. Copyright 2003 American Chemical Society.

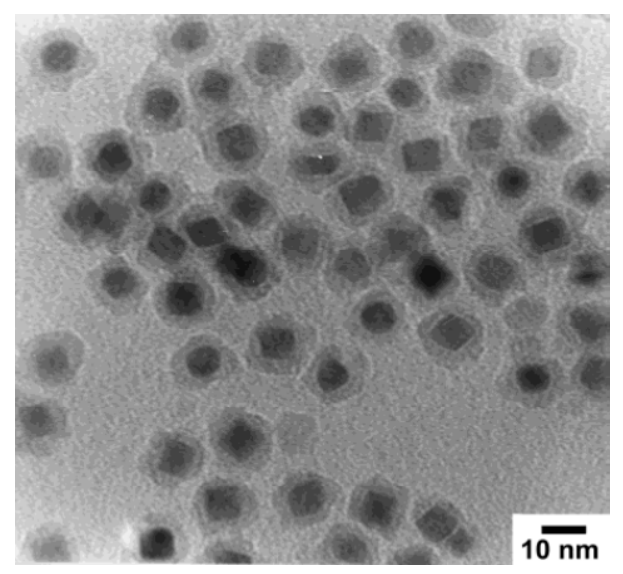




\subsubsection{Hierarchical Structures}

A hierarchy is a feature of self-assembly, where primary building blocks associate into more complex structures which are integrated into the next size level in the hierarchy. Self-assembly is emerging as an elegant, "bottom-up" method for the construction of nanostructured materials and is distinct from the template-directed assembly [126]. The feature of an integrated chemical, biological, etc. system is the assembly of components into a specific architecture that performs a certain function. Many examples of hierarchical structural designs are seen in nature and are characteristic of many self-assembling biological structures (e.g., lobster cuticle [127] and tendon [128]) (Figure 7).

Figure 7. Hierarchical structure of lobster cuticle. Reproduced with permission from [127]. Copyright 2010 WILEY-VCH Verlag GmbH.

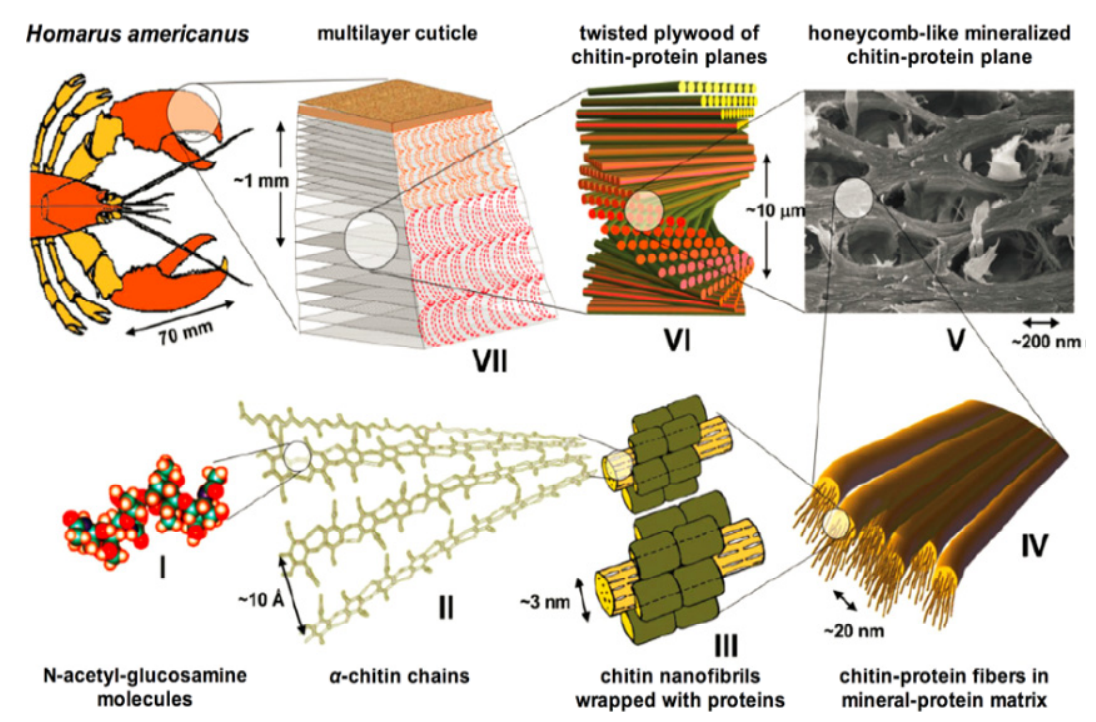

Also, the hierarchy has resulted in the discovery of versatile nanoparticles with many applications [129], synthetic bone implant materials [130], mesostructured solid electrolytes [131], $\mathrm{TiO}_{2}$-graphene composite [132], etc. For example, the incorporation of interconnected macropores in mesoporous films of $\mathrm{TiO}_{2}$-graphene composite (Supporting information Figure S2) augments the capacity of composite film for adsorption and photodegrading organic molecules and can be used for the treatment of waters.

\subsection{Interpenetrating Networks (IPNs)}

IPNs comprise organic and inorganic networks that are microscopically phase-separated. However, they seem uniform macroscopically and there are weak interactions between moieties of IPNs (class I interactions). These components are partially interlaced and, upon separating IPNs, chemical bonds are broken. IPNs are synthesized by (1) the formation of a secondary network in a primary one (a sequential two-step process); (2) the simultaneous formation of two networks and (3) IPN components connect to each other through covalent bonds in which the compound is named a dual organic-inorganic hybrid polymer (class II interactions) [99] (Figure 8). In the first method, IPNs are prepared by polymerization in a sol-gel network [133] or sol-gel process in the presence of preformed polymer [134]. In the third case, either bifunctional precursors are used or a preformed inorganic or 
organic polymer are functionalized by the required functional groups for the formation of other types of networks [135].

But, when three-dimensional frameworks such as zeolites or mesoporous silicates, are used as inorganic components and polymer is formed without crosslinking, the polymer chains could be partially or completely removed from the product. In this case, the composite is called pseudo-interpenetrating polymer network (PIPN) [136,137].

At the end of this section, it is noteworthy that the inclusion of metals in organic-inorganic hybrid polymers occurs at the molecular scale and the incorporation of metal complexes and metallic ions in polymers by coordination interactions does not produce organic-inorganic hybrid polymers [99]. For example, metal-centered polymers [138] and products of coordination of metallic ions to the polymer backbone [139] and polymerization of metal-coordinated monomers [140] are called metal-containing polymers [99].

Figure 8. Schematic representation of IPNs (a) without chemical bonds between moieties and (b) dual hybrid network. Reprinted with permission from [99]. Copyright 2003 Elsevier.

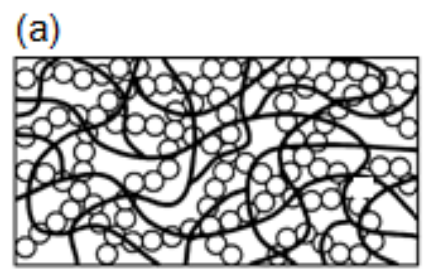

(b)

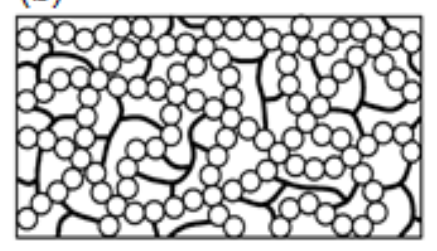

\section{Removal of Heavy Metals by Organic-Inorganic Hybrid Polymers}

Based on the classifications of these kinds of compounds in the previous section, by analysis some comprehensive references, we study their synthesis methods, structure and mechanisms of heavy metal adsorption from water or wastewater.

\subsection{Adsorption of Heavy Metals Using Materials Synthesized from Sol-Gel Method}

As extensive researches have been done on producing silica-based compounds by the sol-gel method, these kinds of materials are discussed here. These compounds can be synthesized either directly through polymerization reaction of their precursors [141] or grafting appropriate functional groups on parent materials formed from sol-gel method such as silica gel and some examples [142-167] are given in Table 1.

Zwitterionic hybrid polymers [142,143] were synthesized on the basis of ring-opening polymerization of pyromellitic acid dianhydride (PMDA) (a network builder) and phenylaminomethyl trimethoxysilane (PAMTMS), followed by the amination (Scheme 4). 
Table 1. Chemicals used for synthesizing adsorbents by sol-gel method, adsorbed heavy metals, maximum adsorption capacity, $\mathrm{pH}$ and temperature for adsorption of heavy metals from waters.

\begin{tabular}{|c|c|c|c|}
\hline Chemicals (interacting group) & Heavy metal $\left[q_{\max }, \mathrm{pH}\right.$ and $\left.t\left({ }^{\circ} \mathrm{C}\right)\right]$ & Isotherm & Reference \\
\hline $\begin{array}{l}\text { Pyromellitic acid dianhydride/phenylaminomethyl } \\
\text { trimethoxysilane }(-\mathrm{COOH})\end{array}$ & $\mathrm{Pb}^{2+}(7.16 \mathrm{mmol} / \mathrm{g}, 5$, room $)$ & Langmuir & [142] \\
\hline Pyromellitic acid dianhydride/phenylaminomethyl & $\mathrm{Cu}^{2+}(0.28 \mathrm{mmol} / \mathrm{g}, 4$, room $)$ & Langmuir & \\
\hline trimethoxysilane $(-\mathrm{COOH})$ & $\mathrm{Pb}^{2+}(1.56 \mathrm{mmol} / \mathrm{g}, 5$, room $)$ & Langmuir & [143] \\
\hline 3-Thiocyanatopropyltriethoxysilane/TEOS (-SH) & $\mathrm{Cd}^{2+}(87.7 \mathrm{mg} / \mathrm{g}, 5,25)$ & Langmuir & {$[144]$} \\
\hline $\begin{array}{l}\text { 3-[2-(2-Aminoethylamino)ethylamino]propyl-trimethoxysilane } \\
\left(\mathrm{Cd}^{2+}-\text { imprinted hybrid sorbent }\right)\left(-\mathrm{NH}_{2}\right)\end{array}$ & $\mathrm{Cd}^{2+}(77.2 \mathrm{mg} / \mathrm{g}, 6,25)$ & Langmuir & [145] \\
\hline $\mathrm{Cd}^{2+}$-imprinted mercapto-functionalized silica gel (-SH) & $\mathrm{Cd}^{2+}(83.89 \mathrm{mg} / \mathrm{g}, 6,27)$ & Experimental & [146] \\
\hline Non-imprinted mercapto-functionalized silica gel $(-\mathrm{SH})$ & $\mathrm{Cd}^{2+}(35.91 \mathrm{mg} / \mathrm{g}, 6,27)$ & Experimental & - \\
\hline $\mathrm{Fe}^{3+}$-imprinted cyanato-functionalized silica gel $(-\mathrm{C} \equiv \mathrm{N})$ & $\mathrm{Fe}^{3+}(35.6 \mathrm{mg} / \mathrm{g}, 3,20)$ & Experimental & [147] \\
\hline $\begin{array}{l}\text { 3-Glycidyloxypropyltrimethoxysilane/potassium tert-butoxide/titanium } \\
\text { isopropoxide (oxygen atoms of adsorbent) }\end{array}$ & $\begin{array}{l}\mathrm{Pb}^{2+}(181.2 \mathrm{mg} / \mathrm{g}, 5.5, \text { room }) \\
\mathrm{Cu}^{2+}(44.64 \mathrm{mg} / \mathrm{g}, 5.5, \text { room }) \\
\mathrm{Cd}^{2+}(35.84 \mathrm{mg} / \mathrm{g}, 5.5, \text { room })\end{array}$ & $\begin{array}{l}\text { Langmuir } \\
\text { Langmuir } \\
\text { Langmuir }\end{array}$ & [148] \\
\hline $\mathrm{Zr}\left(\mathrm{OCH}_{2} \mathrm{CH}_{2} \mathrm{CH}_{3}\right)_{4} / 3$-mercapto-1-propanesulfonic acid (-SH) & $\begin{array}{l}\mathrm{Pb}^{2+}(0.36 \mathrm{mmol} / \mathrm{g} \text {, neutral, room }) \\
\mathrm{Hg}^{2+}(0.87 \mathrm{mmol} / \mathrm{g}, \text { neutral, room })\end{array}$ & $\begin{array}{l}\text { Experimental } \\
\text { Experimental }\end{array}$ & [149] \\
\hline $\mathrm{Ti}\left(\mathrm{OCH}_{2} \mathrm{CH}_{2} \mathrm{CH}_{3}\right)_{4} / 3$-mercapto-1-propanesulfonic acid (-SH) & $\begin{array}{l}\mathrm{Pb}^{2+}(1.24 \mathrm{mmol} / \mathrm{g} \text {, neutral, room }) \\
\mathrm{Hg}^{2+}(1.41 \mathrm{mmol} / \mathrm{g}, \text { neutral, room })\end{array}$ & $\begin{array}{l}\text { Experimental } \\
\text { Experimental }\end{array}$ & - \\
\hline 7-Amine-4-aza-heptyltrimethoxisilane/TEOS (amine group) & $\mathrm{Pb}^{2+}(36.64 \mathrm{mg} / \mathrm{g}$, neutral, room $)$ & Langmuir & {$[150]$} \\
\hline 10-Amine-4-aza-decyltrimethoxisilane/TEOS (amine group) & $\mathrm{Pb}^{2+}(30.27 \mathrm{mg} / \mathrm{g}$, neutral, room $)$ & Langmuir & - \\
\hline 3-Chloropropyltrimethoxysilane/TEOS (nitrogen center of sorbent) & $\mathrm{Ni}^{2+}(0.47 \mathrm{mmol} / \mathrm{g}, 4.5$, room $)$ & Langmuir & {$[151]$} \\
\hline 3-Aminopropyl triethoxysilane/TEOS $\left(-\mathrm{NH}_{2}\right)$ & $\begin{array}{l}\mathrm{Pb}^{2+}(45.45 \mathrm{mg} / \mathrm{g}, 6,25) \\
\mathrm{Cu}^{2+}(35.71 \mathrm{mg} / \mathrm{g}, 6,25)\end{array}$ & $\begin{array}{l}\text { Langmuir } \\
\text { Langmuir }\end{array}$ & {$[152]$} \\
\hline 3-Chloropropyltrimethoxysilane/TEOS (nitrogen center of sorbent) & $\mathrm{Mn}^{2+}(0.35 \mathrm{mmol} / \mathrm{g}, 4.5$, room $)$ & Langmuir & - \\
\hline $\begin{array}{l}\text { Amino-terminated dendrimer-like PAMAM polymer/silica gel } \\
\text { (amino content } 1.91 \mathrm{mmol} / \mathrm{g})\left(-\mathrm{NH}-\text { and }-\mathrm{NH}_{2}\right)\end{array}$ & $\mathrm{Cu}^{2+}(78.7 \mathrm{mg} / \mathrm{g}$, ethanolic, 25$)$ & Langmuir & [153] \\
\hline $\begin{array}{l}\text { 2-Aminoethyl-3-aminopropyltrimethoxysilane/ } \\
\text { poly(dimethyl siloxane) }\left(-\mathrm{NH} / \mathrm{NH}_{2}\right)\end{array}$ & $\begin{array}{l}\mathrm{Cu}^{2+}(1.2 \mathrm{mmol} / \mathrm{g} \text {, ethanolic, } 25) \\
\mathrm{Ni}^{2+}(0.37 \mathrm{mmol} / \mathrm{g} \text {, ethanolic, } 25) \\
\mathrm{Fe}^{3+}(1.3 \mathrm{mmol} / \mathrm{g} \text {, ethanolic, } 25)\end{array}$ & Langmuir & [154] \\
\hline Bis[3-(triethoxysilyl)propyl]disulfide/TEOS (-S-S-) & $\begin{array}{l}\mathrm{Cd}^{2+}(26.8 \mathrm{mg} / \mathrm{g}, 6,25) \\
\mathrm{Pb}^{2+}(56.7 \mathrm{mg} / \mathrm{g}, 6,25) \\
\mathrm{Cu}^{2+}(13.3 \mathrm{mg} / \mathrm{g}, 6,25)\end{array}$ & $\begin{array}{l}\text { Langmuir } \\
\text { Langmuir } \\
\text { Langmuir }\end{array}$ & {$[155]$} \\
\hline Salen $\left(\mathrm{NEt}_{2}\right)_{2} /$ silica gel $\left(-\mathrm{OH}\right.$ and $\left.-\mathrm{N}\left(\mathrm{C}_{2} \mathrm{H}_{5}\right)_{2}\right)$ & $\begin{array}{l}\mathrm{Cu}^{2+}(4.36 \mathrm{mg} / \mathrm{g}, 11, \text { room }) \\
\mathrm{Mn}^{2+}(2.34 \mathrm{mg} / \mathrm{g}, 11, \text { room }) \\
\mathrm{Pb}^{2+}(10.06 \mathrm{mg} / \mathrm{g}, 11, \text { rom }) \\
\mathrm{Zn}^{2+}(11.3 \mathrm{mg} / \mathrm{g}, 11, \text { room })\end{array}$ & $\begin{array}{l}\text { Langmuir } \\
\text { Langmuir } \\
\text { Langmuir } \\
\text { Langmuir }\end{array}$ & {$[156]$} \\
\hline $\begin{array}{l}\text { 2-Acrylamido-2-methylpropanesulfonic acid/silica gel } \\
\left(-\mathrm{OH},-\mathrm{NH}-\text { and }-\mathrm{SO}_{3} \mathrm{H}\right)\end{array}$ & $\mathrm{Cu}^{2+}(0.66 \mathrm{mmol} / \mathrm{g}$, ethanolic, 25$)$ & Langmuir & {$[157]$} \\
\hline Amino-terminated dendrimer-like polyamidoamine polymer/silica gel $\left(-\mathrm{NH}_{2}\right)$ & $\begin{array}{l}\mathrm{Pd}^{2+}(0.7 \mathrm{mmol} / \mathrm{g}, \text { neutral, room }) \\
\mathrm{Pt}^{4+}(0.41 \mathrm{mmol} / \mathrm{g}, \text { neutral, room }) \\
\mathrm{Au}^{3+}(0.12 \mathrm{mmol} / \mathrm{g}, \text { neutral, room })\end{array}$ & $\begin{array}{l}\text { Experimental } \\
\text { Experimental } \\
\text { Experimental }\end{array}$ & [158] \\
\hline Polyethylene glycol/3-mercaptopropyl trimethoxysilane (-SH) & $\mathrm{Cu}^{2+}(0.4 \mathrm{mmol} / \mathrm{g}, 4,40)$ & Langmuir & {$[159]$} \\
\hline Polyvinilalcohol/3-(2-aminoethylamino)propyl trimethoxysilane $\left(-\mathrm{NH} / \mathrm{NH}_{2}\right)$ & $\mathrm{Pb}^{2+}(67.6 \mathrm{mg} / \mathrm{g}, 5,30)$ & Langmuir & {$[160]$} \\
\hline
\end{tabular}


Table 1. Cont.

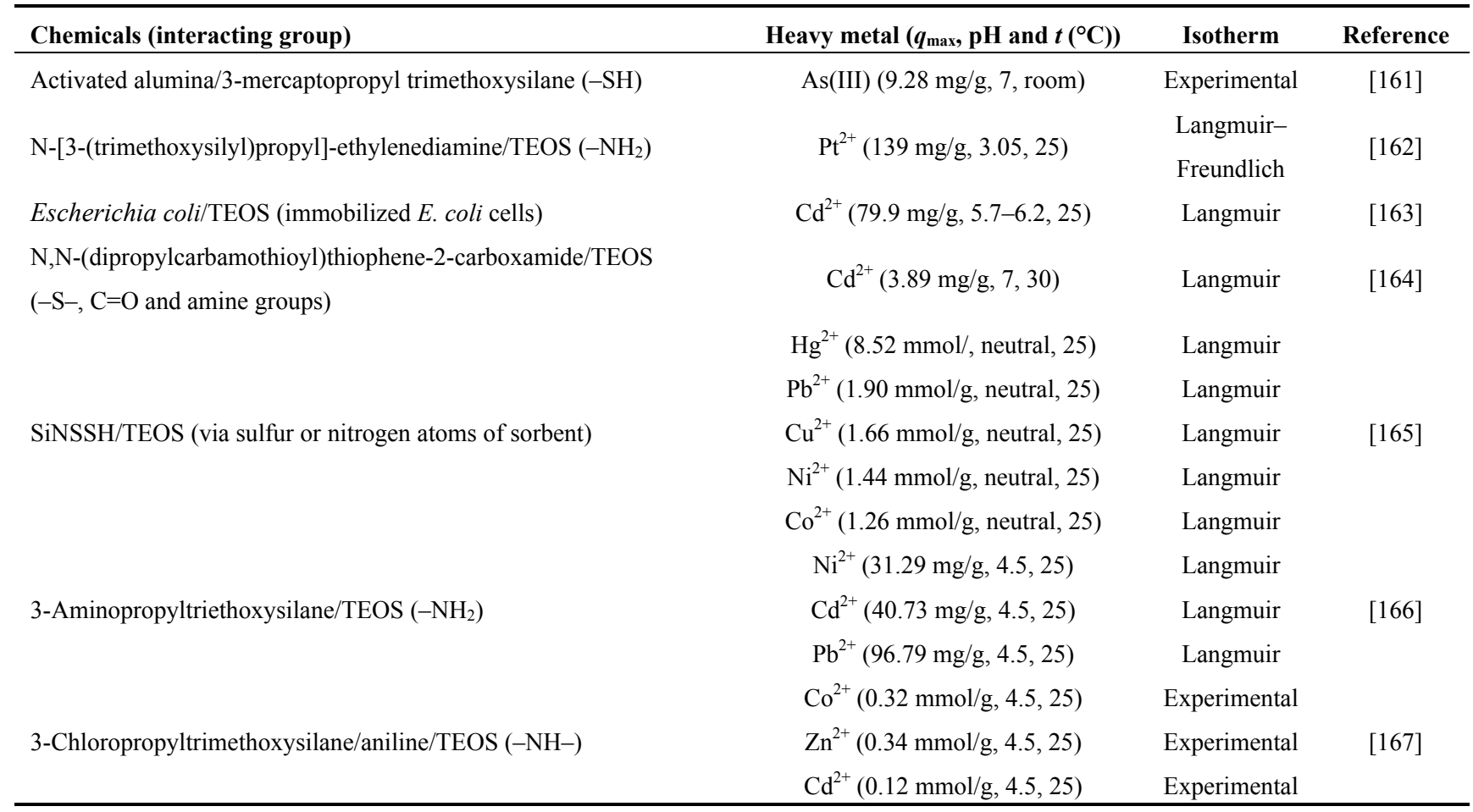

Ionic groups of opposite charges on the polymer chain (quaternary amines and carboxylic groups) allowed their electrostatic interactions with heavy metals. TGA analysis showed a higher PDMA content of prepared samples, increased their thermal degradation temperature [143].

Scheme 4. The preparation steps of zwitterionic hybrid polymers. Reprinted with permission from [142]. Copyright 2010 Elsevier.

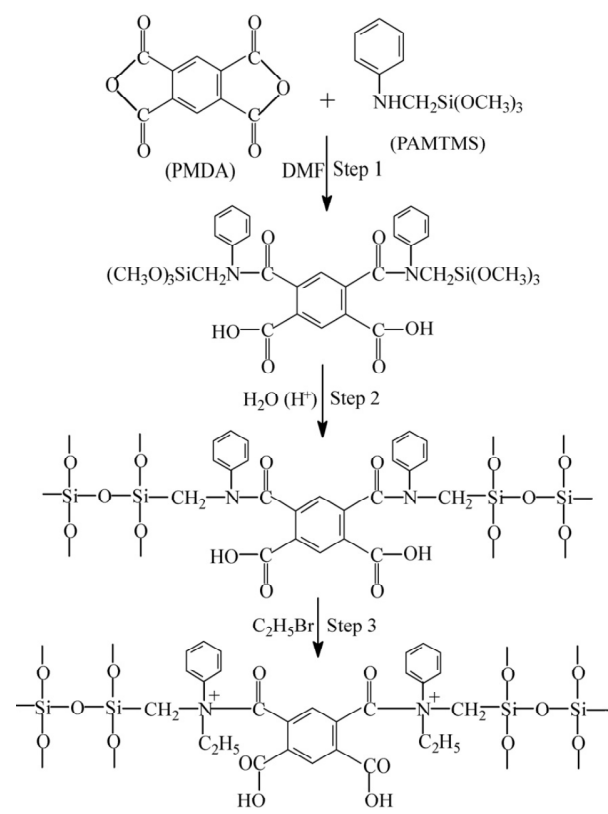

Kinetics experiments showed about $80 \%$ of $\mathrm{Pb}^{2+}$ and $\mathrm{Cu}^{2+}$ ions were adsorbed after approximately $3 \mathrm{~h}$. Kinetics and thermodynamics measurements of $\mathrm{Cu}^{2+}$ and $\mathrm{Pb}^{2+}$ were carried out at $\mathrm{pH}=4$ and 5, respectively in which these metal ions exist mainly as their free forms. 
Some researchers prepared imprinted ionic polymers (IIPs) for adsorption of metal ions [144-147]. IIPs were prepared by either the functionalization of a support surface (e.g., silica gel) using an organic chelating group and subsequently imprinted with metal ions as a template or by the co-condensation of monomers containing functional groups (in the presence of metal ions) and then co-condensation of them by sol-gel processes and finally releasing metal ion from the prepared compound. For example, thiocyanato- [144] and amino-functionalized [145] monomers were used to synthesize $\mathrm{Cd}^{2+}$-imprinted polymers. These compounds showed high adsorption capacity and high selectivity toward templating ions.

SEM images of $\mathrm{Cd}^{2+}$-imprinted and non-imprinted amino-functionalized hybrid polymers show that the former exhibits the porous feature [145]. The amino-functionalized $\mathrm{Cd}^{2+}$-imprinted adsorbent [145] had rough surface and smaller size and thus larger surface area $\left(152 \mathrm{~m}^{2} / \mathrm{g}\right)$, compared to its non-imprinted form $\left(101 \mathrm{~m}^{2} / \mathrm{g}\right)$. Optimum $\mathrm{pHs}$ for the adsorption of $\mathrm{Cd}^{2+}$ were in the range of 4-8 where adsorption sites were deporotonated and $\mathrm{Cd}^{2+}$ ions were not hydroxilated. Kinetics experiments showed that the saturation of these sites was after about $20 \mathrm{~min}$. The $q_{\max }$ (maximum adsorption capacity) value for the adsorption of $\mathrm{Cd}^{2+}$ on adsorbent was $77.2 \mathrm{mg} / \mathrm{g}$. An IIP synthesized using mercapto-functionalized monomers [146] was applied for the separation of $\mathrm{Cd}^{2+}$ from $\mathrm{Ni}^{2+}, \mathrm{Cu}^{2+}$ and $\mathrm{Zn}^{2+}$ that have similar ionic radii. The relative selective factor values of $\mathrm{Cd}^{2+} / \mathrm{Ni}^{2+}, \mathrm{Cd}^{2+} / \mathrm{Cu}^{2+}$ and $\mathrm{Cd}^{2+} / \mathrm{Zn}^{2+}$ (imprinted relative to non-imprinted) were 41.687, 65.617 and 66.937, respectively. The $q_{\text {max }}$ values for the adsorption of $\mathrm{Cd}^{2+}$ on $\mathrm{Cd}^{2+}$-imprinted and non-imprinted adsorbents were 83.89 and $35.91 \mathrm{mg} / \mathrm{g}$, respectively which were due to larger surface area of $\mathrm{Cd}^{2+}$-imprinted adsorbent and its selectivity toward $\mathrm{Cd}^{2+}$.

For a $\mathrm{Fe}^{3+}$-imprinted adsorbent [147] prepared by grafting silica gel with cyanato functional groups, the $q_{\max }$, optimum $\mathrm{pH}$, and the time for the equilibrium binding of $\mathrm{Fe}^{3+}$ on the $\mathrm{Fe}^{3+}$-imprinted adsorbent were $35.6 \mathrm{mg} / \mathrm{g}, 3$ and $20 \mathrm{~min}$, respectively. The selective coefficient values of $\mathrm{Fe}^{3+} / \mathrm{Co}^{2+}, \mathrm{Fe}^{3+} / \mathrm{Pb}^{2+}$, $\mathrm{Fe}^{3+} / \mathrm{Cd}^{2+}$ and $\mathrm{Fe}^{3+} / \mathrm{Ni}^{2+}$ of the $\mathrm{Fe}^{3+}$-imprinted adsorbent were 11.95, 50.71, 16.96 and 8.56 times greater than those of a non-imprinted adsorbent, respectively. Due to the high affinity of these functional groups for $\mathrm{Fe}^{3+}$ and $\mathrm{Cd}^{2+}$, the adsorption rate in these kinds of adsorbents is rapid. As reported by a number of authors [144-147], they washed the used imprinted adsorbents with $3 \mathrm{M} \mathrm{HCl}$ and reused the regenerated adsorbent repeatedly without significant loss of adsorption capacity.

Some researchers are interested in synthesizing silicon and metal containing compounds [148,149] which one of them is poly-GPTS/Ti(O)OH [148]. Poly-GPTS is prepared from the hydrolysis of 3-glycidyloxypropyltrimethoxysilane (GPTS) and poly-GPTS/Ti(O)OH from the hydrolysis of poly-GPTS and titanium isopropoxide, respecyively (Scheme 5).

Scheme 5. Silicon and titanium-contained adsorbent. Reprinted with permission from [148]. Copyright 2013 Taylor and Francis.

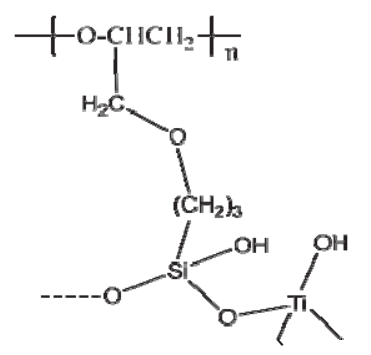


According to the kinetics experiments, the adsorption equilibrium was attained after about $10 \mathrm{~min}$. Their experiments showed that at $\mathrm{pH} \approx 5.5, \mathrm{~Pb}^{2+}, \mathrm{Cu}^{2+}$ and $\mathrm{Cd}^{2+}$ interact with oxygen atoms of $-\mathrm{OH}$ groups of these adsorbents. Authors believed that due to stronger interactions between metal ions and -OH groups of poly-GPTS/Ti(O)OH, the $q_{\text {max }}$ values for the adsorption of $\mathrm{Pb}^{2+}, \mathrm{Cu}^{2+}$ and $\mathrm{Cd}^{2+}$ on poly-GPTS/Ti(O)OH (199, 42.79 and $39.41 \mathrm{mg} / \mathrm{g}$, respectively) were bigger than those of poly-GPTS.

Another example of metal containing compounds is a series of macroporous thiol-functionalized titania and zirconia frameworks with propyl-siloxane, ethyl-sulfonate and propyl-sulfonate linkages [149] (Figure 9). The $q_{\max }$ values for the adsorption of $\mathrm{Pb}^{2+}$ and $\mathrm{Hg}^{2+}$ were in the ranges of $0.27-0.82$ and $0.33-1.41 \mathrm{mmol} / \mathrm{g}$, respectively.

Figure 9. (a) Scheme of macroporous thiol-titania material with propyl-siloxane linkages and (b) its SEM image. Reproduced with permission from [149]. Copyright 2002 The Royal Society of Chemistry.

(a)
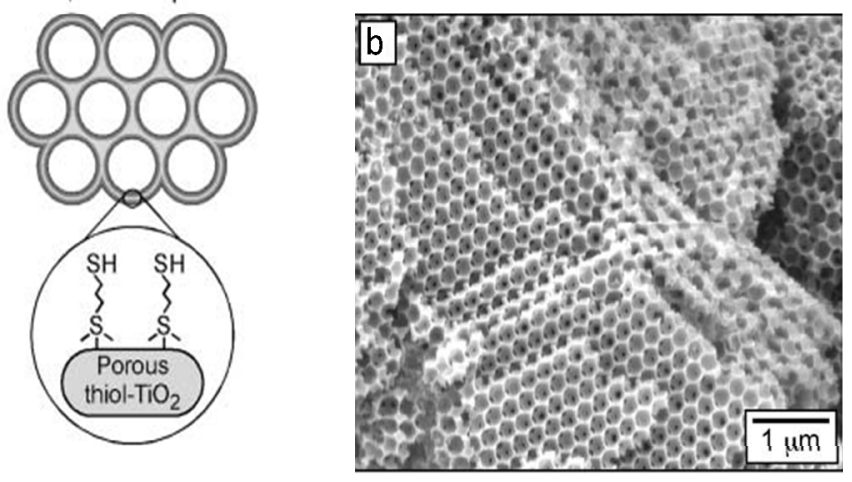

The ratio of adsorbed moles of $\mathrm{Hg}^{2+}$ and $\mathrm{Pb}^{2+}$ per mole of - $\mathrm{SH}$ groups (or their adsorption efficiency) were in the ranges of $0.19-0.82$ and $0.21-0.72$, respectively. This showed that the inner surface of these compounds were not completely accessible for these metal ions and had a smaller $q_{\max }$ value for $\mathrm{Pb}^{2+}$ compared to that of Poly-GPTS.

Xerogels [150,151] and aerogels [152] have been used for the adsorption of heavy metals [150,151]. Lima et al. [150] used mesoporous 7-amine-4-azahepthylsilica and 10-amine-4-azadecylsilica xerogels (abbreviated as AAH-Si and AAD-Si, respectively) for the adsorption of $\mathrm{Pb}^{2+}$ on which silica gels were functionalized with $-\left(\mathrm{CH}_{2}\right)_{3}-\mathrm{NH}-\left(\mathrm{CH}_{2}\right)_{3}-\mathrm{NH}_{2}$ and $-\left(\mathrm{CH}_{2}\right)_{3}-\mathrm{NH}-\left(\mathrm{CH}_{2}\right)_{6}-\mathrm{NH}_{2}$ groups, respectively. $\mathrm{AAH}-\mathrm{Si}$ and $\mathrm{AAD}-\mathrm{Si}$ interacted with $\mathrm{Pb}^{2+}$ through their amine groups and $q_{\text {max }}$ values for the adsorption of $\mathrm{Pb}^{2+}$ on $\mathrm{AAH}-\mathrm{Si}$ and $\mathrm{AAD}-\mathrm{Si}$ were 36.64 and $30.27 \mathrm{mg} / \mathrm{g}$, respectively and the equilibrium time of process was about $120 \mathrm{~min}$. The higher adsorption capacity of AAH-Si over AAD-Si was due to the ability of $\mathrm{AAH}-\mathrm{Si}$ to form a stable six-member ring with $\mathrm{Pb}^{2+}$ whereas AAD-Si was expected to form a nine-member ring that shows a transannular strain. In another work, an aniline-functionalized silica xerogel [151] was used for adsorption of $\mathrm{Ni}^{2+}$ and $\mathrm{Mn}^{2+}$ at $\mathrm{pH} 4-5$. The adsorption equilibrium was achieved after about 20 and $30 \mathrm{~min}$ for $\mathrm{Ni}^{2+}$ and $\mathrm{Mn}^{2+}$, respectively. The enthalpies of adsorption, obtained from calorimetric measurements, showed that weak interactions occur between xerogel and metal ions. It implied that the steric hindrance of phenyl group limits the accessibility of amine groups towards metal ions. Similar to above-mentioned xerogels, an amino 
propyl-modified aerogel used for adsorption of $\mathrm{Pb}^{2+}$ and $\mathrm{Cd}^{2+}$ [152]. However, in spite of xerogels, the equilibrium time was $24 \mathrm{~h}$.

Some efforts were done for the separation of metal ions from ethanol [153,154]. Qu et al. [153] investigated it through functionalization of silica gel using a series of amino-terminated dendrimer-like polyamidoamine (PAMAM) polymers. This process was endothermic and the $\mathrm{Cu}^{2+}$ adsorption capacities of these compounds with different amino contents were in the range of $9.8-78.7 \mathrm{mg} / \mathrm{g}$. Kinetic experiments showed its adsorption equilibrium time was about $10 \mathrm{~h}$. Pissetti et al. [154] synthesized an ethylenediamine-modified poly(dimethylsiloxane) elastomeric network (Pen) for the adsorption of $\mathrm{Cu}^{2+}, \mathrm{Fe}^{3+}$ and $\mathrm{Ni}^{2+}$ from ethanol. In these compounds, the ethylenediamine functional groups were located at the nodes of the networks constituted by silsesquioxane clusters. The nodes of the polymeric network were constituted of clusters rich in $\mathrm{CSi}(\mathrm{OSi})_{3}$ units. The interacting groups of this polymer were amine groups too (Supporting information Figure S3). Also, characteristics of a number of adsorbents [155-167] prepared by sol-gel method, have been given in Table 1.

\subsection{Adsorption of Heavy Metals on Organically-Functionalized Mesoporous Compounds}

In this section, adsorption capacities and operation conditions of silica-based mesopores are studied. As referred in Section 2.2, these compounds are synthesized through grafting, co-condensation or in situ grafting of mesopores and by synthesis of periodic mesoporous silicas. Details of a number of examples [168-198] are given in Table 2. One characteristic of mesoporous compounds is their high surface area. For example, it was shown that [168] when under similar conditions SBA-16 mesoporous compound was used or preparation of organic-inorganic hybrid compounds, its $q_{\max }$ values for adsorption of $\mathrm{Cu}^{2+}$ and $\mathrm{Co}^{2+}$ were higher than those of adsorbent prepared by silica gel.

Table 2. Adsorbed heavy metals, maximum adsorption capacity, $\mathrm{pH}$ and temperature for adsorption of heavy metals by mesoporous compounds.

\begin{tabular}{|c|c|c|c|}
\hline Adsorbent (interacting group) & Heavy metal $\left(q_{\max }, \mathrm{pH}\right.$ and $\left.t\left({ }^{\circ} \mathrm{C}\right)\right)$ & Isotherm & Reference \\
\hline SBA-16 modified with n-propyl-salicylaldimine $\left(-\mathrm{NH}_{2}\right)$ & $\begin{array}{l}\mathrm{Cu}^{2+}(58 \mathrm{mg} / \mathrm{g}, 4, \text { room }) \\
\mathrm{Co}^{2+}(16 \mathrm{mg} / \mathrm{g}, 4, \text { room })\end{array}$ & $\begin{array}{l}\text { Experimental } \\
\text { Experimental }\end{array}$ & {$[168]$} \\
\hline $\begin{array}{l}\text { SBA-16 modified with n-propyl-salicylaldimine and } \\
\text { salicylaldehyde }(-\mathrm{N}=)\end{array}$ & $\begin{array}{l}\mathrm{Cu}^{2+}(15.2 \mathrm{mg} / \mathrm{g}, 4, \text { room }) \\
\mathrm{Co}^{2+}(4.5 \mathrm{mg} / \mathrm{g}, 4, \text { room })\end{array}$ & $\begin{array}{l}\text { Experimental } \\
\text { Experimental }\end{array}$ & - \\
\hline $\mathrm{SiO}_{2}$ modified with n-propyl-salicylaldimine $\left(-\mathrm{NH}_{2}\right)$ & $\begin{array}{l}\mathrm{Cu}^{2+}(45.2 \mathrm{mg} / \mathrm{g}, 4, \text { room }) \\
\mathrm{Co}^{2+}(11.2 \mathrm{mg} / \mathrm{g}, 4, \text { room })\end{array}$ & $\begin{array}{l}\text { Experimental } \\
\text { Experimental }\end{array}$ & - \\
\hline $\begin{array}{l}\mathrm{SiO}_{2} \text { modified with n-propyl-salicylaldimine and } \\
\text { salicylaldehyde }(-\mathrm{N}=)\end{array}$ & $\begin{array}{l}\mathrm{Cu}^{2+}(10.2 \mathrm{mg} / \mathrm{g}, 4, \text { room }) \\
\mathrm{Co}^{2+}(3.6 \mathrm{mg} / \mathrm{g}, 4, \text { room })\end{array}$ & $\begin{array}{l}\text { Experimental } \\
\text { Experimental }\end{array}$ & - \\
\hline 3-Aminopropyl-functionalized MCM-41 (ammonium group) & $\begin{array}{l}\text { Arsenate }(64.4 \mathrm{mg} / \mathrm{g}, 3-4, \text { room }) \\
\text { Chromate }(52.9 \mathrm{mg} / \mathrm{g}, 7-8, \text { room })\end{array}$ & $\begin{array}{l}\text { Experimental } \\
\text { Experimental }\end{array}$ & [169] \\
\hline 3-Aminopropyl-functionalized SBA-1 (ammonium group) & $\begin{array}{l}\text { Arsenate (94.2 mg/g, 3-4,room) } \\
\text { Chromate (132.7 mg/g, 7-8,room) }\end{array}$ & $\begin{array}{l}\text { Experimental } \\
\text { Experimental }\end{array}$ & - \\
\hline $\mathrm{H}_{2} \mathrm{~N}-\left(\mathrm{CH}_{2}\right)_{2}-\mathrm{NH}-\left(\mathrm{CH}_{2}\right)_{3}-$ functionalized SBA-15 $\left(-\mathrm{NH}_{2}\right.$ and $\left.-\mathrm{NH}-\right)$ & $\mathrm{Cu}^{2+}(0.83 \mathrm{mmol} / \mathrm{g}$, neutral, 25$)$ & Langmuir & {$[170]$} \\
\hline 3-Aminopropyl-functionalized SBA-15-N-C-H $\left(-\mathrm{NH}_{2}\right)$ & $\mathrm{Cu}^{2+}(0.39 \mathrm{mmol} / \mathrm{g}$, neutral, 25$)$ & Langmuir & - \\
\hline 3-Aminopropyl-functionalized SBA-15-N-E $\left(-\mathrm{NH}_{2}\right)$ & $\mathrm{Cu}^{2+}(0.35 \mathrm{mmol} / \mathrm{g}$, neutral, 25$)$ & Langmuir & - \\
\hline 3-Aminopropyl-functionalized SBA-15-N-C $\left(-\mathrm{NH}_{2}\right)$ & $\mathrm{Cu}^{2+}(0.24 \mathrm{mmol} / \mathrm{g}$, neutral, 25$)$ & Langmuir & - \\
\hline
\end{tabular}


Table 2. Cont.

\begin{tabular}{|c|c|c|c|}
\hline Adsorbent (interacting group) & Heavy metal $\left(q_{\max }, \mathrm{pH}\right.$ and $\left.t\left({ }^{\circ} \mathrm{C}\right)\right)$ & Isotherm & Reference \\
\hline $\begin{array}{l}\text { 3-(2-Aminoethylamino) propyltrimethoxysilane modified } \\
\text { ordered mesoporous silica }\end{array}$ & $\operatorname{As}(\mathrm{V})(10.3 \mathrm{mg} / \mathrm{g}, 7$, room $)$ & Experimental & [171] \\
\hline N-propyl aniline-functionalized MCM-41 (-NH-) & $\begin{array}{c}\text { Arsenate }(0.85 \mathrm{mmol} / \mathrm{g}, 4.2, \text { room }) \\
\mathrm{Hg}^{2+}(0.92 \mathrm{mmol} / \mathrm{g}, 3.5, \text { room }) \\
\mathrm{Pb}^{2+}(0.78 \mathrm{mmol} / \mathrm{g}, 5.8, \text { room })\end{array}$ & $\begin{array}{l}\text { Experimental } \\
\text { Experimental } \\
\text { Experimental }\end{array}$ & [172] \\
\hline $\mathrm{H}_{2} \mathrm{~N}$-functionalized SBA-15 $\left(-\mathrm{NH}_{2}\right)$ & $\begin{array}{l}\mathrm{Cu}^{2+}(1.28 \mathrm{mg} / \mathrm{g}, \text { neutral, room }) \\
\mathrm{Pb}^{2+}(1.31 \mathrm{mg} / \mathrm{g} \text {, neutral, room }) \\
\mathrm{Cd}^{2+}(1.35 \mathrm{mg} / \mathrm{g}, \text { neutral, room })\end{array}$ & $\begin{array}{l}\text { Experimental } \\
\text { Experimental } \\
\text { Experimental }\end{array}$ & [173] \\
\hline Imidazole-functionalized SBA-15 (N atoms of imidazole) & $\begin{array}{l}\mathrm{Pd}^{2+}(0.091 \mathrm{mmol} / \mathrm{g}, 4, \text { room }) \\
\mathrm{Pt}^{2+}(0.091 \mathrm{mmol} / \mathrm{g}, 4, \text { room })\end{array}$ & $\begin{array}{l}\text { Experimental } \\
\text { Experimental }\end{array}$ & [174] \\
\hline $\begin{array}{l}\text { SBA-15 modified with 3-aminopropyl-triethoxysilane and } \\
\text { salicylaldehyde ( }-\mathrm{N}=\text { and }-\mathrm{O}^{-} \text {groups) }\end{array}$ & $\begin{array}{l}\mathrm{Cu}^{2+}(46 \mathrm{mg} / \mathrm{g}, 4.8, \text { room }) \\
\mathrm{Ni}^{2+}(22 \mathrm{mg} / \mathrm{g}, 4.8, \text { room }) \\
\mathrm{Co}^{2+}(19 \mathrm{mg} / \mathrm{g}, 4.8, \text { room }) \\
\mathrm{Zn}^{2+}(26 \mathrm{mg} / \mathrm{g}, 4.8, \text { room })\end{array}$ & $\begin{array}{l}\text { Experimental } \\
\text { Experimental } \\
\text { Experimental } \\
\text { Experimental }\end{array}$ & [175] \\
\hline Amino-functionalized mesoporous silica $\left(-\mathrm{NH}_{2}\right.$ and $\left.-\mathrm{OH}\right)$ & $\mathrm{Ni}^{2+}(2.48 \mathrm{mmol} / \mathrm{g}, 8.5,25)$ & Sips & {$[176]$} \\
\hline 2-Mercaptopyrimidine-functionalized SBA-15 ( $\mathrm{N}$ and $\mathrm{S}$ atoms) & $\mathrm{Cd}^{2+}(0.99 \mathrm{mmol} / \mathrm{g}, 6,25)$ & Experimental & [177] \\
\hline 3-Aminopropyl-functionalized MCM-41 (- $\left.\mathrm{NH}_{2}\right)$ & $\mathrm{Au}^{3+}(0.4 \mathrm{mmol} / \mathrm{g}, 2.5$, room $)$ & Experimental & {$[178]$} \\
\hline NH(propyl)-functionalized MCM-41 (-NH-) & $\mathrm{Au}^{3+}(0.33 \mathrm{mmol} / \mathrm{g}, 2.5$, room $)$ & Experimental & - \\
\hline $\mathrm{N}$ (propyl) $)_{2}$-functionalized MCM-41 ( $\mathrm{N}$ atom of amine group) & $\mathrm{Au}^{3+}(0.2 \mathrm{mmol} / \mathrm{g}, 2.5$, room $)$ & Experimental & - \\
\hline Chemically modified MCM-41 (-NH- and $\left.-\mathrm{NH}_{2}\right)$ & $\mathrm{Hg}^{2+}(0.7 \mathrm{mmol} / \mathrm{g}, 5,25)$ & Langmuir & [179] \\
\hline 3-Aminopropyl-functionalized MCM-41 $\left(-\mathrm{NH}_{2}\right)$ & $\begin{array}{l}\mathrm{Ag}^{+}(0.62 \mathrm{mmol} / \mathrm{g}, 5,22) \\
\mathrm{Cu}^{2+}(0.84 \mathrm{mmol} / \mathrm{g}, 5,22)\end{array}$ & $\begin{array}{l}\text { Experimental } \\
\text { Experimental }\end{array}$ & {$[180]$} \\
\hline 3-Mercaptopropyl-functionalized MCM-41 (-SH) & $\begin{array}{l}\mathrm{Ag}^{+}(0.97 \mathrm{mmol} / \mathrm{g}, 5,22) \\
\mathrm{Cu}^{2+}(0.02 \mathrm{mmol} / \mathrm{g}, 5,22)\end{array}$ & $\begin{array}{l}\text { Experimental } \\
\text { Experimental }\end{array}$ & - \\
\hline 3-Mercaptopropyl-functionalized SBA-16 (-SH) & $\mathrm{Cu}^{2+}(36.42 \mathrm{mg} / \mathrm{g}, 5.5,25)$ & Langmuir & [181] \\
\hline 3-Aminopropyl-modified SBA-15 (-NH & $\mathrm{Cu}^{2+}(73.5 \mathrm{mg} / \mathrm{g}, 6.3,25)$ & Langmuir & {$[182]$} \\
\hline $\begin{array}{l}\text { SBB or } N \text {-((trimethoxysilyl)propyl)- } N, N, N \text {-tri- } n \text {-butylammonium } \\
\text { chloride-functionalized SBA-15 (quaternary ammonium) }\end{array}$ & $\mathrm{ReO}_{4}^{-}(1.85 \mathrm{mmol} / \mathrm{g}, 6.4$, room $)$ & Experimental & [183] \\
\hline $\begin{array}{l}\text { 3-Aminopropyl and 3-mercaptopropyl bi-functionalized } \\
\text { mesoporous silica }(-\mathrm{SH})\end{array}$ & $\mathrm{Hg}^{2+}(1.51 \mathrm{mmol} / \mathrm{g}$, neutral, room $)$ & Experimental & [184] \\
\hline $\begin{array}{l}\text { Meso-structured silica modified with 3-mercaptopropyltrimethoxy } \\
\text { silane and 9-(chloromethyl)anthracene (-SH) }\end{array}$ & $\begin{array}{l}\mathrm{Pb}^{2+}(13.96 \mathrm{mg} / \mathrm{g}, \text { neutral, 25) } \\
\mathrm{Cu}^{2+}(12.56 \mathrm{mg} / \mathrm{g}, \text { neutral, 25) } \\
\mathrm{Hg}^{2+}(12.09 \mathrm{mg} / \mathrm{g}, \text { neutral, 25) } \\
\mathrm{Zn}^{2+}(3.69 \mathrm{mg} / \mathrm{g}, \text { neutral, 25) }\end{array}$ & $\begin{array}{l}\text { Experimental } \\
\text { Experimental } \\
\text { Experimental } \\
\text { Experimental }\end{array}$ & [185] \\
\hline 3-Mercaptopropyl-functionalized SBA-15 (-SH) & $\mathrm{Hg}^{2+}(2.88 \mathrm{mmol} / \mathrm{g}, 4.5,20)$ & Langmuir & {$[186]$} \\
\hline $\begin{array}{l}\text { Ordered mesoporous silica modified with } \\
\text { 2,5-dimercapto-1,3,4-thiadiazole (-SH) }\end{array}$ & $\mathrm{Hg}^{2+}(1.7 \mathrm{~g} / \mathrm{g}$, neutral, room $)$ & Experimental & [187] \\
\hline $\begin{array}{l}\text { 1-Benzoyl-3-propylthiourea-functionalized MCM-41 } \\
\left(=\mathrm{N},=\mathrm{O},-\mathrm{NH}-\text { and }-\mathrm{NH}_{2} \text { groups }\right)\end{array}$ & $\mathrm{Hg}^{2+}(1 \mathrm{~g} / \mathrm{g}$, neutral, room $)$ & Experimental & [188] \\
\hline Disulfide-bridged periodical mesoporous organosilica (-S-S-) & $\mathrm{Hg}^{2+}(716 \mathrm{mg} / \mathrm{g}, 2$, room $)$ & Experimental & [189] \\
\hline 3-Mercaptopropyl-functionalized MCM-41 (-SH) & $\mathrm{Hg}^{2+}(0.59 \mathrm{mmol} / \mathrm{g}$, neutral, room $)$ & Experimental & [36] \\
\hline 3-Mercaptopropyl-functionalized HMS (-SH) & $\mathrm{Hg}^{2+}(1.5 \mathrm{mmol} / \mathrm{g}$, neutral, room $)$ & Experimental & - \\
\hline $\begin{array}{l}\text { Mesoporous thioether-functionalized polyvinylpyrrolidone } \\
(\mathrm{PVP}) / \mathrm{SiO}_{2} \text { composite }(-\mathrm{S}-)\end{array}$ & $\mathrm{Hg}^{2+}(4.26 \mathrm{mmol} / \mathrm{g}, 2$, room $)$ & Experimental & [190] \\
\hline
\end{tabular}


Table 2. Cont.

\begin{tabular}{|c|c|c|c|}
\hline Adsorbent (interacting group) & Heavy metal $\left(q_{\max }, \mathrm{pH}\right.$ and $\left.t\left({ }^{\circ} \mathrm{C}\right)\right)$ & Isotherm & Reference \\
\hline Disulfide-functionalized SBA-1 (-SH) & $\mathrm{Hg}^{2+}(849 \mathrm{mg} / \mathrm{g}, 2$, room $)$ & Experimental & [191] \\
\hline $\begin{array}{l}\text { 3-(((5-ethoxybenzenethiol)imino)methyl)-salicylic acid } \\
\text { immobilized onto mesoporous silica ( }-\mathrm{N}=\text { and }-\mathrm{SH} \text { groups) }\end{array}$ & $\mathrm{Pd}^{2+}(164.2 \mathrm{mg} / \mathrm{g}, 3$, room $)$ & Langmuir & [192] \\
\hline $\begin{array}{l}\text { 3-(3-(Methoxycarbonyl)benzylidene) hydrazinyl)benzoic acid } \\
\text { immobilized onto mesoporous silica }(\mathrm{C}=\mathrm{O} \text { and }-\mathrm{N}=\mathrm{NH}-)\end{array}$ & $\mathrm{Cu}^{2+}(145.98 \mathrm{mg} / \mathrm{g}, 7$, room $)$ & Langmuir & [193] \\
\hline $\begin{array}{l}\text { 3-(2-Aminoethylamino)propyl-functionalized mesoporous silica } \\
\left(-\mathrm{NH}-\text { and }-\mathrm{NH}_{2}\right)\end{array}$ & $\mathrm{Cu}^{2+}(0.107 \mathrm{mmol} / \mathrm{g}, 3$, room $)$ & Experimental & [194] \\
\hline 3-Aminopropyl-functionalized MCM-41 $\left(-\mathrm{NH}_{2}\right)$ & $\begin{array}{l}\mathrm{Cd}^{2+}(0.71 \mathrm{mmol} / \mathrm{g}, 5,22) \\
\mathrm{Ni}^{2+}(0.69 \mathrm{mmol} / \mathrm{g}, 5,22)\end{array}$ & $\begin{array}{l}\text { Experimental } \\
\text { Experimental }\end{array}$ & [195] \\
\hline Diamino-functionalized MCM-41 & $\begin{array}{l}\mathrm{Co}^{2+}(0.69 \mathrm{mmol} / \mathrm{g}, \text { neutral, } 25) \\
\mathrm{Ni}^{2+}(0.52 \mathrm{mmol} / \mathrm{g}, \text { neutral }, 25)\end{array}$ & $\begin{array}{l}\text { Experimental } \\
\text { Experimental }\end{array}$ & [196] \\
\hline Diamino-functionalized MCM-48 & $\begin{array}{c}\mathrm{Co}^{2+}(1 \mathrm{mmol} / \mathrm{g}, \text { neutral, } 25) \\
\mathrm{Ni}^{2+}(0.86 \mathrm{mmol} / \mathrm{g}, \text { neutral }, 25)\end{array}$ & $\begin{array}{l}\text { Experimental } \\
\text { Experimental }\end{array}$ & - \\
\hline $\begin{array}{l}\text { Aminopropyl grafted SBA-15 modified with EDTA } \\
\left(-\mathrm{NH}-\text { and }-\mathrm{COO}^{-}\right)\end{array}$ & $\mathrm{Pb}^{2+}(273.2 \mathrm{mg} / \mathrm{g}, 5,25)$ & Langmuir & [197] \\
\hline $\mathrm{CONH}_{2}$-functionalized SBA-15 ( $\mathrm{CONH}_{2}$ group $)$ & $\mathrm{Cu}^{2+}(1.4 \mathrm{mmol} / \mathrm{g}, 5,298)$ & Langmuir & {$[198]$} \\
\hline
\end{tabular}

Another factor affecting the adsorption capacity of an adsorbent is the density of its functional groups [169,170]. Yoshitale et al. [169] studied and compared effects of functional group density on the adsorption of chromate and arsenate oxyanions and other heavy metals. The $\mathrm{H}_{2} \mathrm{~N}-\left(\mathrm{CH}_{2}\right)_{3}-$, $\mathrm{H}_{2} \mathrm{~N}-\left(\mathrm{CH}_{2}\right)_{2}-\mathrm{NH}-\left(\mathrm{CH}_{2}\right)_{3}-$ and $\mathrm{H}_{2} \mathrm{~N}-\left(\mathrm{CH}_{2}\right)_{2}-\mathrm{NH}-\left(\mathrm{CH}_{2}\right)_{2}-\mathrm{NH}-\left(\mathrm{CH}_{2}\right)_{3}-$ groups were grafted on the surface of MCM-41and SBA-1 to prepare their mono-, di- and triamino-functionalized derivatives, respectively [169]. These amino groups are abbreviated as $\mathrm{N}-, \mathrm{NN}-$ and $\mathrm{NNN}-$, respectively. They showed that the pore size and the surface area of these compounds decrease with the increase of their amine density and similar results have been reported for mono-, di- and triamino-functionalized SBA-15 [170]. Experimental results implied that the interaction between the amine groups and oxyanions was ionic and all amine groups can involve in the adsorption process. Thus, $q_{\max }$ values for the adsorption of $\mathrm{CrO}_{4}{ }^{-}$and $\mathrm{HAsO}_{4}{ }^{2-}$ increase from mono- to triamino-functionalized derivatives of both MCM-41 and SBA-1 (Figure 10) [169]. As reported [169,171,172], amino groups under acidic conditions had much higher $q_{\max }$ for the adsorption of arsenate. At the adsorption saturation, the stoichiometries of oxyanions to $\mathrm{N}$ atoms were 0.5 for all adsorbents derived from SBA-1, whereas they were $0.25-0.35$ for MCM-41 derivatives [169]. This was due to, on SBA-1, all amino heads were randomly distributed and acted as adsorption sites but, on MCM-41, they formed domains on MCM-41.

Arencibia et al. [170] compared effect of synthesis condition on the adsorption of a number of metallic ions by monoamino-functionalized SBA-15 prepared by calcination, extraction and further hydration of calcined silica. They showed that $q_{\max }$ values of these adsorbents for $\mathrm{Ni}^{2+}, \mathrm{Cu}^{2+}, \mathrm{Zn}^{2+}$, $\mathrm{Cd}^{2+}$ and $\mathrm{Pb}^{2+}$ were different from each other and there was no relation between the pore size and surface area of mesopores with their $q_{\max }$ values for the adsorption of metallic ions from solutions. Also, different functional groups on SBA-15 can adsorb different metal cations [173-177]. 
Figure 10. Adsorption isotherms of (a) arsenate and (b) chromate on mono-, di- and triamino-functionalized MCM-41 which are shown with $\mathrm{N}-\mathrm{MCM}-41$, NN-MCM-41 and NNN-MCM-41, respectively. Reprinted with permission from [169]. Copyright 2002 American Chemical Society.
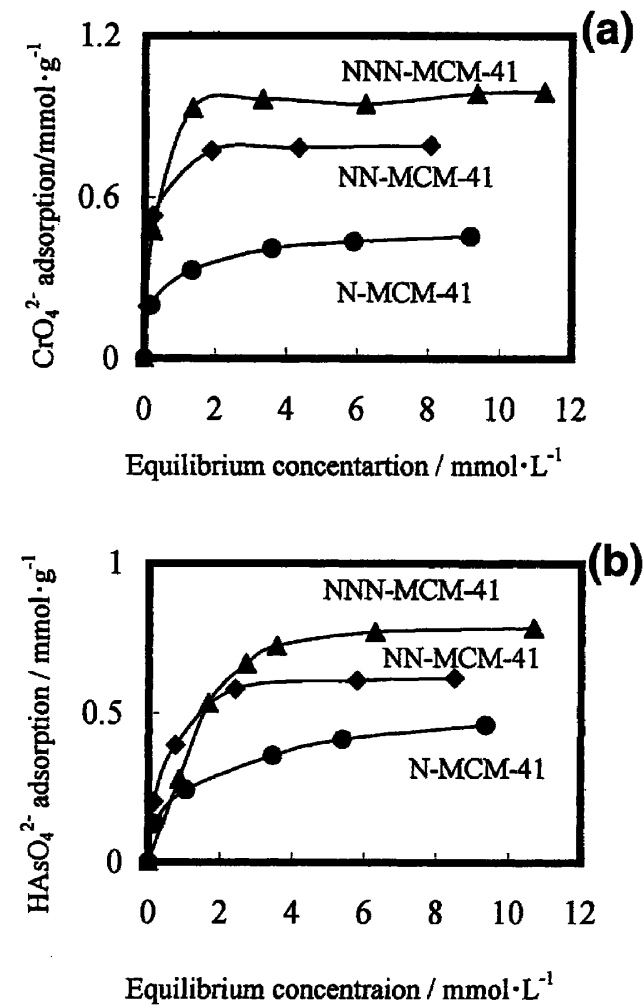

In some works, amino-functionalized MCM-41 mesopores were used for adsorption of heavy metal cations [178-180]. Yeoung et al. [178] studied the steric hindrance effect on the adsorption of $\mathrm{Au}^{3+}, \mathrm{Cu}^{2+}$ and $\mathrm{Ni}^{2+}$ on $\mathrm{NH}_{2} \mathrm{CH}_{2} \mathrm{CH}_{2} \mathrm{CH}_{2-}, \mathrm{CH}_{3} \mathrm{CH}_{2} \mathrm{CH}_{2} \mathrm{NHCH}_{2} \mathrm{CH}_{2} \mathrm{CH}_{2}-$ and $\left(\mathrm{CH}_{3} \mathrm{CH}_{2} \mathrm{CH}_{2}\right)_{2} \mathrm{NCH}_{2} \mathrm{CH}_{2} \mathrm{CH}_{2}$-functionalized $\mathrm{MCM}-41$ which their abbreviated names are $\mathrm{NH}_{2}-\mathrm{MCM}-41$, NHR-MCM-41 and $\mathrm{NR}_{2}-\mathrm{MCM}-41$, respectively. The results showed that only $\mathrm{Au}^{3+}$ (from the mixture of these ions) was selectively adsorbed on these compounds, resulted from interactions of $\mathrm{Au}^{3+}$ ions with lone pair electrons of $\mathrm{N}$ atom of amine groups. They observed that the adsorption capacity of $\mathrm{Au}^{3+}$ decreased from $\mathrm{NH}_{2}-\mathrm{MCM}-41$ to $\mathrm{NR}_{2}-\mathrm{MCM}-41$ which was due to the increase in steric hindrance of these spacious groups on the lone-pair electrons of $\mathrm{N}$ atoms. Authors showed that $\mathrm{Au}^{3+}$ was adsorbed on $\mathrm{NH}_{2}-\mathrm{MCM}-41$ with the amine loading ratios higher than $0.6 \mathrm{mmol} / \mathrm{g}$. This was because, at low amine loading ratios $(<0.6)$, strong $\mathrm{H}$-bonding between silanol and amine groups prevented interactions of amine groups with $\mathrm{Au}^{3+}$ ions whereas at the amine loading ratio higher than 0.6 amine groups formed patches of amino-derived areas and this destroys $\mathrm{H}$-bonding between silanol and amine groups which was revealed at the peak shifting of around $1300 \mathrm{~cm}^{-1}$ in the FT-IR spectra (Figure 11). The used $\mathrm{NH}_{2}-\mathrm{MCM}-41$ was washed by $5 \mathrm{M} \mathrm{HCl}$ and all the adsorbed gold ions were recovered and the regenerated adsorbent retained its adsorption capacity after repeating usages. 
Figure 11. FTIR spectrum of $\mathrm{NH}_{2}-\mathrm{MCM}-41$ with different $\mathrm{NH}_{2}$ loadings. The insert figure displays the peak shift caused by the interaction between the amino and surface silanol groups. Reprinted with permission from [178]. Copyright 2006 American Chemical Society.

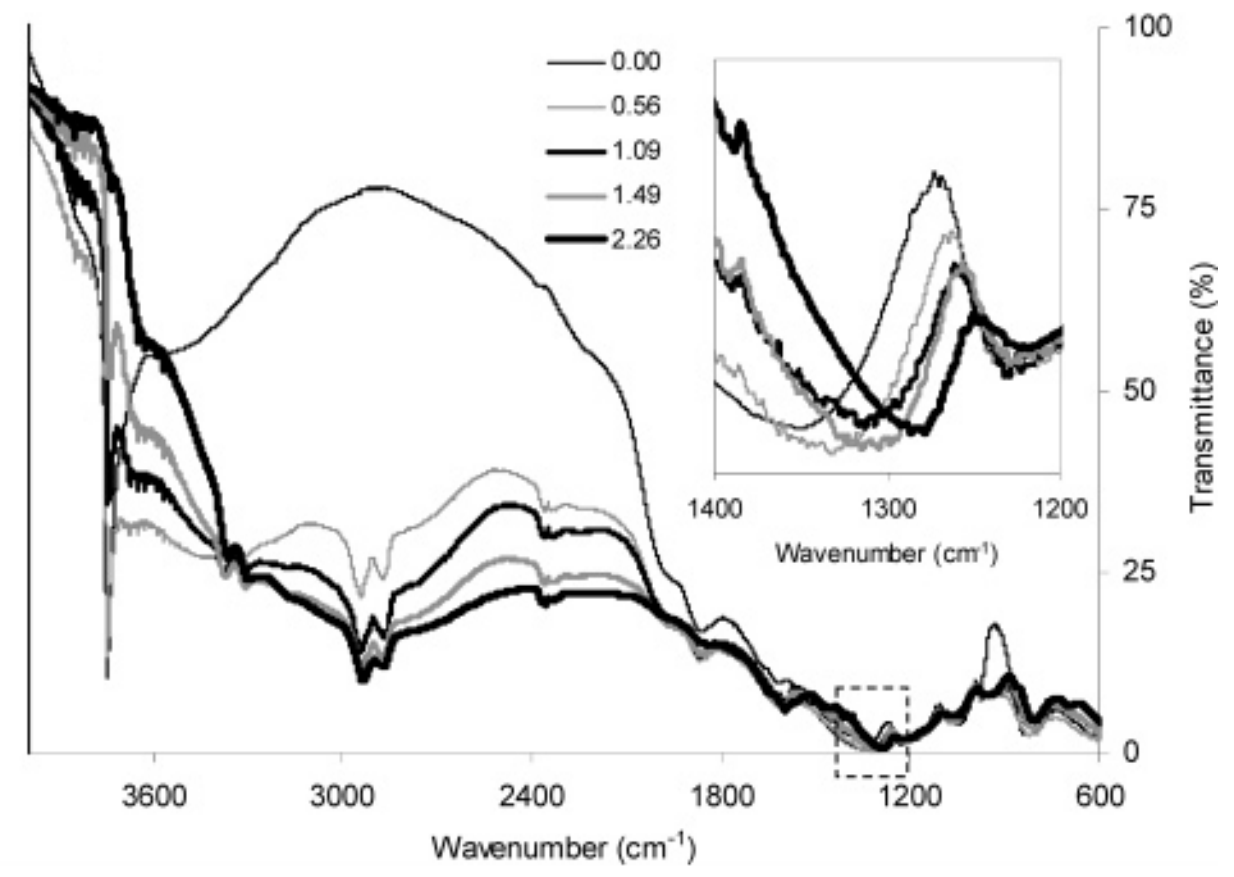

In another work, researchers changed contents of functional groups and used different ratios of 3-mercaptopropyl triethoxysilane (TMMPS) and TEOS to synthesize thiol-functionalized SBA-16 (SH-SBA-16) samples [181]. With the increase in the sulfur content of samples, -SH groups on the surface partially blocked the adsorption of nitrogen molecules and decrease their surface areas and pore sizes and the adsorption capacity of SH-SBA-16 samples increases. The used SH-SBA-16 sample for the adsorption of $\mathrm{Cu}^{2+}$ was recovered by $1 \mathrm{M} \mathrm{HCl}$ and after the seventh stripping cycle, its adsorption capacity was $90.5 \%$ of its initial value.

The adsorption of $\mathrm{Cu}^{2+}$ on aminopropyl-substituted SBA-15 (SBA-15-N) and a temperature-aged sample (SBA-15-N-T) was studied by Soler-Illia et al. [182]. It was observed that upon the addition of functional groups, the surface area of SBA-15-N and SBA-15-N-T decrease compared to SBA-15. Experiments showed that the $q_{\max }$ value for the adsorption of $\mathrm{Cu}^{2+}$ on SBA-15-N was bigger than that of SBA-15-N-T which was due to the rearrangement of inorganic network in SBA-15-N-T. Due to the thermal treatment of SBA-15-N intensive H-bond interactions between its amino groups and the surface silanols disrupted and this improved the accessibility of amino groups on the pore surface.

Dai et al. [183] studied effect of hydrophobicity of functional groups on their adsorption capacity. HMS, SBA-15 and PME (PMO material bridged with ethylene groups) functionalized with $N$-((trimethoxysilyl)propyl)- $N, N, N$-tri- $n$-butylammonium (TSPBC) and $N$-((trimethoxysilyl)propyl)$N, N, N$-trimethylammonium (TSPMC) ions were used for the adsorption of hydrophobic $\mathrm{ReO}_{4}{ }^{-}$ ions [183]. The results showed that TSPBC-functionalized HMS, SBA-15 and PME had bigger $q_{\max }$ values for the adsorption of $\mathrm{ReO}_{4}{ }^{-}$than those functionalized with TSPMC. This was due to the higher hydrophobic character of butyl groups compared to methyl groups that enhanced the adsorption of 
$\mathrm{ReO}_{4}{ }^{-}$ions. When a cationic surfactant (here CTAC) was used for synthesizing mesopores (called as MEB sample), its chloride ions attached to the protonated silanol groups and anion-exchange sites and hindered the adsorption of $\mathrm{ReO}_{4}{ }^{-}$ions. To avoid high chloride content in these mesopores, authors used TSPBC and a neutral surfactant (rather than CTAC) to synthesize mesoporous compound (called as NMEB) that increased greatly its $q_{\max }$ for the adsorption of $\mathrm{ReO}_{4}{ }^{-}$ions compared to MEB. In another work, a bifunctional HMS, prepared by mercaptopropyl and aminopropyl groups, was used for the adsorption of $\mathrm{Hg}^{2+}, \mathrm{Cu}^{2+}$ and $\mathrm{Cd}^{2+}$ [184]. Heavy Metal ions were adsorbed by -SH heads of mercaptopropyl groups. Due to higher affinity between - SH group and different mechanisms of its adsorption, the $\mathrm{Hg}^{2+}$ adsorption and its adsorption selectivity increased greatly compared to $\mathrm{Cu}^{2+}$ and $\mathrm{Cd}^{2+}$ (Figure 12). $\mathrm{Hg}^{2+}$ can be adsorbed on the inner surface of pores whereas $\mathrm{Cu}^{2+}$ and $\mathrm{Cd}^{2+}$ were adsorbed on the outer surface of adsorbent or near the pore openings. As reported [36,180,185-187], -SH groups of organically-functionalized mesopores have a great $q_{\max }$ for adsorption of $\mathrm{Hg}^{2+}$. An example of a compound with two functional groups is 1-benzoyl-3-propylthiourea-functionalized MCM-41 (MCM-41 BTU) which was synthesized through a two-step modification process [188] to better control removal of $\mathrm{Hg}^{2+}$ and to prevent unnecessary pore blocking. In the first step they prepared 3-aminopropyl-MCM-41 (MCM-41 $\left.\mathrm{NH}_{2}\right)$ and in the second step, they prepared MCM-41 BTU using MCM-41 $\mathrm{NH}_{2}$. Their surface area and pore size were decreased as in order as MCM-41 > MCM-41 $\mathrm{NH}_{2}>\mathrm{MCM}-41$ BTU.

The concentration of 1-benzoyl-3-propylthiourea and (unreacted) aminopropyl groups on the surface of MCM-41 BTU were 1.5 and $0.65 \mathrm{mmol} / \mathrm{g}$, respectively (Figure 13). The adsorption isotherm of $\mathrm{Hg}^{2+}$ on MCM-41 BTU had two regions (Figure 13). In the first region, $\mathrm{Hg}^{2+}$ strongly were adsorbed on 3-aminopropyl residuals $\left(K_{1}=1.41 \times 10^{5} \mathrm{M}^{-1}\right.$ and $\left.q_{\max }=1.55 \mathrm{mmol} / \mathrm{g}\right)$ and then in the second region the ions were adsorbed on the 1-benzoyl-3-propylthiourea residuals $\left(K_{2}=1.08 \times 10^{2} \mathrm{M}^{-1}\right.$ and $\left.q_{\max }=3.48 \mathrm{mmol} / \mathrm{g}\right)$.

Figure 12. Difference between adsorption mechanism of $\mathrm{Hg}^{2+}$ and other metallic ions. Reprinted with permission from [184]. Copyright 2001 Elsevier.

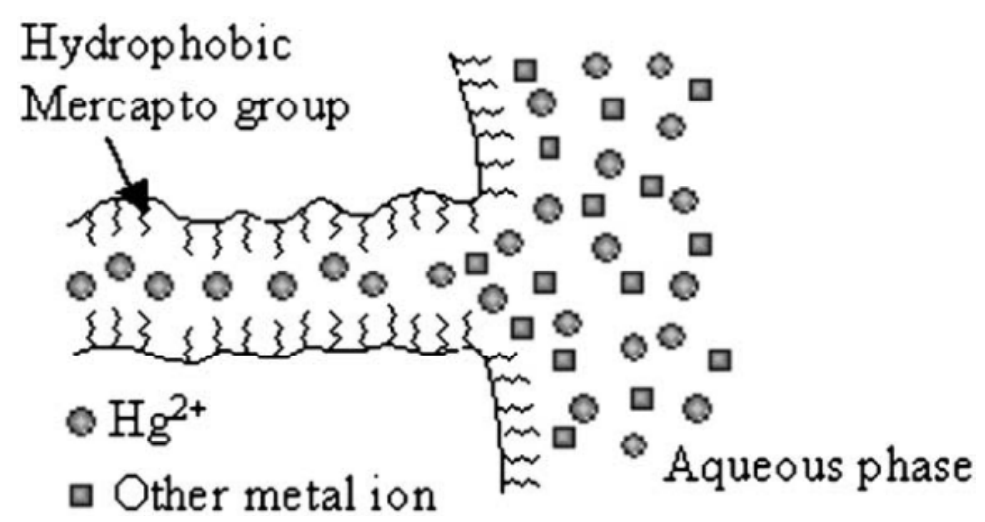


Figure 13. (a) Functional groups of $M C M-41 B T U$ and (b) adsorption isotherm for adsorption of $\mathrm{Hg}^{2+}$ on MCM-41 BTU. The initial sharp part of adsorption isotherm is related to adsorption by 3-aminopropyl residuals. Reprinted with permission from [188]. Copyright 2003 Springer Science and Business Media.

(a)

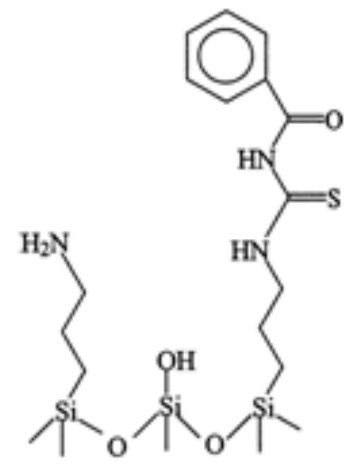

(b)

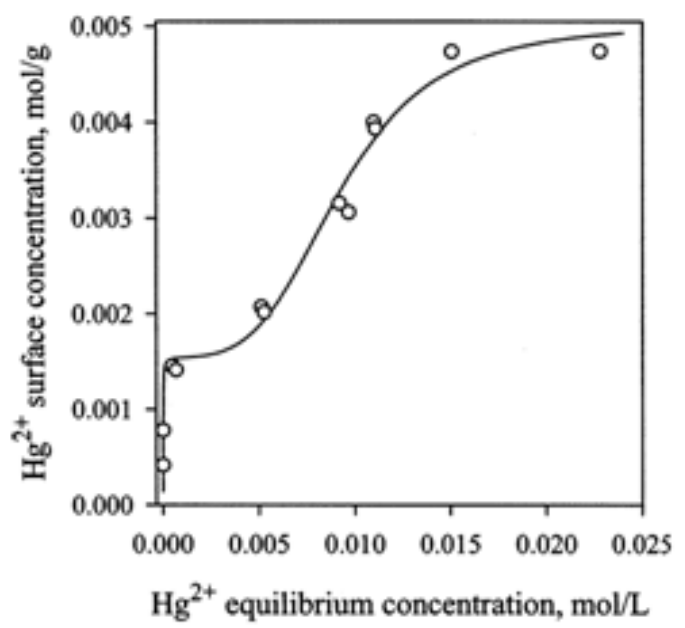

Zhao et al. [189] synthesized a number of two-dimensional disulfide-bridged periodical mesoporous organosilicas (PMO) with high sulfide contents for the adsorption of $\mathrm{Hg}^{2+}$. They used bis(triethoxysilylpropyl) disulfide (BTSPDS) and TEOS as precursors and also applied $\mathrm{Zn}\left(\mathrm{NO}_{3}\right)_{2}$ in a number of syntheses. XRD patterns demonstrate that in the presence of $\mathrm{Zn}^{2+}$ highly ordered hexagonal disulfide-bridged PMO composites were obtained. Eventually, $\mathrm{Zn}^{2+}$ ions were etched off in a strong acid solution. XRD patterns of the $\mathrm{Zn}^{2+}$ treated compounds showed their high hydrothermal stability which was enhanced with the increase in their BTSPDS/TEOS ratios. $\mathrm{Hg}^{2+}$ ions interacted with sulfur atoms of -S-S- bridges of adsorbents. Adsorption capacities of these compounds for $\mathrm{Hg}^{2+}$, similar to those of tetrasulfide-functionalized polyvinylpyrrolidone (PVP)/SiO 2 composite mesopores [190] or disulfide-functionalized SBA-1 [191], were high and increased with increase in their BTSPDS content [189]. This shows that double sulfide functioalized mesopores are emerging candidates for adsorption of $\mathrm{Hg}^{2+}$.

Also, other kinds of mesoporous compounds with various functional groups were used for adsorption of heavy metals [192-198]. Yeung et al. [195] increased selectivity of an aminopropyl-grafted MCM-41 $\left(\mathrm{NH}_{2}-\mathrm{MCM}-41\right)$ for the adsorption of $\mathrm{Ni}^{2+}$ and $\mathrm{Cd}^{2+}$ through chelation of these ions. The isoelectric point of $\mathrm{NH}_{2}-\mathrm{MCM}-41$ was 3.2. Below this $\mathrm{pH}$, the adsorbent did not adsorb $\mathrm{Ni}^{2+}$ and $\mathrm{Cd}^{2+}$ and at $\mathrm{pH}=5$, its $q_{\max }$ values of $\mathrm{Cd}^{2+}$ and $\mathrm{Ni}^{2+}$ were 0.71 and $0.69 \mathrm{mmol} / \mathrm{g}$, respectively. In binary mixtures of $\mathrm{Ni}^{2+}$ and $\mathrm{Cd}^{2+}$ at $\mathrm{pH}>3.2$, the $q_{\max }$ values of $\mathrm{NH}_{2}-\mathrm{MCM}-41$ for $\mathrm{Ni}^{2+}$ and $\mathrm{Cd}^{2+}$ were 0.60 and $0.16 \mathrm{mmol} / \mathrm{g}$, respectively. The authors tuned the selectivity of adsorbent by an appropriate chelate, EDTA. EDTA selectively bound to $\mathrm{Ni}^{2+}$ (as $\mathrm{NiEDTA}^{2-}$ complex) and changed its adsorption selectivity toward $\mathrm{Cd}^{2+}$. Authors tried to separate these ions by adding EDTA and adjusting the $\mathrm{pH}$ of solution. At $\mathrm{pH}=2$, only $\mathrm{Ni}^{2+}$ ions (as $\mathrm{NiEDTA}^{2-}$ ) were adsorbed by $-\mathrm{NH}_{3}{ }^{+}$ headgroups in mesopores and, at $\mathrm{pH}=5$, only $\mathrm{Cd}^{2+}$ ions were adsorbed by $-\mathrm{NH}_{2}$ groups of adsorbent (Supporting information Figure S4).

The $\mathrm{H}_{2} \mathrm{~N}\left(\mathrm{CH}_{2}\right)_{2} \mathrm{NH}\left(\mathrm{CH}_{2}\right)_{3}$-functionalized MCM-41 and MCM-48 (abbreviated as NN-MCM-41 and NN-MCM-48) [196] were used for the adsorption of $\mathrm{Fe}^{3+}, \mathrm{Cu}^{2+}, \mathrm{Co}^{2+}$ and $\mathrm{Ni}^{2+}$. Then, the authors 
applied the used mesopores for the adsorption of arsenate. The $\mathrm{Fe}^{3+}, \mathrm{Cu}^{2+}$ and $\mathrm{Co}^{2+}$ ions bound to ethylenediamine (en) headgroups of mesoperes as $\mathrm{Fe}(\mathrm{en})_{2}, \mathrm{Cu}(\mathrm{en})_{2}$ and $\mathrm{Co}(\mathrm{en})$ whereas $\mathrm{Ni}^{2+}$ interacted with surface silanol groups. The adsorption capacities of NN-MCM-48 for these metal ions were much larger than those of NN-MCM-41. Also, it was shown that $\mathrm{Cl}^{-}$and $\mathrm{SO}_{4}{ }^{2-}$ anions inhibited arsenate adsorption on these kinds of adsorbents by different extents.

\subsection{Adsorption of Heavy Metals on Composites of Layered Compounds with Organic Polymers}

As pointed in Section 2.3.3, these kinds of compounds are prepared as phase separated, intercalated and exfoliated structures [118]. Here, we study a number of works carried out regarding their abilities for the adsorption of heavy metals. Some examples [199-232] are summarized in Table 3.

Chitosan is a natural polycationic biopolymer that can chelate with heavy metals by its amino and hydroxyl groups and its nanocomposites with clays and zeolites are used for adsorption of heavy metals. However, it has a low surface area, with weak chemical and mechanical properties. Thus, physical and chemical modifications are necessary to overcome these limitations. On the other hand, the clay has a lamellar structure with negatively charged surface that interacts with polycationic chitosan. There is high possibility that one or both surfaces of the clay layers can be modified by chitosan. Chitosan-functionalized closite 10A [199], bentonite [200], perlite [201-204], clinoptilolite [205], alumina [206,207], montmerilonite [208,209] and calcium alginate [210] were used for the adsorption of heavy metals from water. In these compounds, functional groups of chitosan $\left(-\mathrm{NH}_{2}\right.$ and $\left.-\mathrm{OH}\right)$ interact with heavy metals, in spite of cellulose/hydyoxyapatite in which negative sites of hydroxylapatite are interacting sites of nanocomposite [211]. XRD showed the interlayer spacing of chitosan-functionalized bilayer compounds increases, which showed a complete [199] or partial exfoliated [209] surface morphology. Electrostatic interaction between chitosan and negatively-charged surface of layer compounds such as closite A [199], perlite [203,204] and, alumina [206,207] resulted in the formation of nanocomposites. As an example for the adsorption of heavy metals by these kinds of compounds, authors studied the adsorption of $\mathrm{Cr}(\mathrm{VI})$ polyanions by closite $10 \mathrm{~A} /$ chitosan nanocomposite (CCN) (Figure 14) [199]. The TEM image demonstrated the formation of exfoliated surface morphology. The zeta potential of $\mathrm{CCN}$ surface at $\mathrm{pH}$ below eight was positive because the amine groups of chitosan were protonated at $\mathrm{pH}$ below eight and $\mathrm{Cr}(\mathrm{VI})$ ions existed as $\mathrm{Cr}_{2} \mathrm{O}_{7}{ }^{2-}$, $\mathrm{CrO}_{4}{ }^{2-}$ and $\mathrm{HCrO}_{4}{ }^{-}$polyanions at $\mathrm{pH}$ range of 2-6. Thus, The optimum $\mathrm{pH}$ for the adsorption process was found to be 3. Similarly, interactions of nanocomposites of chitosan with perlite [201], alumina [206,207], montmorillonite [208], with Cr(VI) oxyanion or chitosan-clay with selenate [209] occur via their protonated amino groups. As reported [200,202-205,210] chitosan-layered nanocomposites interaction with metal cations occurs through $-\mathrm{OH}$ and $-\mathrm{NH}_{2}$ groups of chitosan. The $q_{\max }$ values of these adsorbents completely depend on the used layered compounds, Table 3 . The used $\mathrm{CCN}$ was regenerated by washing with $0.01 \mathrm{~N} \mathrm{H}_{2} \mathrm{SO}_{4}$ and, after four cycles, its adsorption capacity was $78.47 \%$ of its initial value [199].

In another work, Wan et al. [212] used chitosan/bentonite and crosslinked chitosan immobilized on bentonite as adsorbent for $\mathrm{Cu}^{2+}$. Crosslinking agents are used to amend mechanical and chemical properties of the adsorbents. 
Figure 14. (a) Schematic structure of chitosan and clay hybrid and (b) mechanism of interaction of closite $10 \mathrm{~A}$ /chitosan nanocomposite (CCN) with $\mathrm{Cr}(\mathrm{VI})$. Reprinted with permission from [199]. Copyright 2011 Elsevier.

(a)

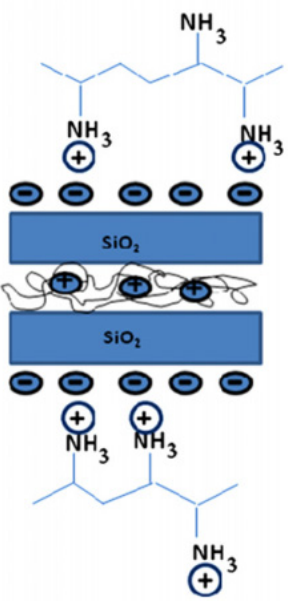

(b)

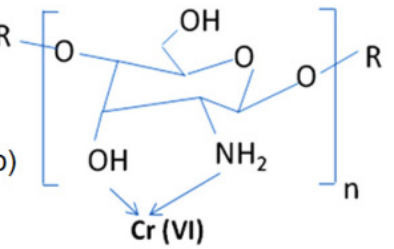

Table 3. Adsorbed heavy metals, maximum adsorption capacity, $\mathrm{pH}$ and temperature for adsorption of heavy metals by organic polymer/layered compound hybrids.

\begin{tabular}{|c|c|c|c|}
\hline Adsorbent (interacting group) & Heavy metal $\left(q_{\max }, \mathrm{pH}\right.$ and $\left.t\left({ }^{\circ} \mathrm{C}\right)\right)$ & Isotherm & Reference \\
\hline Chitosan/cloisite $10 \mathrm{~A}$ (protonated $-\mathrm{NH}_{2}$ ) & $\mathrm{Cr}(\mathrm{VI})(357.14 \mathrm{mg} / \mathrm{g}, 3,35)$ & Langmuir & [199] \\
\hline \multirow{3}{*}{$\begin{array}{l}\text { Chitosan/bentonite (ion exchange property of bentonite and }-\mathrm{OH} \text { and } \\
-\mathrm{NH}_{2} \text { groups of chitosan) }\end{array}$} & $\mathrm{Pb}^{2+}(15 \mathrm{mg} / \mathrm{g}, 4,25)$ & Langmuir & \multirow{3}{*}{ [200] } \\
\hline & $\mathrm{Cu}^{2+}(12.6 \mathrm{mg} / \mathrm{g}, 4,25)$ & Langmuir & \\
\hline & $\mathrm{Ni}^{2+}(6.1 \mathrm{mg} / \mathrm{g}, 4,25)$ & Langmuir & \\
\hline Chitosan/perlite (protonated $-\mathrm{NH}_{2}$ ) & $\mathrm{Cr}(\mathrm{VI})(153.8 \mathrm{mg} / \mathrm{g}, 4,25)$ & Experimental & [201] \\
\hline \multirow{2}{*}{ Chitosan/perlite $\left(-\mathrm{NH}_{2}\right.$ and $\left.-\mathrm{OH}\right)$} & $\mathrm{Cu}^{2+}(196.08 \mathrm{mg} / \mathrm{g}, 5$, room $)$ & Langmuir & \multirow{2}{*}{ [202] } \\
\hline & $\mathrm{Ni}^{2+}(114.95 \mathrm{mg} / \mathrm{g}, 5$, room $)$ & Langmuir & \\
\hline Chitosan/perlite $\left(-\mathrm{NH}_{2}\right)$ & $\mathrm{Cd}^{2+}(178.6 \mathrm{mg} / \mathrm{g}, 6,25)$ & Experimental & [203] \\
\hline \multirow[t]{2}{*}{ Chitosan/perlite $\left(-\mathrm{NH}_{2}\right.$ and $\left.-\mathrm{OH}\right)$} & $\mathrm{Cu}^{2+}(1.59 \mathrm{mmol} / \mathrm{g}, 4.5,25)$ & Langmuir & \multirow[t]{2}{*}{ [204] } \\
\hline & $\mathrm{Cu}^{2+}(11.32 \mathrm{mmol} / \mathrm{g}, 5,25)$ & Langmuir & \\
\hline \multirow[t]{2}{*}{ Chitosan/clinoptilolite $\left(-\mathrm{NH}_{2}\right)$} & $\mathrm{Co}^{2+}(7.94 \mathrm{mmol} / \mathrm{g}, 5,25)$ & Langmuir & \multirow[t]{2}{*}{ [205] } \\
\hline & $\mathrm{Ni}^{2+}(4.21 \mathrm{mmol} / \mathrm{g}, 5,25)$ & Langmuir & \\
\hline Chitosan/alumina (protonated amino groups) & $\mathrm{Cr}(\mathrm{VI})(9.71 \mathrm{mg} / \mathrm{g}, 4,40)$ & Langmuir & [206] \\
\hline Chitosan/alumina (protonated $-\mathrm{NH}_{2}$ ) & $\mathrm{Cr}(\mathrm{VI})(153.85 \mathrm{mg} / \mathrm{g}, 4,25)$ & Langmuir & [207] \\
\hline Chitosan/montmorillonite (protonated $-\mathrm{NH}_{2}$ ) & $\mathrm{Cr}(\mathrm{VI})(40.65 \mathrm{mg} / \mathrm{g}, 4,35)$ & Langmuir & [208] \\
\hline Chitosan/montmorillonite (protonated $-\mathrm{NH}_{2}$ group of chitosan) & Selenate $(18.4 \mathrm{mg} / \mathrm{g}, 4$, room $)$ & Langmuir & [209] \\
\hline Chitosan/calcium alginate $\left(-\mathrm{NH}_{2}\right.$ and $\left.-\mathrm{OH}\right)$ & $\mathrm{Ni}^{2+}(222.2 \mathrm{mg} / \mathrm{g}, 5$, room $)$ & Langmuir & [210] \\
\hline Cellulose/hydroxyapatite (ion exchange property of hydroxyapatite) & $\mathrm{Pb}^{2+}(16.32 \mathrm{mg} / \mathrm{g}$, neutral, 25) & Langmuir & [211] \\
\hline Chitosan/bentonite $\left(-\mathrm{NH}_{2}\right)$ & $\mathrm{Cu}^{2+}(9.85 \mathrm{mg} / \mathrm{g}, 4,25)$ & Langmuir & [212] \\
\hline Epichlorohydrin-crosslinked chitosan/bentonite $\left(-\mathrm{NH}_{2}\right)$ & $\mathrm{Cu}^{2+}(11.75 \mathrm{mg} / \mathrm{g}, 4,25)$ & Langmuir & - \\
\hline Ethylene glycol diglycidyl ether-crosslinked chitosan/bentonite $\left(-\mathrm{NH}_{2}\right)$ & $\mathrm{Cu}^{2+}(10.52 \mathrm{mg} / \mathrm{g}, 4,25)$ & Langmuir & - \\
\hline Glutaraldehyde-crosslinked chitosan/bentonite $\left(-\mathrm{NH}_{2}\right)$ & $\mathrm{Cu}^{2+}(4.17 \mathrm{mg} / \mathrm{g}, 4,25)$ & Langmuir & - \\
\hline $\begin{array}{l}\text { Chitosan- } g \text {-poly }(\text { acrylic acid }) / \text { attapulgite/sodium humate }\left(-\mathrm{COO}^{-} \text {, }\right. \\
\left.-\mathrm{COOH},-\mathrm{NH}_{2} \text { and }-\mathrm{O}^{-}\right)\end{array}$ & $\mathrm{Pb}^{2+}(809.5 \mathrm{mg} / \mathrm{g}, 5.5,35)$ & Langmuir & [213] \\
\hline Chitosan-g-poly(acrylic acid)/attapulgite $\left(-\mathrm{COO}^{-}\right)$ & $\mathrm{Cu}^{2+}(303.03 \mathrm{mg} / \mathrm{g}, 5.5,30)$ & Langmuir & [214] \\
\hline Chitosan-g-poly(acrylic acid)/attapulgite ( $-\mathrm{COOH},-\mathrm{NH}_{2}$ and $\left.-\mathrm{OH}\right)$ & $\mathrm{Hg}^{2+}(785.2 \mathrm{mg} / \mathrm{g}, 5,30)$ & Langmuir & [215] \\
\hline Poly(methacrylic acid) grafted chitosan/bentonite $(-\mathrm{COOH})$ & $\mathrm{U}(\mathrm{VI})(117.2 \mathrm{mg} / \mathrm{g}, 5.5,30)$ & Langmuir & [216] \\
\hline
\end{tabular}


Table 3. Cont.

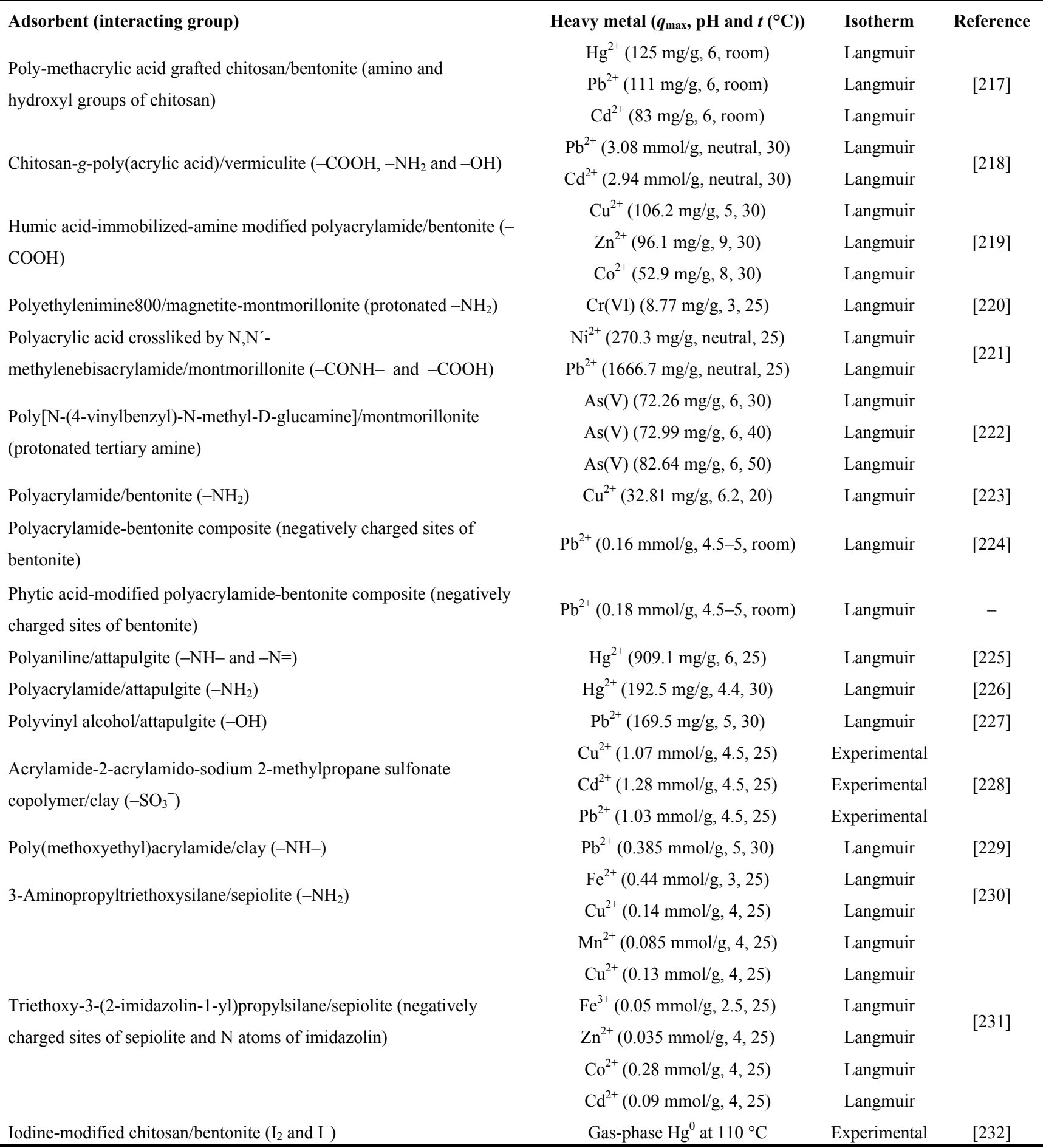

Some researchers prepared nanocomposites using a natural carbohydrate (e.g., chitosan), a polymer and a layered compound [213-219]. Wang et al. [213] increased the number of compounds for synthesizing hybrid polymer and prepared chitosan-g-poly(acrylic acid)/attapulgite/sodium humate composite hydrogels for the adsorption of $\mathrm{Pb}^{2+}$. In this adsorbent, $-\mathrm{NH}_{2}$ groups of chitosan (CSA), $-\mathrm{COOH}$ and $-\mathrm{COO}^{-}$groups of polyacrylic acid (PAA), $-\mathrm{COO}^{-}$and $\mathrm{Ph}-\mathrm{CO}^{-}$groups of sodium humate (SH) and $\mathrm{Si}-\mathrm{OH}$ groups of attapulgite (APT) adsorbed $\mathrm{Pb}^{2+}$ ions. Depending on the used quantity of the above constituents, the adsorption capacity of hybrid polymer for $\mathrm{Pb}^{2+}$ was in the range of 702.35 to $843.86 \mathrm{mg} / \mathrm{g}$. 
Chitosan-g-poly(acrylic acid)/attapulgite (CTS-g-PAA/APT) composites were used for the fast adsorption of $\mathrm{Cu}^{2+}$ [214]. Results showed that attapulgite (APT) really reacted with the CTS-g-PAA polymer (Supporting information Figure S5). Adsorption experiments were carried out at $\mathrm{pH}=5.5$. It was fast and more than $90 \%$ of $\mathrm{Cu}^{2+}$ was adsorbed after about $15 \mathrm{~min}$. FTIR spectra of CTS-g-PAA/APT compound before and after the adsorption of $\mathrm{Cu}^{2+}$ showed that $-\mathrm{NH}_{2},-\mathrm{OH}$ groups of chitosan and $-\mathrm{COOH}$ groups of PAA in the composites interacted with $\mathrm{Cu}^{2+}$. This compound had a high $q_{\max }(785.2 \mathrm{mg} / \mathrm{g})$ for the adsorption of $\mathrm{Hg}^{2+}$ [215], as well.

Poly(methacrylic acid)-grafted chitosan/bentonite (CTS-g-PMAA/Bent) composite (Supporting information Figure S6) was synthesized for the adsorption of U(VI) [216]. They used $N, N^{\prime}$-methylenebisacrylamide as a crosslinking agent. XRD patterns showed that bentonite was exfoliated during the formation of composite. The adsorption process was carried out at $\mathrm{pH}=5.5$ in which the CTS-g-PMAA/Bent surface charge was negative and $\mathrm{UO}_{2}(\mathrm{OH})^{+}$was the predominant species. XPS spectra showed that $-\mathrm{COO}^{-}$groups of composite interacted with $\mathrm{UO}_{2}{ }^{2+}$. Similarly, methacrylic acid grafted chitosan/bentonite [217], Chitosan-g-poly(acrylic acid)/vermiculite [218] and humic acid-immobilized-amine modified polyacrylamide immobilized on bentonite [219] were used for the adsorbtion of a number of heavy metal cations.

In another groups of organically-functioalized layered compounds, synthetic polymers were used as organic moiety. $\mathrm{Fe}_{3} \mathrm{O}_{4}$ nanoparticles coated with polyethylenimine (PEI) polymer were intercalated between sodium rich montmorillonite (MMT) layers [220] under acidic conditions $(\mathrm{pH}=2)$ and used it as a magnetic sorbent for the adsorption of $\mathrm{Cr}(\mathrm{VI})$. At $\mathrm{pH}=2$, amine groups of PEI were protonated and intercalated between MMT platelets by cationic exchange (Scheme 6). Two different molecular weights of PEI were investigated ( $x=800$ or $25,000 \mathrm{~g} / \mathrm{mol}$ ). The TEM images of $\mathrm{Fe}_{3} \mathrm{O}_{4}-\mathrm{PEI} x-\mathrm{MMT}$ compound showed MMT existed as individual exfoliated platelets and intercalation tactoids composed by a few sheets (Figure 15).

Scheme 6. Schematic representation of $\mathrm{Fe}_{3} \mathrm{O}_{4}-\mathrm{PEI} x-\mathrm{MMT}$ formation. Reprinted with permission from [220]. Copyright 2012 Elsevier.
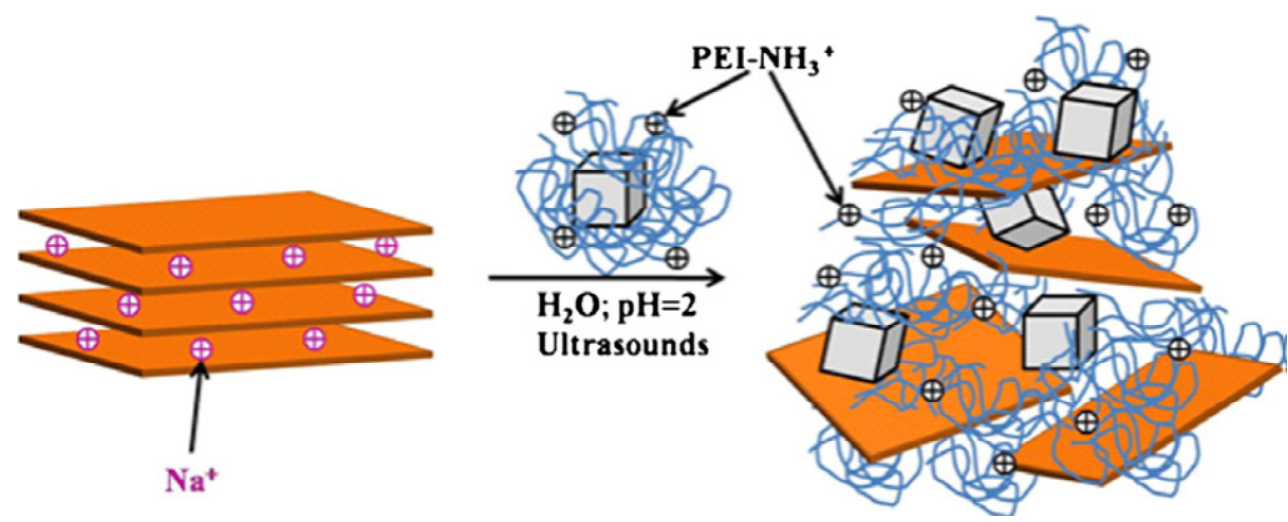
Figure 15. TEM images of (a) $\mathrm{Fe}_{3} \mathrm{O}_{4}-\mathrm{PEI} 800-\mathrm{MMT}$ and (b) $\mathrm{Fe}_{3} \mathrm{O}_{4}-\mathrm{PEI} 2500-\mathrm{MMT}$ hybrid materials. Reprinted with permission from [220]. Copyright 2012 Elsevier.
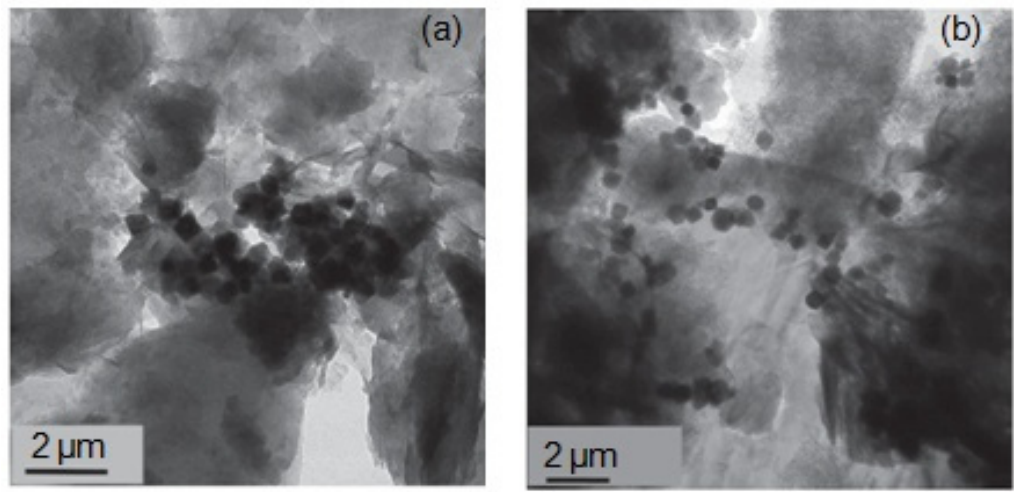

A better dispersion of magnetites was obtained in $\mathrm{Fe}_{3} \mathrm{O}_{4}-\mathrm{PEI} 2500-\mathrm{MMT}$. The $\mathrm{pH}$ of zero point of charge of magnetite was 8.3 and the amine groups of PEI were protonated at $\mathrm{pH}$ below 10.4 and adsorbed $\mathrm{Cr}(\mathrm{VI})$ polyanions $\left(\mathrm{CrO}_{4}{ }^{2-}, \mathrm{HCrO}_{4}{ }^{-}\right.$and $\left.\mathrm{Cr}_{2} \mathrm{O}_{7}{ }^{2-}\right)$ through electrostatic interactions. In $\mathrm{pH}$ lower than 2, $\mathrm{Cr}(\mathrm{VI})$ ions were mainly as $\mathrm{H}_{2} \mathrm{CrO}_{4}$ and the adsorption decreased. Experiments showed that they can be used for a wide $\mathrm{pH}$ range and the optimum $\mathrm{pH}$ for the adsorption process was 6 . The $q_{\text {max }}$ values of $\mathrm{Fe}_{3} \mathrm{O}_{4}-\mathrm{PEI} 800-\mathrm{MMT}$ and $\mathrm{Fe}_{3} \mathrm{O}_{4}-\mathrm{PEI} 25000-\mathrm{MMT}$ compounds were 8.77 and $7.69 \mathrm{mg} / \mathrm{g}$, respectively.

A novel superabsorbent composite was synthesized by copolymerization reaction of partially neutralized acrylic acid (AA) on bentonite micropowder using $N, N^{\prime}$-methylenebisacrylamide as a crosslinker [221]. The superabsorbent composite (SAC) was characterized by Fourier transform infrared spectroscopy (FTIR), thermogravimetric analysis (TGA) and scanning electron microscopy (SEM). The $q_{\max }$ values for adsorption of $\mathrm{Pb}^{2+}, \mathrm{Ni}^{2+}, \mathrm{Cd}^{2+}$ were $1666.67,270.27,416.67$ and $222.22 \mathrm{mg} / \mathrm{g}$ respectively, Scheme 7.

Scheme 7. Adsorption isotherms of $\mathrm{Pb}^{2+}, \mathrm{Ni}^{2+}, \mathrm{Cd}^{2+}$ and $\mathrm{Cu}^{2+}$. Reprinted with permission from [221]. Copyright 2009 Elsevier.

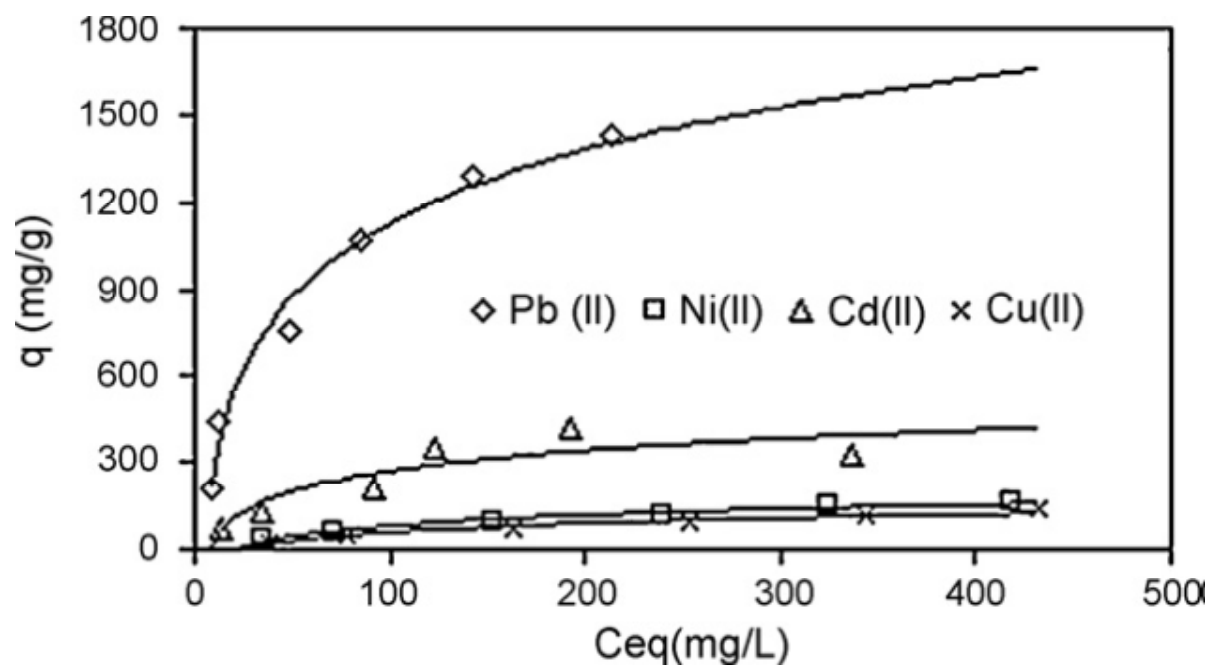

Organic-modified montmorillonite coated by $N$-(4-vinylbenzyl)- $N$-methyl- $D$-glucamine polymer was studied in the presence of a crosslinking reagent for the adsorption of arsenate [222]. XRD 
patterns showed that the intercalation process was not complete. Also, TEM images confirmed the dispersion of montmorillonite within matrix. Adsorption experiments were carried out at $\mathrm{pH}=6$ and $\mathrm{As}(\mathrm{V})$ polyanions (as $\mathrm{H}_{2} \mathrm{AsO}_{4}{ }^{-}$) interacted with ammonium groups of adsorbent and its $q_{\max }$ was $72.99 \mathrm{mg} / \mathrm{g}$.

Bentonite (BENT) embedded in polyacrylamide (PAAm) composite was used [223] for the removal of $\mathrm{Cu}^{2+}$ from water. XRD patterns of BENT and BENT-PAAm (Figure 16) shows that acrylamide polymerization destroyed BENT structure and resulted in the crystal confusion. Results showed that the optimum $\mathrm{pH}$ for the adsorption of $\mathrm{Cu}^{2+}$ was 6.2. Increasing $\mathrm{pH}$, increased the negatively charged or deprotonated amines and $\mathrm{SiOH}$ groups of BENT-PAAm and also increased the hydrolysis of $\mathrm{Cu}(\mathrm{II})$.

Below $\mathrm{pH}=6.5, \mathrm{Cu}(\mathrm{II})$ is mainly as $\mathrm{Cu}^{2+}$ (Supporting information Figure S7). In pHs of 5 and 6.2, $q_{\max }$ values of BENT-PAAm were bigger than those of BENT which was due to the presence of amine groups of PAAm. On the other hand, it was reported that negatively charged sites of bentonite in BENT-PAAm composite adsorbed $\mathrm{Pb}^{2+}$ [224]. In this compound, polyacrylamide chains just increase thermal and mechanical stabilities of the nanocomposite and its $q_{\max }$ for the adsorption of $\mathrm{Pb}^{2+}$ is less than that of pure bentonite.

Polyaniline/attapulgite (PANI/ATP) composite was used achieving a high adsorption of mercury [225]. X-ray photoelectron spectroscopy showed that after the adsorption of $\mathrm{Hg}^{2+}$ on PANI/ATP, its amine (-NH-) content reduced from 6.97 to 4.55 atom $\%$ and its imine $\left(-\mathrm{NH}^{+}-\right)$content also diminished from 4.54 to 0.96 atom\%. This showed that $\mathrm{Hg}^{2+}$ was adsorbed on both amine and imine functional groups. The optimum $\mathrm{pH}$ for the adsorption process was 6 and its $q_{\max }$ values at ionic strengths of 0.01, 0.1 and 1M were 909.1, 813.1 and $781.3 \mathrm{mg} / \mathrm{g}$, respectively. As reported before [226], polyacrylamide/attapulgite adsorbed $\mathrm{Hg}^{2+}$ via its $-\mathrm{NH}_{2}$ functional groups and its $q_{\max }$ value was $192.5 \mathrm{mg} / \mathrm{g}$. It was observed that $\mathrm{Cl}^{-}$decreased drastically its adsorption capacity of $\mathrm{Hg}^{2+}$ via forming $\mathrm{HgCl}_{4}{ }^{2-}$ compound. The adsorption capacity of PANI/ATP was preserved at $93 \%$ by the fifth cycle. Also, as seen in Table 3,-OH, $-\mathrm{SO}_{3}{ }^{-}$and $-\mathrm{NH}-$ groups of organic moiety in polyvinyl alcohol/attapulgite [227], acrylamide-2-acrylamido-sodium 2-methylpropane sulfonate/clay [228] and poly(methoxyethyl)acrylamide/clay [229], respectively had a relatively high affinity for adsorption of $\mathrm{Pb}^{2+}$.

Figure 16. XRD patterns of Bentonite (BENT) and BENT-PAAm. Reprinted with permission from [223]. Copyright 2010 Elsevier.

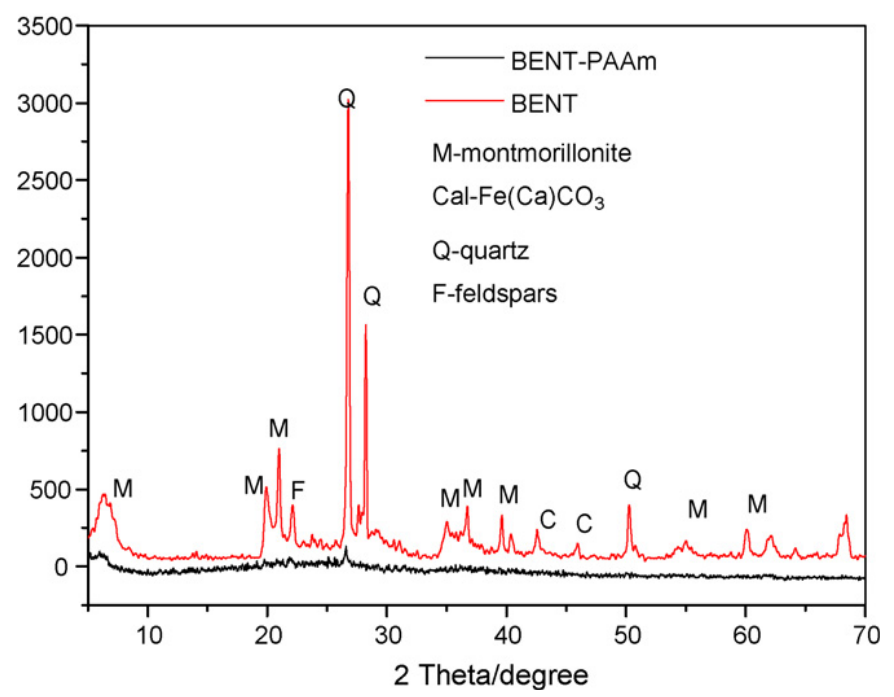




\subsection{Adsorption of Heavy Metals on Organic-Inorganic Core-Shell Nanocomposites (CSNs)}

CSNs have different applications and were studied briefly in Section 2.3.4. Here, we discuss the role of these compounds in the adsorption of metal ions. A number of examples [233-252] have been given in Table 4.

Table 4. Adsorbed heavy metals, maximum adsorption capacity, $\mathrm{pH}$ and temperature for adsorption of heavy metals by organic-inorganic core/shell and hierarchically structured nanocomposites.

\begin{tabular}{|c|c|c|c|}
\hline Adsorbent (interacting group) & Heavy metal $\left(q_{\max }, \mathrm{pH}\right.$ and $\left.t\left({ }^{\circ} \mathrm{C}\right)\right)$ & Isotherm & Reference \\
\hline \multicolumn{4}{|c|}{ Core/shell nanocomposites } \\
\hline $\begin{array}{l}\mathrm{SiO}_{2} / \text { salicyclic acid functionalized polystyrene }(\mathrm{O} \text { atom of }-\mathrm{COOH} \\
\text { and } \mathrm{N} \text { atom of }-\mathrm{N}=\mathrm{N}-\text { ) }\end{array}$ & $\begin{array}{c}\mathrm{Cu}^{2+}(1.29 \mathrm{mmol} / \mathrm{g}, 5, \text { room }) \\
\mathrm{Ag}^{+}(1.85 \mathrm{mmol} / \mathrm{g}, 5, \text { room }) \\
\mathrm{Au}^{3+}(1.61 \mathrm{mmol} / \mathrm{g}, 2.7, \text { room })\end{array}$ & $\begin{array}{l}\text { Langmuir } \\
\text { Langmuir } \\
\text { Langmuir }\end{array}$ & [233] \\
\hline $\mathrm{SiO}_{2} /$ amino functionalized polystyrene $\left(-\mathrm{NH}_{2}\right)$ & $\begin{array}{l}\mathrm{Cu}^{2+}(0.17 \mathrm{mmol} / \mathrm{g}, \text { neutral, room }) \\
\mathrm{Ag}^{+}(0.47 \mathrm{mmol} / \mathrm{g}, \text { neutral, room }) \\
\mathrm{Au}^{3+}(0.59 \mathrm{mmol} / \mathrm{g}, \text { neutral, room })\end{array}$ & $\begin{array}{l}\text { Experimental } \\
\text { Experimental } \\
\text { Experimental }\end{array}$ & [234] \\
\hline $\mathrm{SiO}_{2} /$ imidazole-functionalized polystyrene $(-\mathrm{N}=\mathrm{N}-$ and imidazole $)$ & $\mathrm{Au}^{3+}(1.7 \mathrm{mmol} / \mathrm{g}, 2.7$, room $)$ & Langmuir & {$[235]$} \\
\hline $\mathrm{SiO}_{2} /$ aniline formaldehyde condensate $\left(-\mathrm{NH}_{2}\right)$ & $\mathrm{Cu}^{2+}(76.33 \mathrm{mg} / \mathrm{g}, 5.4-5.7$, room $)$ & Langmuir & {$[236]$} \\
\hline $\mathrm{SiO}_{2} /$ polyacrylamide $\left(-\mathrm{NH}_{2}\right)$ & $\mathrm{Hg}^{2+}(26.5 \mathrm{mg} / \mathrm{g}$, acidic, 40$)$ & Experimental & [237] \\
\hline $\mathrm{SiO}_{2} /$ Chetoceros sp microalgae & $\mathrm{Pb}^{2+}(0.19 \mathrm{mmol} / \mathrm{g}, 5,27)$ & Langmuir & [238] \\
\hline $\mathrm{SiO}_{2} /$ chitosan imprinted by sucrose (amino groups) & $\mathrm{Cu}^{2+}(3.2 \mathrm{mg} / \mathrm{g}, 6,25)$ & Langmuir & [239] \\
\hline $\mathrm{SiO}_{2} /$ chitosan imprinted by polyethylene glycol 4000 (amino groups) & $\mathrm{Cu}^{2+}(9.1 \mathrm{mg} / \mathrm{g}, 6,25)$ & Langmuir & - \\
\hline $\begin{array}{l}\mathrm{SiO}_{2} / \text { chitosan imprinted by sucrose and polyethylene glycol } 4000 \\
\text { (amino groups) }\end{array}$ & $\mathrm{Cu}^{2+}(10.5 \mathrm{mg} / \mathrm{g}, 6,25)$ & Langmuir & - \\
\hline $\mathrm{SiO}_{2} / \mathrm{Cd}^{2+}$-imprinted chitosan (amino groups) & $\mathrm{Cd}^{2+}(1.14 \mathrm{mmol} / \mathrm{g}, 6$, room $)$ & Experimental & [240] \\
\hline $\mathrm{SiO}_{2} /$ chitosan (amino groups) & $\mathrm{Cd}^{2+}(0.58 \mathrm{mmol} / \mathrm{g}, 6$, room $)$ & - & - \\
\hline $\mathrm{SiO}_{2} /$ chitosan $\left(-\mathrm{NH}_{2}\right.$ and $\left.-\mathrm{OH}\right)$ & $\mathrm{Cu}^{2+}(0.2 \mathrm{mmol} / \mathrm{g}, 5.5,25)$ & Experimental & [241] \\
\hline $\mathrm{SiO}_{2} /$ chitosan (amino groups) & $\mathrm{Ni}^{2+}(182 \mathrm{mg} / \mathrm{g}, 7,25)$ & Langmuir & {$[242]$} \\
\hline $\mathrm{SiO}_{2}\left(\mathrm{CO}_{2} \mathrm{H}\right) /$ chitosan (amino groups) & $\mathrm{Ni}^{2+}(210 \mathrm{mg} / \mathrm{g}, 7,25)$ & Langmuir & - \\
\hline $\mathrm{Fe}_{3} \mathrm{O}_{4} /$ poly(3,4-ethylenedioxythiophene) $(-\mathrm{O}-)$ & $\begin{array}{l}\mathrm{Ag}^{+}(27.96 \mathrm{mmol} / \mathrm{g}, \text { neutral, room }) \\
\mathrm{Hg}^{2+}(16.02 \mathrm{mmol} / \mathrm{g} \text {, neutral, room }) \\
\mathrm{Pb}^{2+}(14.99 \mathrm{mmol} / \mathrm{g}, \text { neutral, room })\end{array}$ & $\begin{array}{l}\text { Experimental } \\
\text { Experimental } \\
\text { Experimental }\end{array}$ & [243] \\
\hline $\begin{array}{l}\gamma-\mathrm{Fe}_{2} \mathrm{O}_{3} / \text { polyrhodanine (oxygen, nitrogen and sulfur atoms of } \\
\text { polyrhodanine) }\end{array}$ & $\mathrm{Hg}^{2+}(179 \mathrm{mg} / \mathrm{g}, 4,25)$ & Langmuir & [244] \\
\hline $\mathrm{Fe}_{3} \mathrm{O}_{4}$ nanoparticle/chitosan (amino groups) & $\mathrm{Cu}^{2+}(21.5 \mathrm{mg} / \mathrm{g}, 5,27)$ & Langmuir & {$[245]$} \\
\hline $\mathrm{Fe}_{3} \mathrm{O}_{4}$ nanoparticle/chitosan (amino groups) & $\mathrm{Au}^{3+}(59.52 \mathrm{mg} / \mathrm{g}, 2,25)$ & Langmuir & {$[246]$} \\
\hline $\begin{array}{l}\mathrm{Fe}_{3} \mathrm{O}_{4} \text { nanoparticle/thiol-functionalized mesoporous } \\
\text { microsphere (-SH) }\end{array}$ & $\begin{array}{l}\mathrm{Hg}^{2+}(185.19 \mathrm{mg} / \mathrm{g}, 5,20) \\
\mathrm{Pb}^{2+}(114.7 \mathrm{mg} / \mathrm{g}, 5,20)\end{array}$ & $\begin{array}{l}\text { Langmuir } \\
\text { Langmuir }\end{array}$ & [247] \\
\hline $\begin{array}{l}\text { Chitosan/zerovalent iron nanoparticles (complexation between } \\
\text { Fe and Arsenic) }\end{array}$ & $\begin{array}{l}\mathrm{As}^{3+}(94 \mathrm{mg} / \mathrm{g}, 7,25) \\
\text { Arsenate }(119 \mathrm{mg} / \mathrm{g}, 7,25)\end{array}$ & $\begin{array}{l}\text { Langmuir } \\
\text { Langmuir }\end{array}$ & [248] \\
\hline Polystyrene/nano- $\mathrm{Fe}_{3} \mathrm{O}_{4}\left(\mathrm{Fe}_{3} \mathrm{O}_{4}\right)$ & Arsenate $(139.3 \mathrm{mg} / \mathrm{g}, 6,25)$ & Langmuir & [249] \\
\hline $\begin{array}{l}\text { Nanosized hydrous } \mathrm{MnO}_{2} / \text { porous polystyrene cation exchanger resin } \\
\left(-\mathrm{SO}_{3}{ }^{-},-\mathrm{Mn}(\mathrm{OH}) \text { and }-\mathrm{Mn}(\mathrm{OH})_{2} \text { groups }\right)\end{array}$ & $\begin{array}{l}\mathrm{Cd}^{2+}(1.96 \mathrm{mmol} / \mathrm{g}, 4.7,25) \\
\mathrm{Zn}^{2+}(1.67 \mathrm{mmol} / \mathrm{g}, 4.7,25)\end{array}$ & $\begin{array}{l}\text { Langmuir } \\
\text { Langmuir }\end{array}$ & {$[250]$} \\
\hline
\end{tabular}


Table 4. Cont.

\begin{tabular}{|c|c|c|c|}
\hline Adsorbent (interacting group) & Heavy metal $\left(q_{\max }, \mathrm{pH}\right.$ and $\left.t\left({ }^{\circ} \mathrm{C}\right)\right)$ & Isotherm & Reference \\
\hline \multicolumn{4}{|c|}{ Hierarchically structured nanocomposites } \\
\hline \multirow{3}{*}{$\mathrm{Fe}_{3} \mathrm{O}_{4} / \mathrm{SiO}_{2} /$ poly $(1,2$-diaminobenzene $)\left(-\mathrm{NH}_{2},-\mathrm{NH}-\right.$ and $\left.-\mathrm{N}=\right)$} & $\mathrm{As}^{3+}(84.5 \mathrm{mg} / \mathrm{g}, 6,25)$ & Langmuir & \multirow{3}{*}{ [251] } \\
\hline & $\mathrm{Cr}^{3+}(77 \mathrm{mg} / \mathrm{g}, 5.3,25)$ & Langmuir & \\
\hline & $\mathrm{Cu}^{2+}(65 \mathrm{mg} / \mathrm{g}, 6,25)$ & Langmuir & \\
\hline $\mathrm{SiO}_{2} / \mathrm{Fe}_{3} \mathrm{O}_{4} /$ ion-imprinted polymer $\left(-\mathrm{NH}-\mathrm{CH}_{2}-\mathrm{CH}_{2}-\mathrm{NH}_{2}\right)$ & $\mathrm{Pb}^{2+}(19.61 \mathrm{mg} / \mathrm{g}, 7.5$, room $)$ & Langmuir & [252] \\
\hline $\mathrm{SiO}_{2} / \mathrm{Fe}_{3} \mathrm{O}_{4} /$ non-imprinted polymer $\left(-\mathrm{NH}-\mathrm{CH}_{2}-\mathrm{CH}_{2}-\mathrm{NH}_{2}\right)$ & $\mathrm{Pb}^{2+}(6.57 \mathrm{mg} / \mathrm{g}, 7.5$, room $)$ & Experimental & - \\
\hline Polyaniline nanorods on graphene oxide nanosheets (amine group) & $\mathrm{Cr}(\mathrm{VI})(1149.4 \mathrm{mg} / \mathrm{g}, 3,25)$ & Langmuir & [253] \\
\hline Silica/polystyrene $(-\mathrm{SH})$ & $\mathrm{Cu}^{2+}(11.33 \mathrm{mg} / \mathrm{g}, 5,15)$ & Langmuir & [254] \\
\hline \multirow{3}{*}{$\begin{array}{l}\mathrm{CaCO}_{3} \text {-pepsin }\left(\mathrm{CaCO}_{3} \text { and adsorption occurs through formation of }\right. \\
\left.\mathrm{PbCO}_{3} \text { and } \mathrm{CuCO}_{3}\right)\end{array}$} & $\mathrm{Pb}^{2+}(1167 \mathrm{mg} / \mathrm{g}$, neutral, room $)$ & Experimental & \multirow{3}{*}{ [255] } \\
\hline & $\mathrm{Cu}^{2+}(611 \mathrm{mg} / \mathrm{g}$, neutral, room $)$ & Experimental & \\
\hline & $\mathrm{Pb}^{2+}(3242.48 \mathrm{mg} / \mathrm{g}, 7,25)$ & Langmuir & \\
\hline \multirow{3}{*}{$\begin{array}{l}\mathrm{CaCO}_{3} \text {-maltose }\left(\mathrm{CaCO}_{3} \text { and adsorption occurs through formation of }\right. \\
\left.\mathrm{PbCO}_{3}, \mathrm{CuCO}_{3}, \mathrm{NiCO}_{3} \text { and } \mathrm{CdCO}_{3}\right)\end{array}$} & $\mathrm{Cd}^{2+}(487.8 \mathrm{mg} / \mathrm{g}, 7,25)$ & Langmuir & \multirow{3}{*}{ [256] } \\
\hline & $\mathrm{Cu}^{2+}(628.93 \mathrm{mg} / \mathrm{g}, 7,25)$ & Langmuir & \\
\hline & $\mathrm{Ni}^{2+}(769.23 \mathrm{mg} / \mathrm{g}, 7,25)$ & Langmuir & \\
\hline
\end{tabular}

Silica gel is a commonly used supporting material in inorganic-organic hybrid materials due to its environmental and economic factors and high thermal and mechanical stabilities [233-241]. Polystyrene diazo-coupled with salicyclic acid [233] (SG-PS-azo-SA) and encapsulated silica gel by polystyrene containing amino groups (SG-PS-NH ${ }_{2}$ ) [234] (Scheme 8) were used for the removal of a number of heavy metals.

Scheme 8. Structures of (a) SG-PS- $\mathrm{NH}_{2}$ and (b) SG-PS-azo-SA. Reprinted with permission from [233]. Copyright 2010 Springer Science and Business Media.

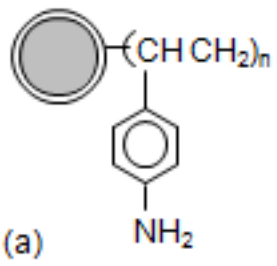

SG-PS-NH

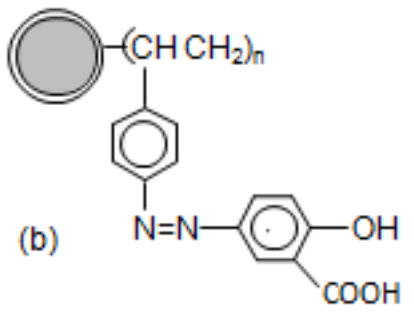

SG-PS-azo-SA

Thermogravimetric analysis of SG-PS- $\mathrm{NH}_{2}$ and $\mathrm{SG}-\mathrm{PS}-\mathrm{azo}-\mathrm{SA}$ showed that the respective organic layer had a high thermal stability. Also, the values of BET surface area, pore volume and pore size decreased greatly from silica gel to SG-PS- $\mathrm{NH}_{2}$ to SG-PS-azo-SA. SEM images of silica gel, SG-PS- $\mathrm{NH}_{2}$ and SG-PS-azo-SA indicated that the spherical shape and sizes of these three samples were similar (Supporting information Figure S8), proving that the microspheres of silica gel had good mechanical stability during the process of reaction. The $q_{\max }$ values of SG-PS- $\mathrm{NH}_{2}$ for $\mathrm{Cu}^{2+}, \mathrm{Ag}^{+}$and $\mathrm{Au}^{3+}$ were $0.17,0.47$ and $0.59 \mathrm{mmol} / \mathrm{g}$ [234] and those of SG-PS-azo-SA were 1.29, 1.85 and $1.61 \mathrm{mmol} / \mathrm{g}$, respectively [233]. Amine groups of $\mathrm{SG}-\mathrm{PS}-\mathrm{NH}_{2}$ and $-\mathrm{N}=\mathrm{N}-$ and salicyclic acid groups of SG-PS-azo-SA are their interacting groups. 
On the other hand, adsorption capacities of organic functional groups change considerably depending on the nature of inorganic moiety. For example, $q_{\max }$ value of polyacrylamide in $\mathrm{SiO}_{2}$ /polyacrylamide [237] for $\mathrm{Hg}^{2+}$ was much less than that of polyacrylamide/attapulgite [226]

Some authors have used natural carbohydrate and biomass as shell of their adsorbents. Immobilization of biomass (Chetoceros sp microalgae) on a $\mathrm{SiO}_{2}$ core resulted in an adsorbent for adsorption of $\mathrm{Pb}^{2+}$ [238]. Chitosan-grafted silica gel imprinted by sucrose and polyethylene glycol 4000 (PEG 4000) was used for the adsorption of $\mathrm{Cu}^{2+}$ [239]. This method has been used for direct preparation of porous sorbent with low mass transfer resistance, available functional ligand and excellent mechanical resistance [240]. Sucrose and PEG 4000 interacted with chitosan via hydrogen bonds and extraction of them, by breakage of H-bonds, resulted in a porous structure. The optimum $\mathrm{pH}$ for the adsorption of $\mathrm{Cu}^{2+}$ on this adsorbent was 6 . At this $\mathrm{pH}$, copper was mostly as $\mathrm{Cu}^{2+}$ form and most of amine groups of chitosan (its interacting group) were as $-\mathrm{NH}_{2}$. TG/DSC analyses showed that the thermal stability of grafted chitosan was higher than pure chitosan (Supporting information Figure S9). The XRD patterns show no peak for crystallization regions of chitosan in non-supported hybrid material compared to those of pure chitosan which might be ascribed to the demolition of its crystallinity (Figure 17). The $q_{\max }$ values of $\mathrm{Cu}^{2+}$ adsorption for the adsorbent imprinted with sucrose and PEG 4000, PEG 4000, sucrose and non-imprinted adsorbent [241] were 10.5, 9.1, 3.2 and $0.2 \mathrm{mmol} / \mathrm{g}$, respectively.

Figure 17. XRD patterns of (a) pure chitosan and (b) chitosan in non-supported hybrid material. Reprinted with permission from [239]. Copyright 2007 Elsevier.

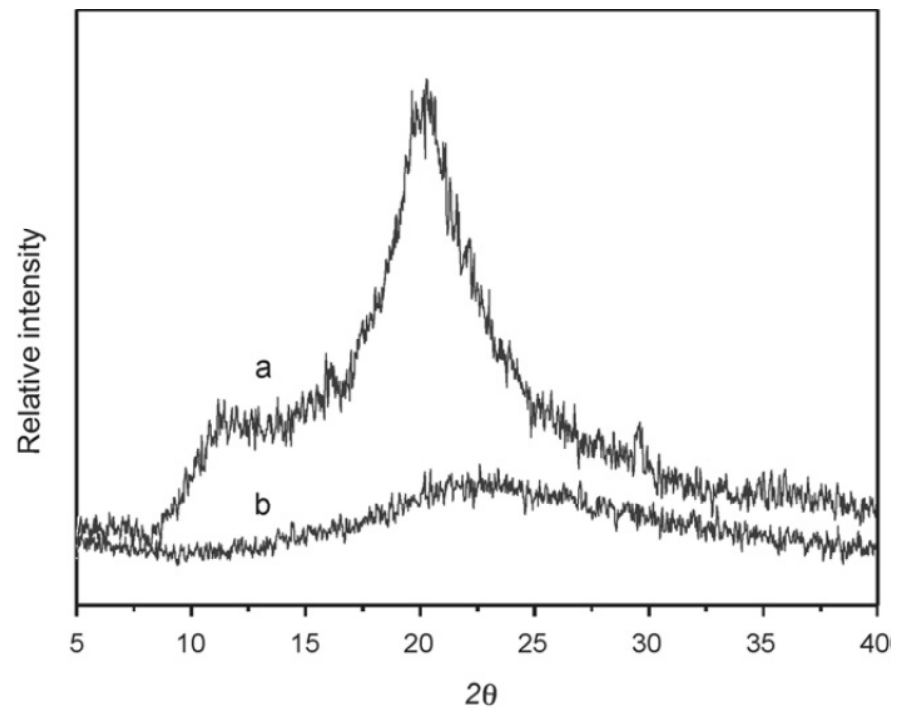

The used adsorbent was washed by $0.1 \mathrm{M} \mathrm{HCl}$ and the capacity of the regenerated sorbent through five cycles was detected to be $94 \%$ of the fresh one and equilibration time in the case of sucrose and PEG 4000 was $25 \mathrm{~min}$. Also, $q_{\max }$ value of $\mathrm{SiO}_{2}\left(\mathrm{CO}_{2} \mathrm{H}\right) /$ chitosan for adsorption of $\mathrm{Ni}^{2+}$ was higher than that of $\mathrm{SiO}_{2} /$ chitosan [241] which shows effect of support on the adsorption property of adsorbent [242]. Another material that was used frequently in core-shell nanocomposites was $\mathrm{Fe}_{3} \mathrm{O}_{4}$ magnetic nanoparticle [243-248]. These kinds of compounds can be separated with the help of an external magnetic force. In a number of works, organic polymers were used as shell for $\mathrm{Fe}_{3} \mathrm{O}_{4}$ core [243,244]. Jang et al. [243] encapsulated $\mathrm{Fe}_{3} \mathrm{O}_{4}$ by poly(3,4-ethylenedioxythiophene) (PEDOT) and used the 
produced compound $\left(\mathrm{Fe}_{3} \mathrm{O}_{4}-\mathrm{PEDOT}\right)$ for the removal of metal ions (Scheme 9). PEDOT has an excellent environmental stability and can interact with positively charged metal ions through its sulfur atom. The PEDOT shell has a lower surface energy than the core of magnetic nanoparticles, thus $\mathrm{Fe}_{3} \mathrm{O}_{4}-\mathrm{PEDOT}$ nanoparticles show amended stability and dispersibility in aqueous solutions, compared to pristine $\mathrm{Fe}_{3} \mathrm{O}_{4}$ nanoparticles. Adsorption experiments showed that adsorption capacities of $\mathrm{Fe}_{3} \mathrm{O}_{4}-\mathrm{PEDOT}$ nanoparticles were: $\mathrm{Ag}^{+}>\mathrm{Hg}^{2+}>\mathrm{Pb}^{2+}$. It was regenerated by acid treatment and the recovered adsorbent by ten cycles showed no loss in its adsorption capacity.

Scheme 9. Synthesis steps of $\mathrm{Fe}_{3} \mathrm{O}_{4}$-PEDOT nanoparticles by seeded polymerization mediated with acidic etching. Reproduced with permission from [243]. Copyright 2007 The Royal Society of Chemistry.

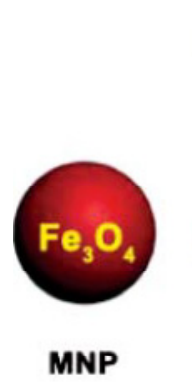

Ething

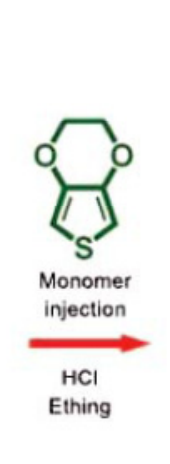

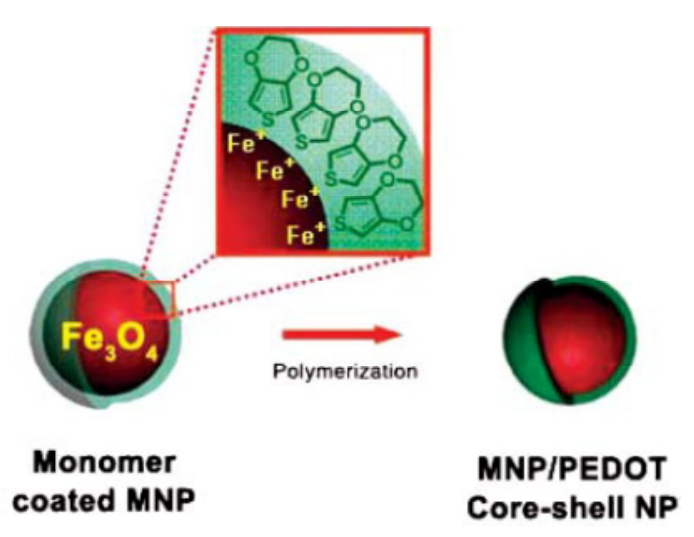

Core-shell NP

Chitosan-bound $\mathrm{Fe}_{3} \mathrm{O}_{4}$ magnetic nanoparticle has been used for the adsorption of $\mathrm{Cu}^{2+}$ and $\mathrm{Au}$ (III) ions [245,246]. TEM images showed that $\mathrm{Fe}_{3} \mathrm{O}_{4}$ and chitosan-bound $\mathrm{Fe}_{3} \mathrm{O}_{4}$ nanoparticles had a similar particle size of $13.5 \mathrm{~nm}$ and were monodisperse [245]. This revealed the reaction between $\mathrm{Fe}_{3} \mathrm{O}_{4}$ and chitosan occured only on the surface of $\mathrm{Fe}_{3} \mathrm{O}_{4}$. Also, XRD patterns showed that the binding of chitosan to the surface of $\mathrm{Fe}_{3} \mathrm{O}_{4}$ did not result in the phase change of $\mathrm{Fe}_{3} \mathrm{O}_{4}$. Experiments showed that the $\mathrm{pH}$ of isoelectric point of chitosan-bound $\mathrm{Fe}_{3} \mathrm{O}_{4}$ nanoparticles was 5.9 and the optimum $\mathrm{pH}$ for the adsorption of $\mathrm{Cu}^{2+}$ ions was in the range of 2-5 [245] and that of $\mathrm{Au}$ (III) negatively-charged complex was 2 [246]. The $q_{\max }$ values for $\mathrm{Cu}^{2+}$ and $\mathrm{Au}(\mathrm{III})$ were 21.5 [245] and $59.52 \mathrm{mg} / \mathrm{g}$ [246], respectively. In a different study, Tao et al. [247] used thiol-functionalized magnetic mesoporous microsphere (TMMM) for adsorption of $\mathrm{Hg}^{2+}$ and $\mathrm{Pb}^{2+}$. The $\mathrm{Fe}_{3} \mathrm{O}_{4}$ nanoparticles were used as a core and coated with two silica layers, a tightly crossed silica thin layer and a mesoporous silica shell. The thiol moiety had a strong affinity towards these metal ions. The porous structure of the silica shell brought large surface area and provided the opportunity to graft organic moiety for adsorption of metal ions. $q_{\max }$ value of $\mathrm{Hg}^{2+}$ was $185.19 \mathrm{mg} / \mathrm{g}$ at $20{ }^{\circ} \mathrm{C}$ and decreased in the presence of $\mathrm{Ca}^{2+}, \mathrm{Mg}^{2+}$ and $\mathrm{Na}^{+}$ions.

In some works, organic moieties (chitosan [248] and polystyrene [249]) were used as core. Polystyrene-supported $\mathrm{Fe}_{3} \mathrm{O}_{4}$ nanoparticles (PS- $\mathrm{Fe}_{3} \mathrm{O}_{4} \mathrm{NPs}$ ) was used for the adsorption of arsenate oxyanion [249]. Zeta potential measurements showed the polystyrene (PS) latex was negatively charged in a wide $\mathrm{pH}$ range and $\mathrm{Fe}_{3} \mathrm{O}_{4}$ nanoparticles were positively charged in acidic or neutral solutions. This was the driving force for the acervation of $\mathrm{Fe}_{3} \mathrm{O}_{4}$ nanoparticles on PS and the formation of PS-Fe $\mathrm{O}_{4}$ NPs. At $\mathrm{pH}$ of $6, \mathrm{As}(\mathrm{V})$ was as $\mathrm{HAsO}_{4}{ }^{2-}$ and $\mathrm{PS}-\mathrm{Fe}_{3} \mathrm{O}_{4}$ NPs had the maximum adsorption capacity for its adsorption. TEM images showed that the diameter of fresh $\mathrm{Fe}_{3} \mathrm{O}_{4}$ spherical beads 
(due to aggregation) were in the range of 350-400 nm, but there was not observed coalescence between PS- $-\mathrm{Fe}_{3} \mathrm{O}_{4}$ NPs. Due to these, the $q_{\text {max }}$ value for the adsorption of arsenate on PS- $\mathrm{Fe}_{3} \mathrm{O}_{4}$ was $139.3 \mathrm{mg} / \mathrm{g}$ whereas that of $\mathrm{Fe}_{3} \mathrm{O}_{4}$ was $78.4 \mathrm{mg} / \mathrm{g}$. The used $\mathrm{PS}-\mathrm{Fe}_{3} \mathrm{O}_{4} \mathrm{NP}$ was recovered by $0.1 \mathrm{M}$ $\mathrm{NaOH}$ and its recycling efficiency after the sixth cycle was $89.6 \%$.

Lv et al. [250] synthesized nanosized hydrous $\mathrm{MnO}_{2}$ encapsulated within porous polystyrene cation exchanger as adsorbent for heavy metals. The $-\mathrm{SO}_{3}{ }^{-}$groups of polymeric matrix and $-\mathrm{MnOH}$ and $-\mathrm{Mn}(\mathrm{OH})_{2}$ groups of $\mathrm{MnO}_{2}$ interacted with $\mathrm{Zn}^{2+}$ and $\mathrm{Cd}^{2+}$. In the presence of $\mathrm{Ca}^{2+}$, due to its electrostatic interaction with $-\mathrm{SO}_{3}{ }^{-}$groups, $q_{\max }$ values of nanocomposite for adsorption with $\mathrm{Zn}^{2+}$ and $\mathrm{Cd}^{2+}$ were decreased greatly.

Some researchers have used two inorganic compounds (e.g., $\mathrm{SiO}_{2}$ and $\mathrm{Fe}_{3} \mathrm{O}_{4}$ ) as the core $[251,252]$. Firstly, they prepared $\mathrm{Fe}_{3} \mathrm{O}_{4}$ on which a layer of $\mathrm{SiO}_{2}$ was synthesized, and then carried out the polymerization on the surface of $\mathrm{SiO}_{2}$. Song et al. [251] synthesized $\mathrm{Fe}_{3} \mathrm{O}_{4}-\mathrm{SiO}_{2}-$ poly(1,2-diaminobenzene) sub-micron particle (FSP) for the removal of $\mathrm{Cr}(\mathrm{III})$, As(III) and $\mathrm{Cu}(\mathrm{II})$. Zhang et al. [252] used 3-(2-aminoethylamino)propyltrimethoxysilane (AAPTS) as the functional monomer and $\mathrm{Pb}^{2+}$ as the template to prepare an ion-imprinted polymer $\left(\mathrm{Fe}_{3} \mathrm{O}_{4} @ \mathrm{SiO}_{2} @ \mathrm{IIP}\right)$ for the separation of $\mathrm{Pb}^{2+}$ ion from water (Scheme 10).

Scheme 10. Schematic structures of (a) FSP (Reprinted with Permission from [251]. Copyright 2012 Elsevier) and (b) template in $\mathrm{Fe}_{3} \mathrm{O}_{4} @ \mathrm{SiO}_{2} @ \mathrm{IIP}$ (Reprinted with permission from [252]. Copyright 2011 Elsevier).

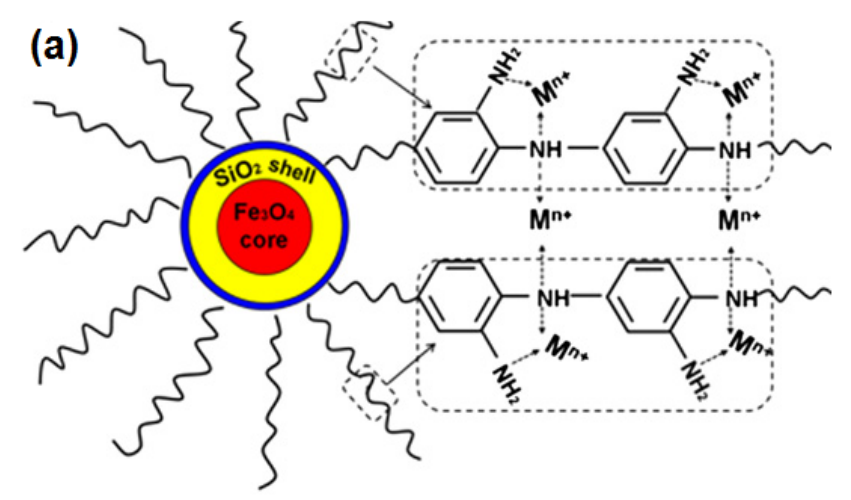

(b)

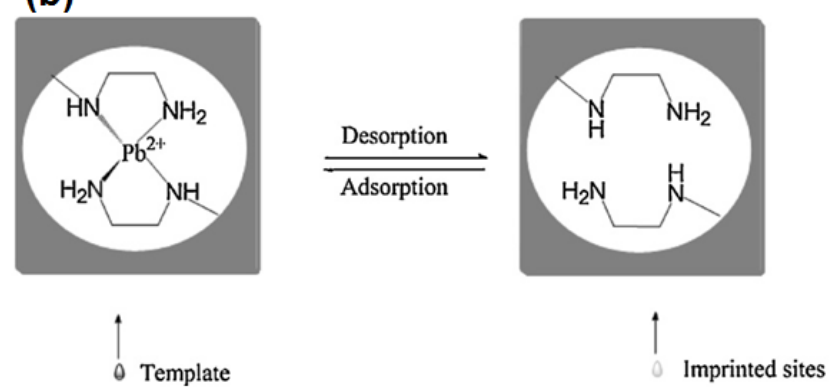

XRD patterns showed that peaks of $\mathrm{Fe}_{3} \mathrm{O}_{4}$ of the core-shell compounds were similar to those of naked $\mathrm{Fe}_{3} \mathrm{O}_{4}$ nanoparticles and the surface modification of $\mathrm{Fe}_{3} \mathrm{O}_{4}$ did not result in its phase change. In both adsorbents, amine groups interacted with metal ions. Experiments using $\mathrm{Fe}_{3} \mathrm{O}_{4} @ \mathrm{SiO}_{2} @ \mathrm{IIP}$ at $\mathrm{pH}=7.5$ showed that in the presence of $\mathrm{Cu}^{2+}, \mathrm{Zn}^{2+}, \mathrm{Cd}^{2+}$ and $\mathrm{Hg}^{2+}$, the relative selectivity factor values of $\mathrm{Pb}^{2+} / \mathrm{Cu}^{2+}, \mathrm{Pb}^{2+} / \mathrm{Zn}^{2+}, \mathrm{Pb}^{2+} / \mathrm{Cd}^{2+}$ and $\mathrm{Pb}^{2+} / \mathrm{Hg}^{2+}$ were $7.41,6.76,3.75$ and 6.39 , respectively [252]. 
However, when authors used a non-imprinted polymer to synthesize this core-shell polymer $\left(\mathrm{Fe}_{3} \mathrm{O}_{4} @ \mathrm{SiO}_{2} @ \mathrm{NIP}\right)$, values of the above-mentioned relative selectivity factor were about 1 and this adsorbent was not selective toward $\mathrm{Pb}^{2+}$.

As we saw in this section, synthesing core-shell nanocomposites does not result in the phase change of its inorganic moiety. In some cases, more than one inorganic compound was used as the core. Functional groups of the shell have a major role in the adsorption of heavy metal ions and core-shell nanocomposites had good mechanical stability and organic moiety of these compounds had higher thermal stability than that of its pure form.

\subsection{Adsorption of Heavy Metals on Organic-Inorganic Hierarchically Structured Materials}

Hierarchically structured compounds were explained briefly in Section 2.3.5. Li et al. [253] synthesized a hierarchical nanocomposite by the polymerization of aniline arrays on the surface of grapheme oxide nanosheets and used it as a superadsorbent for the adsorption of $\mathrm{Cr}(\mathrm{VI})$ oxyanion from water (Figure 18 and Table 4). Aniline monomers (ANI) were adsorbed on the surface of graphene oxide (GO) through electrostatic interactions with its reactive oxygen-containing functional groups and further the polymerization of ANIs resulted in the formation of aligned polyaniline (PANI) nanorods on the surface of GO (PANI/GO).

Figure 18. Mechanism of formation of polyaniline (PANI) nanorods on the surface of graphene oxide (GO) (PANI/GO) hierarchical nanocomposites. Reproduced with permission from [253]. Copyright 2013 The Royal Society of Chemistry.

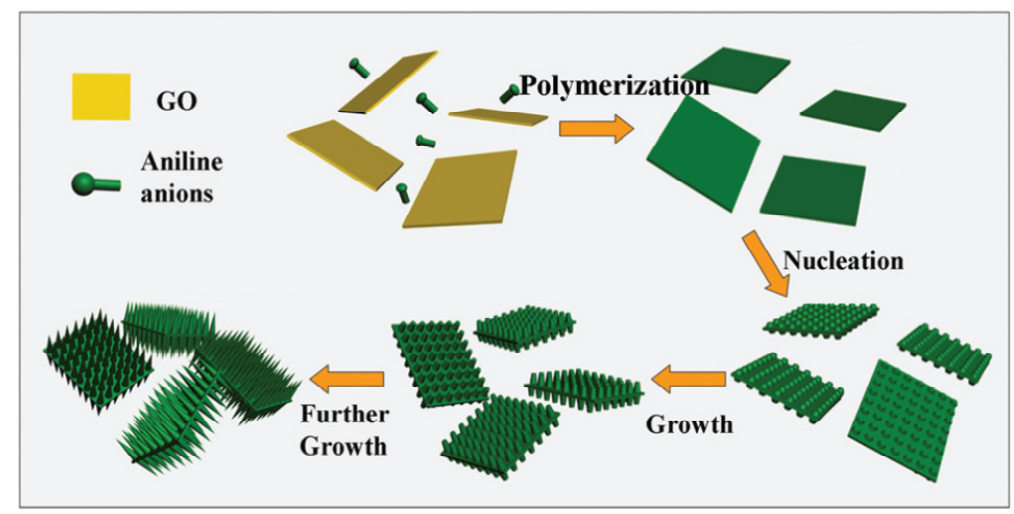

XRD patterns showed that the interplanar distance of GO nanosheets was $0.88 \mathrm{~nm}$ (as agglomerated) and PANI/GO demonstrated characteristic peaks of PANI (Supporting information Figure S10). These evidence proved that GO and PANI/GO were as agglomerated and separated nanosheets, respectively. Adsorption experiments were carried out at $\mathrm{pH}=2$ in which $\mathrm{Cr}(\mathrm{VI})$ adapting the form of $\mathrm{HCrO}_{4}{ }^{-}$ interacted with the protonated nitrogen atoms of PANI in pure PANI and PANI/GO. Pure PANI was simply aggregated and its surface area was smaller than PANI/GO and the $q_{\max }$ values of PANI and PANI/GO were 490.2 and $1149.4 \mathrm{mg} / \mathrm{g}$, respectively.

In a novel work, Li et al. [254] fabricated polystyrene (PS) nanofibrous mats by an electrospinning method and used as a skeleton for thiol-functionalized mesoporous silica compound (Figure 19 and Table 4). In this hierarchical structure the PS nanofibers had macroporous structures (diameters of 3-10 $\mu \mathrm{m}$ ) and were randomly distributed in the membrane (Supporting information Figure S11). The 
optimum $\mathrm{pH}$ for the adsorption of $\mathrm{Cu}^{2+}$ was about 5 and its $q_{\max }$ value was $11.33 \mathrm{mg} / \mathrm{g}$. $\mathrm{Cu}^{2+}$ ions were adsorbed by - $\mathrm{SH}$ groups within mesopores. The amount of thiol groups in the adsorbent was $0.32 \mathrm{mmol} / \mathrm{g}$ and the adsorption efficiency $\left(\mathrm{Cu}^{2+} / \mathrm{SH}\right.$ molar ratio) of adsorbent was about $80 \%$. After the recovery of adsorbent by $0.5 \mathrm{M} \mathrm{HCl}$, its adsorption capacity of $\mathrm{Cu}^{2+}$ was basically maintained after five cycles.

In another different works with hierarchical structure compounds, Ma et al. synthesized $\mathrm{CaCO}_{3}$-pepsin [255] and $\mathrm{CaCO}_{3}$-maltose [256] and used them as adsorbents. Here, structure and adsorption characteristics of $\mathrm{CaCO}_{3}$-pepsin [255] are studied (Figure 20). Pepsin is an enzyme which is made up of 327 amino acids. SEM images showed that $\mathrm{CaCO}_{3}$-pepsin consisted of a large number of tetrahedral micro-aggregates that were composed of smaller tetrahedral building nano-blocks (Supporting information Figure S12).

XRD, SEM and IR results showed that $\mathrm{CaCO}_{3}$ and pepsin interacted through both coordination of $\mathrm{Ca}^{2+}$ and pepsin and interactions between the surface of $\mathrm{CaCO}_{3}$ nanocrystals and $-\mathrm{OH}$ and $-\mathrm{CO}$ groups of pepsin.

Figure 19. Schematic illustration of preparing thiol-functionalized membranes using electrospun nanofibrous mats as the skeleton. Reproduced with permission from [254]. Copyright 2012 The Royal Society of Chemistry.

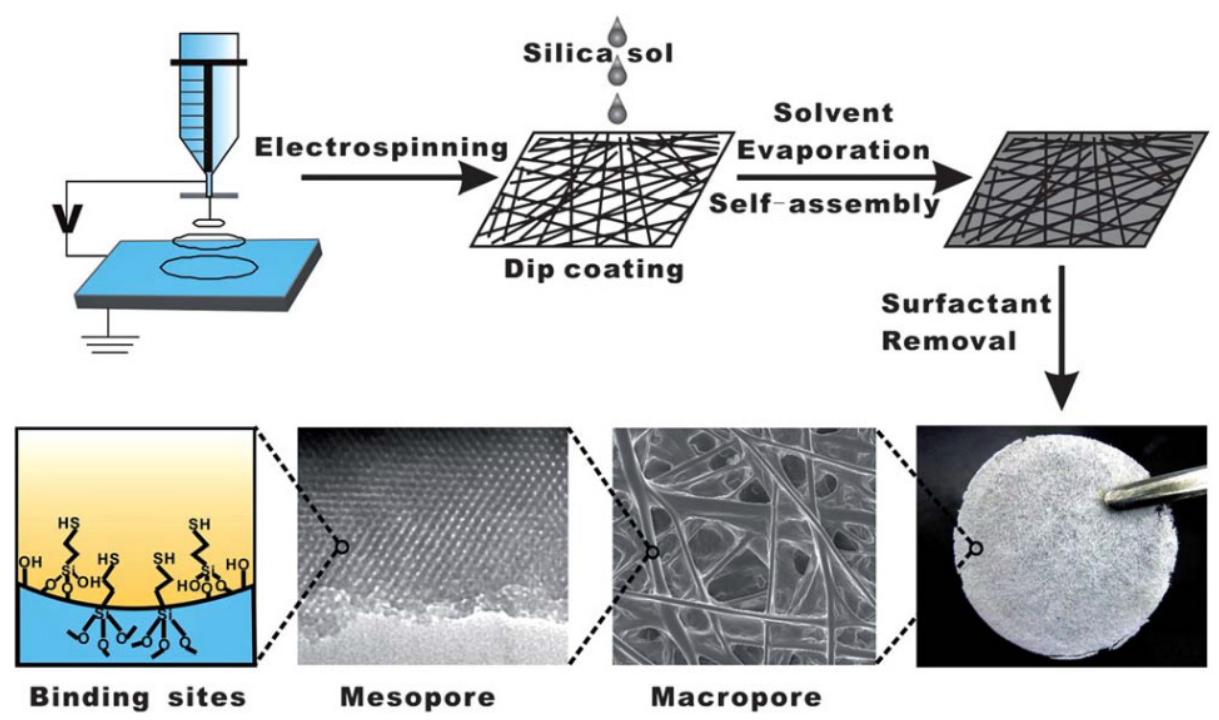

Adsorption experiments were carried out in neutral $\mathrm{pH}$ and the adsorption capacity of $\mathrm{CaCO}_{3}$-pepsin for $\mathrm{Pb}^{2+}$ and $\mathrm{Cu}^{2+}$ were 1167 and $611 \mathrm{mg} / \mathrm{g}$, respectively and the removal of $\mathrm{Pb}^{2+}$ was very rapid (about 20 min). Solubility product of $\mathrm{PbCO}_{3}$ and $\mathrm{CuCO}_{3}$ are less than $\mathrm{CaCO}_{3}$ and thus $\mathrm{Cu}^{2+}$ and $\mathrm{Pb}^{2+}$ precipitate as their carbonates.

On the other hand, adsorption capacities of $\mathrm{CaCO}_{3}$-maltose [256], another hierarchical structure superadsorbent, for $\mathrm{Pb}^{2+}, \mathrm{Ni}^{2+}, \mathrm{Cu}^{2+}$ and $\mathrm{Cd}^{2+}$ (as metal carbonate) were 3242.48, 769.23, 628.93 and $487.8 \mathrm{mg} / \mathrm{g}$, respectively whereas adsorption capacity of $\mathrm{CaCO}_{3}$ for $\mathrm{Pb}^{2+}$ is $62.5 \mathrm{mg} / \mathrm{g}$ and this showed clearly synergic effects between organic and inorganic moieties in these compounds. As we saw, the organic-inorganic hierarchically structured compounds are superadsorbent. 
Figure 20. Mechanism of the formation of hierarchical structures of $\mathrm{CaCO}_{3}$-pepsin from amorpuus precursors. Reprinted with permission from [255]. Copyright 2012 Elsevier.

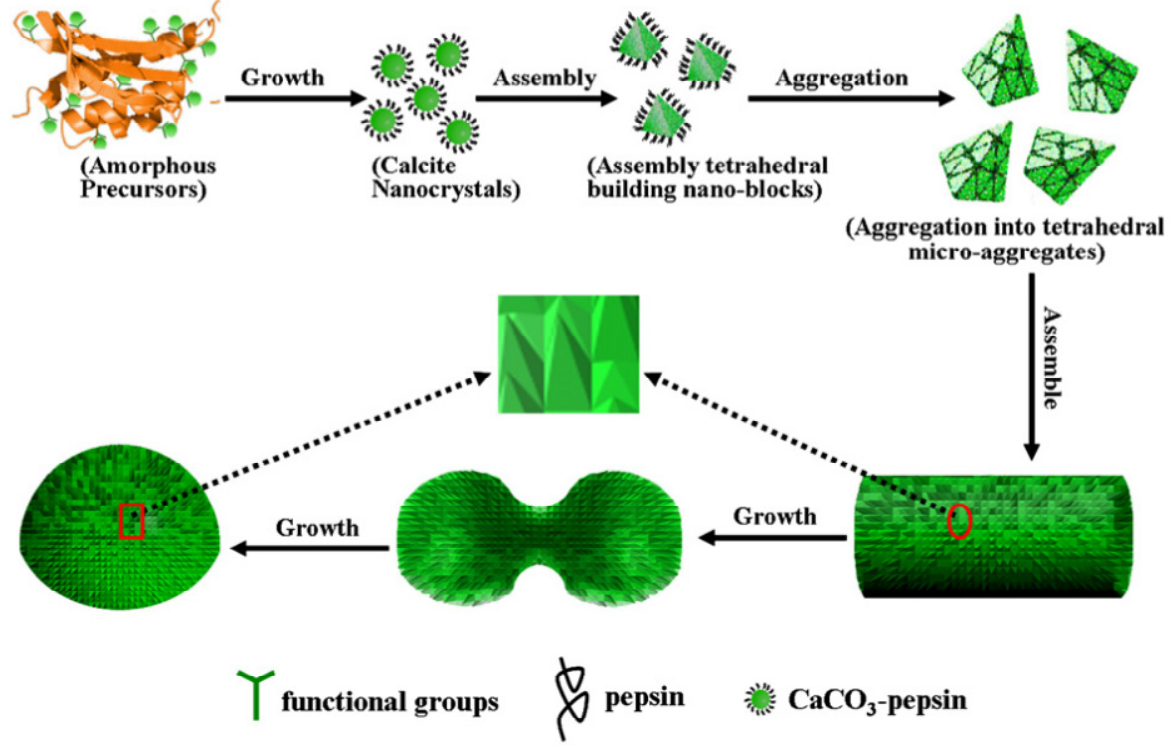

\subsection{Characteristics of Organic-Inorganic Hybrid Polymers}

To study Sections 3.1-3.5, the characteristics of different kinds of organic-inorganic hybrid polymers were as follows: (1) Some functional groups of these adsorbents are $-\mathrm{SH},-\mathrm{COOH}$, amines and $-\mathrm{S}-\mathrm{S}-,-\mathrm{OH},-\mathrm{SO}_{3}{ }^{-}$and ion exchange sites of hybrid polymer; (2) adsorption processes mostly obey the Langmuir isotherm that shows the adsorption is monolayer and there is a uniform distribution of sites on the surface of adsorbents; (3) the adsorption capacity of each certain organic functional group changes depending on its content [181,214], the used organic compound, inorganic support [166,195], crosslinking agent [212], aggregation of nanoparticles [253] and the used synthesis method [182,189]; (4) in some cases, organic compounds are used only for increasing thermal and mechanical stability of adsorbents and without adsorbing heavy metal ions [224]; (5) mesoprous compounds, due to their porous structures have a rather higher adsorption capacities compared to those of organically-functionalized layered, core-shell compounds and products of sol-gel method; (6) heavy metals as cations and oxyanions are adsorbed via electrostatic interactions and the increase in the hydrophobicity of functional groups of adsorbent (e.g., $-\mathrm{N}\left(\mathrm{C}_{2} \mathrm{H}_{5}\right)_{2}$ [156] or from $-\mathrm{NH}_{2}$ to $-\mathrm{NH}$ (propyl) to $-\mathrm{N}$ (propyl) $)_{2}[178]$ ) decreases their adsorption capacity for metal cations and increases their $q_{\max }$ values (e.g., from trimethylammonium to tri- $n$-butylammonium functional groups) for the adsorption of some hydrophobic oxyanions [183]; (7) In the most cases, for example [141-147,216,221,225,241,243,249,252], the used adsorbents are recovered by acid treatment and in the cases that acid dissolves the adsorbent [199], they have used another washing solutions; (8) some ions may react with metallic ions, e.g., $\mathrm{Cl}^{-}$with $\mathrm{Hg}^{2+}$ [226], and inhibit their adsorption; (9) some ions, e.g., $\mathrm{Cl}^{-}$[183], $\mathrm{SO}_{4}{ }^{2-}$ [196] or metallic cations [252], may react with functional groups of hybrid adsorbents and decrease their adsorption capacity for heavy metal ions; (10) steric hindrance on functional group decreases its adsorption capacity [151]; (11) in most cases, adsorption capacities of organic-inorganic hybrid polymers are bigger than those of their organic or inorganic constituents; (12) most of heavy metals were adsorbed in the $\mathrm{pH}$ range 4-7. With the increase in alkalinity of 
solution, heavy metal ions convert to metal hydroxides and this decreases their affinity for interaction with binding sites of adsorbents [224] and in highly acidic solutions, $\mathrm{H}^{+}$ions compete with metal ions for adsorption on the adsorbent surface [212]; (13) increasing the content of functional groups increases the adsorption capacity of these kinds of hybrid polymers although it decreases their pore size and surface area [153,169,170]; and (14) adsorption capacities of hierarchically structure compounds are much greater than the other kinds of discussed organic-inorganic hybrid polymers and in the future they can be used as superadsorbents for the adsorption of heavy metals.

\section{Conclusions and Outlook}

Organic-inorganic hybrid polymers are obtained through sol-gel processes, self-assembly processes, assembling or dispersion of nanobuilding blocks, hierarchical structures and interpenetrating networks. In these compounds, the functional variation of organic materials combines with the benefits of a sturdy and thermally stable inorganic substrate. These materials have strong binding affinities toward selected metal ions (as cations or oxyanions) and relatively high metal ion adsorption capacities and can be used for wastewater treatment and solid-state separation of heavy metals. They are modified by suitable functional groups for high efficiency adsorption of heavy metal ions under the used experimental conditions. Techniques such as XRD and SEM show that in hybrid polymers, the structure of organic and inorganic moieties change and synergy effects between them increase their adsorption capacities, compared to their individual pristine organic or inorganic moieties. Heavy metal selective adsorbents can be prepared by methods such as cation-IIP. Although adsorbents similar to activated carbon are used routinely for their low cost and high adsorption capacity, different combinations of organic and inorganic moieties provide us a large number of selections of hybrid adsorbents that can be used under different experimental conditions, are reusable and can be prepared for selective adsorption of heavy metals and in some cases act as superadsorbents. For synthesis of these compounds, environmentally friendly compounds such as chitosan, humic acid, cellulose and bentonite are used and their partial leaching during adsorption processes has no negative impact on the environment.

\section{Conflicts of Interest}

The authors declare no conflict of interest.

\section{References}

1. Bohn, H.L.; McNeal, B.L.; O’Connor, G.A. Soil Chemistry; John Wiely: New York, NY, USA, 1985.

2. Bradl, H.B. Heavy Metals in the Environment: Origin, Interaction and Remediation; Elsevier: Amsterdam, The Netherlands, 2005.

3. Fergusson, J.E. The Heavy Elements: Chemistry, Environmental Impact and Health Effects; Pergamon Press: Exeter, UK, 1990. 
4. Jha, M.K.; Lee, J.-C.; Kim, M.-S.; Jeong, J.; Kim, B.-S.; Kumar, V. Hydrometallurgical recovery/recycling of platinum by the leaching of spent catalysts: A review. Hydrometallurgy 2013, 133, 23-32.

5. Syed, S. Recovery of gold from secondary sources-A review. Hydrometallurgy 2012, 115-116, $30-51$.

6. Esalah, O.J.; Weber, M.E.; Vera, J.H. Removal of lead, cadmium and zinc from aqueous solutions by precipitation with sodium di-(n-octyl) phosphinate. Can. J. Chem. Eng. 2000, 78, 948-954.

7. Lertlapwasin, R.; Bhawawet, N.; Imyim, A.; Fuangswasdi, S. Ionic liquid extraction of heavy metal ions by 2-aminothiophenol in 1-butyl-3-methylimidazolium hexafluorophosphate and their association constants. Sep. Purif. Technol. 2010, 72, 70-76.

8. Emamjomeh, M.M.; Sivakumar, M. Review of pollutants removed by electrocoagulation and electrocoagulation/flotation processes. J. Environ. Manag. 2009, 90, 1663-1679.

9. Mahmoud, A.; Hoadley, A.F. An evaluation of a hybrid ion exchange electrodialysis process in the recovery of heavy metals from simulated dilute industrial wastewater. Water Res. 2012, 46, 3364-3376.

10. Yurloval, L.; Kryvoruchko, A.; Kornilovich, B. Removal of Ni (II) ions from wastewater by micellar-enhanced ultrafiltration. Desalination 2002, 144, 255-260.

11. Greenlee, L.F.; Lawler, D.F.; Freeman, B.D.; Marrot, B.; Moulin, P. Reverse osmosis desalination: Water sources, technology, and today's challenges. Water Res. 2009, 43, 2317-2348.

12. Benit, Y.; Ruiz, M.L. Reverse osmosis applied to metal finishing wastewater. Desalination 2002, 142, 229-234.

13. Rubio, J.; Souza, M.L.; Smith, R.W. Overview of flotation as a wastewater treatment technique. Miner. Eng. 2002, 15, 139-155.

14. Ghurye, G.; Clifford, D.; Tripp, A. Iron coagulation and direct microfiltration to remove arsenic from groundwater. $A W W A$ 2004, 96, 143-152.

15. Barakat, M.A. New trends in removing heavy metals from industrial wastewater. Arab. J. Chem. 2011, 4, 361-377.

16. Pan, B.J.; Pan, B.C.; Zhang, M.W.; Lv, L.; Zhang, Q.X.; Zheng, S.R. Development of polymeric and polymer-based hybrid adsorbents for pollutants removal from waters. Chem. Eng. J. 2009, $151,19-29$.

17. Mishra, S.P.; Singh, V.K.; Tiwari, D. Radiotracer technique in adsorption study. 14. Efficient removal of mercury from aqueous solutions by hydrous zirconium oxide. Appl. Radiat. Isot. 1996, 47, 15-21.

18. Uzun, I.; Güzel, F. Adsorption of some heavy metal ions from aqueous solution by activated carbon and comparison of percent adsorption results of activated carbon with those of some other adsorbents. Turk. J. Chem. 2000, 24, 291-297.

19. Biskup, B.; Subotic, B. Kinetic analysis of the exchange processes between sodium ions from zeolite A and cadmium, copper and nickel ions from solutions. Sep. Purif. Technol. 2004, 37, 17-31.

20. Cincotti, A.; Mameli, A.; Locci, A.M.; Orru, R.; Cao, G. Heavy metals uptake by Sardinian natural zeolites: Experiment and modeling. Ind. Eng. Chem. Res. 2006, 45, 1074-1084. 
21. Gier, S.; Johns, W.D. Heavy metal-adsorption on micas and clay minerals studied by X-ray photoelectron spectroscopy. Appl. Clay Sci. 2000, 16, 289-299.

22. Koppelman, M.H.; Dillard, J.G. A study of the adsorption of $\mathrm{Ni}(\mathrm{II})$ and $\mathrm{Cu}(\mathrm{II})$ by clay minerals. Clays Clay Miner. 1977, 25, 457-462.

23. O’Connell, D.W.; Birkinshaw, C.; O’Dwyer, T.F. Heavy metal adsorbents prepared from the modification of cellulose: A review. Bioresour. Technol. 2008, 99, 6709-6724.

24. Dang, V.B.H.; Doan, H.D.; Dang-Vuc, T.; Lohi, A. Equilibrium and kinetics of biosorption of cadmium(II) and copper(II) ions by wheat straw. Bioresour. Technol. 2009, 100, 211-219.

25. Zewail, T.M.; El-Garf, S.A.M. Preparation of agriculture residue based adsorbents for heavy metal removal. Desalin. Water Treat. 2010, 22, 363-370.

26. Nagarale, R.K.; Gohil, G.S.; Shahi, V.K. Recent developments on ion-exchange membranes and electro-membrane processes. Adv. Colloid Interface Sci. 2006, 119, 97-130.

27. Wang, L.; Wu, X.L.; Xu, W.-H.; Huang, X.-J.; Liu, J.-H.; Xu, A.-W. Stable organic-inorganic hybrid of polyaniline/ $\alpha$-zirconium phosphate for efficient removal of organic pollutants in water environment. Appl. Mater. Interfaces 2012, 4, 2686-2692.

28. Gao, B.; Gao, Y.; Li, Y. Preparation and chelation adsorption property of composite chelating material poly(amidoxime) $/ \mathrm{SiO}_{2}$ towards heavy metal ions. Chem. Eng. J. 2010, 158, 542-549.

29. Zaitseva, N.; Zaitsev, V.; Walcarius, A. Chromium(VI) removal via reduction-sorption on bi-functional silica adsorbents. J. Hazard. Mater. 2013, 250-251, 454-461.

30. Simsek, E.B.; Duranoglu, D.; Beker, U. Heavy metal adsorption by magnetic hybrid-sorbent: An experimental and theoretical approach. Sep. Sci. Technol. 2012, 47, 1334-1340.

31. Suchithra, P.S.; Vazhayal, L.; Mohamed, A.P.; Ananthakumar, S. Mesoporous organic-inorganic hybrid aerogels through ultrasonic assisted sol-gel intercalation of silica-PEG in bentonite for effective removal of dyes, volatile organic pollutants and petroleum products from aqueous solution. Chem. Eng. J. 2012, 200-202, 589-600.

32. Repo, E.; Warchoł, J.K.; Bhatnagar, A.; Sillanpää, M. Heavy metals adsorption by novel EDTA-modified chitosan-silica hybrid materials. J. Colloid Interface Sci. 2011, 358, 261-267.

33. Ge, P.; Li, F.; Zhang, B. Synthesis of modified mesoporous materials and comparative studies of removal of heavy metal from aqueous solutions. Pol. J. Environ. Stud. 2010, 19, 301-308.

34. Pang, Y.; Zeng, G.; Tang, L.; Zhang, Y.; Liu, Y.; Lei, X.; Li, Z.; Zhang, J.; Xie, G. PEI-grafted magnetic porous powder for highly effective adsorption of heavy metal ions. Desalination 2011, $281,278-284$.

35. Wang, L.; Zhang, J.; Wang, A. Fast removal of methylene blue from aqueous solution by adsorption onto chitosan-g-poly (acrylic acid)/attapulgite composite. Desalination 2011, 266, 33-39.

36. Mercier, L.; Pinnavaia, T.J. Heavy metal ion adsorbents formed by the grafting of a thiol functionality to mesoporous silica molecular sieves: Factors affecting $\mathrm{Hg}$ (II) uptake. Environ. Sci. Technol. 1998, 32, 2749-2754.

37. Sanchez, C.; Julián, B.; Belleville, P.; Popall, M. Applications of hybrid organic-inorganic nanocomposites. J. Mater. Chem. 2005, 15, 3559-3592.

38. Walcarius, A. Electrochemical applications of silica-based organic-inorganic hybrid materials. Chem. Mater. 2001, 13, 3351-3372. 
39. Kim, D.-G.; Kang, H.; Han, S.; Lee, J.-C. Dual effective organic/inorganic hybrid star-shaped polymer coatings on ultrafiltration membrane for bio- and oil-fouling resistance. Appl. Mater. Interfaces 2012, 4, 5898-5906.

40. Paun, G.; Neagu, E.; Tache, A.; Radu, G.L.; Parvulescu, V. Application of the nanofiltration process for concentration of polyphenolic compounds from geranium robertianum and salvia officinalis extracts. Chem. Biochem. Eng. Quart. 2011, 25, 453-460.

41. Wen, X.F.; Wang, K.; Pi, P.-H.; Yang, J.-X.; Cai, Z.-Q.; Zhang, L.-J.; Qian, Y.; Yang, Z.-R.; Zheng, D.-F.; Cheng, J. Organic-inorganic hybrid superhydrophobic surfaces using methyltriethoxysilane and tetraethoxysilane sol-gel derived materials in emulsion. Appl. Surf. Sci. 2011, 258, 991-998.

42. Sparks, B.J.; Hoff, E.F.; Xiong, L.; Goetz, J.T.; Patton, D.L. Superhydrophobic hybrid inorganic-organic thiol-ene surfaces fabricated via spray-deposition and photopolymerization. Appl. Mater. Interfaces 2013, 5, 1811-1817.

43. Yu, Y.-Y.; Chen, W.-C. Transparent organic-inorganic hybrid thin films prepared from acrylic polymer and aqueous monodispersed colloidal silica. Mater. Chem. Phys. 2003, 82, 388-395.

44. Nagappan, S.; Choi, M.-C.; Sung, G.; Park, S.S.; Moorthy, M.S.; Chu, S.-W.; Lee, W.-K.; Ha, C.-S. Highly transparent, hydrophobic fluorinated polymethylsiloxane/silica organic-inorganic hybrids for anti-stain coating. Macromol. Res. 2013, 21, 669-680.

45. Rottman, C.; Grader, G.; de Hazan, Y.; Melchior, S.; Avnir, D. Surfactant-induced modification of dopants reactivity in sol-gel matrixes. J. Am. Chem. Soc. 1999, 121, 8533-8543.

46. Date, J.D.; Moet, L.; Koster, J.A.; de Boer, B.; Blom, P.W.M. Hybrid polymer solar cells from highly reactive diethylzinc: MDMO-PPV versus P3HT. Chem. Mater. 2007, 19, 5856-5861.

47. He, M.; Qiu, F.; Lin, Z. Toward high-performance organic-inorganic hybrid solar cells: Bringing conjugated polymers and inorganic nanocrystals in close contact. J. Phys. Chem. Lett. 2013, 4, 1788-1796.

48. Souza, F.L.; Bueno, P.R.; Longo, E.; Leite, E.R. Sol-gel nonhydrolytic synthesis of a hybrid organic-inorganic electrolyte for application in lithium-ion devices. Solid State Ion. 2004, 66, 83-88.

49. Lee, C.-F.; Leigh, D.A.; Pritchard, R.G.; Schultz, D.; Teat, S.J.; Timco, G.A.; Winpenny, R.E.P. Hybrid organic-inorganic rotaxanes and molecular shuttles. Nature 2009, 458, 314-318.

50. Singh, A.; Singh, N.P.; Singh, R.A. Biomimetic synthesis and characterization of semiconducting hybrid organic-inorganic composite materials based on polyaniline-polyethylene glycol-CdS system. Bull. Mater. Sci. 2011, 34, 1017-1026.

51. Collins, D.J.; Zhou, H.-C. Hydrogen storage in metal-organic frameworks. J. Mater. Chem. 2007, 17, 3154-3160.

52. Rowsell, J.L.C.; Millward, A.R.; Park, K.S.; Yaghi, O.M. Hydrogen sorption in functionalized metal-organic frameworks. J. Am. Chem. Soc. 2004, 126, 5666-5667.

53. Raj, G.; Swalus, C.; Guillet, A.; Devillers, M.; Nysten, B.; Gaigneaux, E.M. Supramolecular organization in organic-inorganic heterogeneous hybrid catalysts formed from polyoxometalate and poly(ampholyte) polymer. Langmuir 2013, 29, 4388-4395. 
54. Fu, G.; Yue, X.; Dai, Z. Glucose biosensor based on covalent immobilization of enzyme in sol-gel composite film combined with Prussian blue/carbon nanotubes hybrid. Biosens. Bioelectron. 2011, 26, 3973-3976.

55. Gwak, G.H.; Paek, S.M.; Oh, J.M. Electrophoretic preparation of an organic-inorganic hybrid of layered metal hydroxide and hydrogel for a potential drug-delivery system. Eur. J. Inorg. Chem. 2012, 2012, 5269-5275.

56. Chou, T.P.; Chandrasekaran, C.; Cao, G.Z. Sol-gel-derived hybrid coatings for corrosion protection. JSST 2003, 26, 321-327.

57. Bourbigot, S.; Duquesne, S. Fire retardant polymers: Recent developments and opportunities. J. Mater. Chem. 2007, 17, 2283-2300.

58. Kim, S.S.; Ahn, K.M.; Park, M.S.; Lee, J.H.; Choi, C.Y.; Kim, B.S. A poly(lactic-co-glycolide)/ hydroxyapatite composite scaffold with enhanced osteoconductivity. J. Biomed. Mater. Res. A 2007, 80A, 206-215.

59. Kwon, Y.K.; Han, J.K.; Lee, J.M.; Ko, Y.S.; Oh, J.H.; Leeb, H.-S.; Lee, E.-H. Organic-inorganic hybrid materials for flexible optical waveguide applications. J. Mater. Chem. 2008, 18, 579-585.

60. Frisch, H.L.; Mark, J.E. Nanocomposites prepared by threading polymer chains through zeolites, mesoporous silica, or silicananotubes. Chem. Mater. 1996, 8, 1735-1738.

61. Hench, L.L.; West, J.K. The sol-gel process. Chem. Rev. 1990, 90, 33-72.

62. Sol-Gel. Available online: http://en.wikipedia.org/wiki/sol-gel (acessed on 10 December 2013).

63. Warrick, E. Forty Years of Firsts a Recollection of Dow Corning Pioneer; McGraw-Hill: New York, NY, USA, 1990.

64. Hay, J.N.; Raval, H.M. Synthesis of organic-inorganic hybrids via the non-hydrolytic sol-gel process. Chem. Mater. 2001, 13, 3396-3403.

65. Wen, J.; Wilkes, G.L. Organic/inorganic hybrid network materials by the sol-gel approach. Chem. Mater. 1996, 8, 1667-1681.

66. Chong, M.N.; Jin, B. Sol-gel synthesis of inorganic mesostructured composite photocatalyst for water purification: An insight into the synthesis fundamentals, reaction, and binding mechanisms. Synth. React. Inorg. Met. Org. Chem. 2012, 42, 68-75.

67. Arkles, B. Comercial applications of sol-gel-derived hybrid materials. MRS Bull. 2001, 26, 402-408.

68. Sol-Gel. Avaliable on line: http://en.wikipedia.org/wiki/Sol-gel (accessed on 10 December 2013).

69. Kessler, V.G.; Spijksma, G.I.; Seisenbaeva, G.A.; Hakansson, S.; Blank, D.H.A.; Bouwmeester, H.J.M. New insight in the role of modifying ligands in the sol-gel processing of metal alkoxide precursors: A possibility to approach new classes of materials. J. Sol-Gel Sci. Technol. 2006, 40, 163-179.

70. Xiao, Y.; Shen, J.; Xie, Z.; Zhou, B.; Wu, G. Microstructure control of nanoporous silica thin film prepared by sol-gel process. J. Mater. Sci. Technol. 2007, 23, 504-508.

71. Ogoshi, T.; Chujo, Y. Organic-inorganic polymer hybrids prepared by the sol-gel method. Compos. Interfaces 2005, 11, 539-566.

72. Loy, D.A. Sol-Gel Processing of Hybrid Organic-Inorganic Materials Based on Polysilsesquioxanes. In Hybrid Materials: Synthesis, Characterization, and Applications; Kickelbick, G., Ed.; Wiley-VCH: Weinheim, Germany, 2006. 
73. Zeolites: Synthesis, Chemistry, and Applications; Andreyev, M.K., Zubkov, O., Eds.; Nova Science Publishers: New York, NY, USA, 2012.

74. Wright, P.A. Microporous Framework Solids; RSC Publishing: Cambridge, UK, 2008; p. 186.

75. Bellussi, G.; Millini, R.; Montanari, E.; Carati, A.; Rizzo, C.; Parker, W.O., Jr.; Cruciani, G.; de Angelis, A.; Bonoldi, L.; Zanardi, S. A highly crystalline microporous hybrid organic-inorganic aluminosilicate resembling the AFI-type zeolite. Chem. Commun. 2012, 48, 7356-7358.

76. Maeda, K.; Kiyozumi, Y.; Mizukami, F. Synthesis of the first microporous aluminum phosphonate with organic groups covalently bonded to the skeleton. Angew. Chem. Int. Ed. 1994, $33,2335-2337$.

77. Zhou, D.; Lu, X.; Xu, J.; Yu, A.; Li, J.; Deng, F.; Xia, Q. Dry gel conversion method for the synthesis of organic-inorganic hybrid MOR zeolites with modifiable catalytic activities. Chem. Mater. 2012, 24, 4160-4165.

78. Jones, C.W.; Tsuji, K.; Davis, M.E. Organic-functionalized molecular sieves as shape-selective catalysts. Nature 1998, 393, 52-54.

79. Inagaki, S.; Yokoi, T.; Kubota, Y.; Tatsumi, T. Unique adsorption properties of organic-inorganic hybrid zeolite IEZ-1 with dimethylsilylene moieties. Chem. Commun. 2007, 48, 5188-5190.

80. Kresge, C.T.; Leonowicz, M.E.; Roth, W.J.; Vartuli, J.C.; Beck, J.S. Ordered mesoporous molecular sieves synthesized by a liquid-crystal template mechanism. Nature 1992, 359, 710-712.

81. Beck, J.S.; Vartuli, J.C.; Roth, W.J.; Leonowicz, M.E.; Kresge, C.T.; Schmitt, K.D.; Chu, C.T.-W.; Olson, D.H.; Sheppard, E.W.; McCullen, S.B.; et al. A new family of mesoporous molecular sieves prepared with liquid crystal templates. J. Am. Chem. Soc. 1992, 114, 10834-10843.

82. Ying, J.Y.; Mehnert, C.P.; Wong, M.S. Synthesis and applications of supramolecular-templated mesoporous materials. Angew. Chem. Int. Ed. 1999, 38, 56-77.

83. Nohair, B.; MacQuarrie, S.; Crudden, C.M.; Kaliaguine, S. Functionalized mesostructured silicates as supports for palladium complexes: Synthesis and catalytic activity for the Suzuki-Miyaura coupling reaction. J. Phys. Chem. C 2008, 112, 6065-6072.

84. Serrano, D.P.; Calleja, G.; Botas, J.A.; Gutierrez, F.J. Adsorption and hydrophobic properties of mesostructured MCM-41 and SBA-15 materials for volatile organic compound removal. Ind. Eng. Chem. Res. 2004, 43, 7010-7018.

85. Zhao, D.; Huo, Q.; Feng, J.; Chmelka, B.F.; Stucky, G.D. Nonionic triblock and star diblock copolymer and oligomeric surfactant syntheses of highly ordered, hydrothermally stable, mesoporous silica structures. J. Am. Chem. Soc. 1998, 120, 6024-6036.

86. Chen, D.; Li, Z.; Wan, Y.; Tu, X.; Shi, Y.; Chen, Z.; Shen, W.; Yu, C.; Tu, B.; Zhao, D. Anionic surfactant induced mesophase transformation to synthesize highly ordered large-pore mesoporous silica structures. J. Mater. Chem. 2006, 16, 1511-1519.

87. Da'na, E.; Sayari, A. Adsorption of heavy metals on amine-functionalised SBA-15 prepared by co-condensation: Applications to real water samples. Desalination 2012, 285, 62-67.

88. Brown, J.; Richer, R.; Mercier, L. One-step synthesis of high capacity mesoporous $\mathrm{Hg}^{2+}$ adsorbents by non-ionic surfactant assembly. Microporous Mesoporous Mater. 2000, 37, 41-48.

89. Antochshuk, V.; Jaroniec, M. Adsorption, thermogravimetric, and NMR studies of FSM-16 material functionalized with alkylmonochlorosilanes. J. Phys. Chem. B 1999, 103, 6252-6261. 
90. Ariga, K.; Vinu, A.; Yamauchi, Y.; Ji, Q.; Hill, J.P. Nanoarchitectonics for mesoporous materials. Bull. Chem. Soc. Jpn. 2012, 85, 1-32.

91. Soler-Illia, G.J.; Sanchez, C.; Lebeau, B.; Patarin, J. Chemical strategies to design textured materials: From microporous and mesoporous oxides to nanonetworks and hierarchical structures. Chem. Rev. 2002, 102, 4093-4138.

92. Huo, Q.; Margolese, D.I.; Ciesla, U.; Demuth, D.G.; Feng, P.; Gier, T.E.; Sieger, P.; Firouzi, A.; Chmelka, B.F.; Schüth, F.; et al. Organization of organic molecules with inorganic molecular species into nanocomposite biphase arrays. Chem. Mater. 1994, 6, 1176-1191.

93. Hoffmann, F.; Cornelius, M.; Morell, J.; Fröba, M. Silica-based mesoporous organic-inorganic hybrid materials. Angew. Chem. Int. Ed. 2006, 45, 3216-3251.

94. Muto, S.; Imai, H. Relationship between mesostructures and $\mathrm{pH}$ conditions for the formation of silica-cationic surfactant complexes. Microporous Mesoporous Mater. 2006, 95, 200-205.

95. Wirnsberger, G.; Yang, P.; Huang, H.C.; Scott, B.; Deng, T.; Whitesides, G.M.; Chmelka, B.F.; Stucky, G.D. Patterned block-copolymer-silica mesostructures as host media for the laser dye rhodamine 6G. J. Phys. Chem. B 2001, 105, 6307-6313.

96. Zhang, Q.; Liu, F.; Nguyen, K.T.; Ma, X.; Wang, X.; Xing, B.; Zhao, Y. Multifunctional mesoporous silica nanoparticles for cancer-targeted and controlled drug delivery. Adv. Funct. Mater. 2012, 22, 5144-5156.

97. Wight, A.P.; Davis, M.E. Design and preparation of organic-inorganic hybrid catalysts. Chem. Rev. 2002, 102, 3589-3614.

98. Pal, N.; Bhaumik, A. Soft templating strategies for the synthesis of mesoporous materials: Inorganic, organic-inorganic hybrid and purely organic solids. Adv. Colloid Interface Sci. 2013, 189-190, 21-41.

99. Kickelbick, G. Concepts for the incorporation of inorganic building blocks into organic polymers on a nanoscale. Prog. Polym. Sci. 2003, 28, 83-114.

100. Schubert, U. Cluster-based inorganic-organic hybrid materials. Chem. Soc. Rev. 2011, 40, $575-582$.

101. Agustin, D.; Dallery, J.; Coelho, C.; Proust, A.; Thouvenot, R. Synthesis, characterization and study of the chromogenic properties of the hybrid polyoxometalates $\left[\mathrm{PW}_{11} \mathrm{O}_{39}(\mathrm{SiR})_{2} \mathrm{O}\right]^{3}-(\mathrm{R}=\mathrm{Et}$, $\left.\left(\mathrm{CH}_{2}\right)_{n} \mathrm{CH}=\mathrm{CH}_{2}(n=0,1,4), \mathrm{CH}_{2} \mathrm{CH}_{2} \mathrm{SiEt}_{3}, \mathrm{CH}_{2} \mathrm{CH}_{2} \mathrm{SiMe}_{2} \mathrm{Ph}\right)$. J. Organomet. Chem. 2007, 692, $746-754$.

102. Li, H.; Eddaoudi, M.; O'Keeffe, M.; Yaghi, O.M. Design and synthesis of an exceptionally stable and highly porous metal-organic framework. Nature 1999, 402, 276-279.

103. Férey, G. Some suggested perspectives for multifunctional hybrid porous solids. Dalton Trans. 2009, 2009, 4400-4415.

104. Guillerm, V.; Gross, S.; Serre, C.; Devic, T.; Bauer, M.; Férey, G. A zirconium methacrylate oxocluster as precursor for the low-temperature synthesis of porous zirconium (IV) dicarboxylates. Chem. Commun. 2010, 46, 767-769.

105. Proust, A.; Matt, B.; Villanneau, R.; Guillemot, G.; Gouzerh, P.; Izzet, G. Functionalization and post-functionalization: A step towards polyoxometalate-based materials. Chem. Soc. Rev. 2012, $41,7605-7622$. 
106. Niederberger, M.; Garnweitner, G.; Krumeich, F.; Nesper, R.; Cölfen, H.; Antonietti, M. Tailoring the surface and solubility properties of nanocrystalline titania by a nonaqueous in-situ functionalization process. Chem. Mater. 2004, 16, 1202-1208.

107. Dimitrijevic, N.M.; Saponjic, Z.V.; Rabatic, B.M.; Rajh, T. Assembly and charge transfer in hybrid $\mathrm{TiO}_{2}$ architectures using biotin-avidin as a connector. J. Am. Chem. Soc. 2005, 127, 1344-1345.

108. Potapova, I.; Mruk, R.; Prehl, S.; Zentel, R.; Basche, T.; Mews, A. Semiconductor nanocrystals with multifunctional polymer ligands. J. Am. Chem. Soc. 2003, 125, 320-321.

109. Vitale, F.; Fratoddi, I.; Battocchio, C.; Piscopiello, E.; Tapfer, L.; Russo, M.V.; Polzonetti, G.; Giannini, C. Mono- and bi-functional arenethiols as surfactants for gold nanoparticles: Synthesis and characterization. NRL 2011, 6, doi:10.1186/1556-276X-6-103.

110. Schroden, R.C.; Blanford, C.F.; Melde, B.J.; Johnson, B.J.S.; Stein, A. Direct synthesis of ordered macroporous silica materials functionalized with polyoxometalate clusters. Chem. Mater. 2001, 13, 1074-1081.

111. Mittal, V. Polymer layered silicate nanocomposites: A review. Materials 2009, 2, 992-1057.

112. Soundararajah, Q.Y.; Karunaratne, B.S.B.; Rajapakse, R.M.G. Montmorillonite polyaniline nanocomposites: Preparation, characterization and investigation of mechanical properties. Mater. Chem. Phys. 2009, 113, 850-855.

113. Lira-Cantu, M.; Gomez-Romero, P. Synthesis and characterization of intercalate phases in the organic-inorganic polyaniline $/ \mathrm{V}_{2} \mathrm{O}_{5}$ system. J. Solid State Chem. 1999, 147, 601-608.

114. Huang, S.; Yang, Z.; Zhu, H.; Ren, L.; Tjiu, W.W.; Liu, T. Poly(vinly alcohol)/nano-sized layered double hydroxides nanocomposite hydrogels prepared by cyclic freezing and thawing. Macromol. Res. 2012, 20, 568-577.

115. Santos, C.M.; Mangadlao, J.; Ahmed, F.; Leon, A.; Advincula, R.C.; Rodrigues, D.F. Graphene nanocomposite for biomedical applications: Fabrication, antimicrobial and cytotoxic investigations. Nanotechnology 2012, 23, 395101.

116. Alexandre, M.; Dubois, P. Polymer layered silicate nanocomposites: Preparation, properties and uses of a new class of materials. Mater. Sci. Eng. R Rep. 2000, 28, 1-63.

117. Kameda, T.; Takeuchi, H.; Yoshioka, T. Kinetics of uptake of $\mathrm{Cu}^{2+}$ and $\mathrm{Cd}^{2+}$ by $\mathrm{Mg}$-Al layered double hydroxides intercalated with citrate, malate, and tartrate. Colloids Surf. A Physicochem. Eng. Asp. 2010, 355, 172-177.

118. Rojas, R.; Perez, M.R.; Erro, E.M.; Ortiz, P.I.; Ulibarri, M.A.; Giacomelli, C.E. EDTA modified LDHs as $\mathrm{Cu}^{2+}$ scavengers: Removal kinetics and sorbent stability. J. Colloid Interface Sci. 2009, $331,425-431$.

119. Gangopadhyay, R.; De, A. Conducting polymer nanocomposites: A brief overview. Chem. Mater. 2000, 12, 608-622.

120. Daigle, J.-C.; Claverie, J.P. A Simple method for forming hybrid core-shell nanoparticles suspended in water. J. Nanomater. 2008, 2008, 609184:1-609184:8.

121. Wei, S.; Wang, Q.; Zhu, J.; Sun, L.; Lin, H.; Guo, Z. Multifunctional composite core-shell nanoparticles. Nanoscale 2011, 3, 4474-4502.

122. Wang, Y.; Teng, X.; Wang, J.-S.; Yang, H. Solvent-free atom transfer radical polymerization in the synthesis of Fe2O3@polystyrene core-shell nanoparticles. Nano Lett. 2003, 3, 789-793. 
123. Huang, C.L.; Matijevic, E. Coating of uniform inorganic particles with polymers. 3. Polypyrrole on different metal oxides. J. Mater. Res. 1995, 10, 1327-1336.

124. Payne, R.; Fritz, G.; Narmann, H. Investigation into the interactions of metals and metal ions in polymer matrixes. Angew. Makromol. Chem. 1986, 144, 51-72.

125. Liu, S.; Zhang, N.; Tang, Z.-R.; Xu, Y.-J. Synthesis of one-dimensional CdS@ $\mathrm{TiO}_{2}$ core-shell nanocomposites photocatalyst for selective redox: The dual role of $\mathrm{TiO}_{2}$ shell. ACS Appl. Mater. Interfaces 2012, 4, 6378-6385.

126. Ozin, G.A.; Ho, K.; Lotsch, B.V.; Cademartiri, L.; Puzzo, D.P.; Scotognella, F.; Ghadimi, A.; Thomson, J. Nanofabrication by self- assembly. Mater. Today 2009, 12, 12-23.

127. Nikolov, S.; Petrov, M.; Lymperakis, L.; Friák, M.; Sachs, C.; Fabritius, H.-O.; Raabe, D.; Neugebauer, J. Revealing the design principles of high-performance biological composites using $\mathrm{Ab}$ initio and multiscale simulations: The example of lobster cuticle. Adv. Mater. 2010, 22, $519-526$.

128. Fratzel, P. Collagen: Structure and Mechanics; Springer: New York, NY, USA, 2008.

129. Kharisov, B.I. A Review for synthesis of nanoflowers. Recent Pat. Nanotechnol. 2008, 2, 190-200.

130. Soten, I.; Ozin, G.A. Porous hydroxyapatite- dodecylphosphate composite film on titania-titanium substrate. J. Mater. Chem. 1999, 9, 703-710.

131. Dag, Ö.; Verma, A.; Ozin, G.A.; Kresge, C.T. Salted mesostructures: Salt-liquid crystal templating of lithium triflate-oligo(ethylene oxide) surfactant-mesoporous silica nanocomposite films and monoliths. J. Mater. Chem. 1999, 9, 1475-1482.

132. Du, J.; Lai, X.; Yang, N.; Zhai, J.; Kisailus, D.; Su, F.; Wang, D.; Jiang, L. Hierarchically ordered macro-mesoporous $\mathrm{TiO}_{2}$-graphene composite films: Improved mass transfer, reduced charge recombination, and their enhanced photocatalytic activities. ACS Nano 2011, 5, 590-596.

133. Pope, E.J.A.; Asami, M.; Mackenzie, J.D. Transparent silica gel-PMMA composites. J. Mater. Res. 1989, 4, 1018-1026.

134. Deng, Q.; Moore, R.B.; Mauritz, K.A. Novel Nafion/ORMOSIL hybrids via in situ sol-gel reactions. 1. Probe of ORMOSIL phase nanostructures by infrared spectroscopy. Chem. Mater. 1995, 7, 2259-2268.

135. Hajji, P.; David, L.; Gerard, J.F.; Pascault, J.P.; Vigier, G. Synthesis, structure, and morphology of polymer-silica hybrid nanocomposites based on hydroxyethyl methacrylate. J. Polym. Sci. B Polym. Phys. 1999, 37, 3172-3187.

136. Frisch, H.L.; Xue, Y.-P.; Maaref, S.; Beaucage, G.; Pu, Z.; Mark, J. Pseudo interpenetrating polymer networks and interpenetrating polymer networks of zeolite $13 \mathrm{X}$ and polystyrene and poly(ethyl acrylate). Macrmol. Symp. 1996, 106, 147-166.

137. Frisch, H.L.; Chen, Z.J.; Chen, X. Electrical conductivity of iodine doped pseudo interpenetrating polymer networks. Macromol. Symp. 1994, 81, 181-194.

138. Abd-El-Aziz, A.S.; Strohm, E.A. Transition metal-containing macromolecules: En route to new functional materials. Polymer 2012, 53, 4879-4921.

139. McCurdie, M.P.; Belfiore, L.A. Solid-state complexes of poly (L-histidine) with metal chlorides from the first row of the d-block. J. Polym. Sci. Part B Polym. Phys. 1999, 37, 301-309.

140. Hardy, C.G.; Ren, L.; Tamboue, T.C.; Tang, C. Side-chain ferrocene-containing (meth)acrylate polymers: Synthesis and properties. J. Polym. Sci. 2011, 49, 1409-1420. 
141. Mori, H. Design and synthesis of functional silsesquioxane-based hybrids by hydrolytic condensation of bulky triethoxysilanes. Int. J. Polym. Sci. 2012, 2012, 173624:1-173624:17.

142. Liu, J.; Ma, Y.; Zhang, Y.; Shao, G. Novel negatively charged hybrids. 3. Removal of $\mathrm{Pb}^{2+}$ from aqueous solution using zwitterionic hybrid polymers as adsorbent. J. Hazard. Mater. 2010, 173, 438-444.

143. Liu, J.; Ma, Y.; Xu, T.; Shao, G. Preparation of zwitterionic hybrid polymer and its application for the removal of heavy metal ions from water. J. Hazard. Mater. 2010, 178, 1021-1029.

144. Wu, J.-B.; Zang, S.-Y.; Yi, Y.-L. Sol-gel derived ion imprinted thiocyanato-functionalized silica gel as selective adsorbent of cadmium(II). J. Sol-Gel Sci. Technol. 2013, 66, 434-442.

145. Wu, J.-B.; Yi, Y.-L. Removal of cadmium from aqueous solution by organic-inorganic hybrid sorbent combining sol-gel processing and imprinting technique. Korean J. Chem. Eng. 2013, 30, 1111-1118.

146. Buhani; Narsito; Nuryono; Kunarti, E.S. Production of metal ion imprinted polymer from mercapto-silica through sol-gel process as selective adsorbent of cadmium. Desalination 2010, 251, 83-89.

147. Fan, H.-T.; Sun, T. Selective removal of iron from aqueous solution using ion imprinted cyanato-functionalized silica gel sorbents. Sep. Sci. Technol. 2012, 47, 507-512.

148. Bozbas, S.K.; Ay, U.; Kayan, A. Novel inorganic-organic hybrid polymers to remove heavy metals from aqueous solution. Desalin. Water Treat. 2013, 51, 7208-7215.

149. Schroden, R.C.; Al-Daous, M.; Sokolov, S.; Melde, B.J.; Lytle, J.C.; Stein, A.; Carbajo, M.C.; Fernández, J.T.; Rodríguez, E.E. Hybrid macroporous materials for heavy metal ion adsorption. J. Mater. Chem. 2002, 12, 3261-3267.

150. Passos, C.G.; Lima, E.C.; Arenas, L.T.; Simon, N.M.; da Cunha, B.M.; Brasil, J.L.; Costa, T.M.H.; Benvenutti, E.V. Use of 7-amine-4-azahepthylsilica and 10-amine-4-azadecylsilica xerogels as adsorbent for $\mathrm{Pb}(\mathrm{II})$ kinetic and equilibrium study. Colloids Surf. A 2008, 316, 297-306.

151. Pavan, F.A.; Lima, I.S.; Benvenutti, E.V.; Gushikem, Y.; Airoldi, C. Hybrid aniline/silica xerogel cation adsorption and thermodynamics of interaction. J. Colloid Interface Sci. 2004, 275, 386-391.

152. Faghihian, H.; Nourmoradi, H.; Shokouhi, M. Performance of silica aerogels modifi ed with amino functional groups in $\mathrm{Pb}(\mathrm{II})$ and $\mathrm{Cd}(\mathrm{II})$ removal from aqueous solutions. PJCHT 2012, 14 , $50-56$.

153. Qu, R.; Sun, C.; Ma, F.; Cui, Z.; Zhang, Y.; Sun, X.; Ji, C.; Wang, C.; Yin, P. Adsorption kinetics and equilibrium of copper from ethanol fuel on silica-gel functionalized with aminoterminated dendrimer-like polyamidoamine polymers. Fuel 2012, 92, 204-210.

154. Pissetti, F.L.; Yoshida, I.V.P.; Gushikem, Y.; Kholin, Y.V. Metal ions adsorption from ethanol solutions on ethylenediamine-modified poly(dimethylsiloxane) elastomeric network. Colloids Surf. A 2008, 328, 21-27.

155. Fan, H.T.; Su, Z.J.; Fan, X.L.; Guo, M.M.; Wang, J.; Gao, S.; Sun, T. Sol-gel derived organic-inorganic hybrid sorbent for removal of $\mathrm{Pb}^{2+}, \mathrm{Cd}^{2+}$ and $\mathrm{Cu}^{2+}$ from aqueous solution. J. Sol-Gel Sci. Technol. 2012, 64, 418-426.

156. Kim, Y.S.; In, G.; Choi, J.M. Solid phase extraction of trace $\mathrm{Cu}(\mathrm{II}), \mathrm{Mn}(\mathrm{II}), \mathrm{Pb}(\mathrm{II})$ and $\mathrm{Zn}(\mathrm{II})$ in water samples with pulverized silica-salen $\left(\mathrm{NEt}_{2}\right)_{2}$. Bull. Korean Chem. Soc. 2006, 27, 1557-1561. 
157. Hongjie, W.; Jin, K.; Huijuan, L.; Jiuhui, Q. Preparation of organically functionalized silica gel as adsorbent for copper ion adsorption. J. Environ. Sci. 2009, 21, 1473-1479.

158. Qu, R.; Niu, Y.; Sun, C.; Ji, C.; Wang, C.; Cheng, G. Syntheses, characterization, and adsorption properties for metal ions of silica-gel functionalized by ester- and amino-terminated dendrimer-like polyamidoamine polymer. Microporous Mesoporous Mater. 2006, 97, 58-65.

159. Zhang, Y.; Wang, X.; Liu, J.; Wu, L. Removal of copper $\left(\mathrm{Cu}^{2+}\right)$ from water using novel hybrid adsorbents: Kinetics and isotherms. J. Chem. Eng. Data 2013, 58, 1141-1150.

160. Prakash, S.; Kumar, M.; Tripathi, B.P.; Shahi, V.K. Sol-gel derived poly(vinylalcohol)-3-(2aminoethylamino) propyl trimethoxysilane: Cross-linked organic-inorganic hybrid beads for the removal of $\mathrm{Pb}$ (II) from aqueous solution. Chem. Eng. J. 2010, 162, 28-36.

161. Hao, J.; Han, M.-J.; Meng, X. Preparation and evaluation of thiol-functionalized activated alumina for arsenite removal from water. J. Hazard. Mater. 2009, 167, 1215-1221.

162. Barczak, M.; Dobrowolski, R.; Dobrzyǹska, J.; Zięba, E.; Dąbrowski, A. Amorphous and ordered organosilicas functionalized with amine groups as sorbents of platinum (II) ions. Adsorption 2013, 19, 733-744.

163. Chen, J.; Lin, Y.-S. Sol-gel-immobilized recombinant E. coli for biosorption of $\mathrm{Cd}^{2+} . J$. Chin. Inst. Chem. Eng. 2007, 38, 235-243.

164. Mehmood, R.F.; Mehmood, F.; Akhtar, J.; Shah, S.S.; Khosa, M.A. Adsorption of Cd(II) by sol-gel silica doped with N (dipropylcarbamothioyl)thiophene-2-carboxamide. J. Dispers. Sci. Technol. 2013, 34, 153-160.

165. Prado, A.G.S.; Arakaki, L.N.H.; Airoldi, C. Adsorption and separation of cations on chemically modified silica gel synthesised via the sol-gel process. J. Chem. Soc. Dalton Trans. 2001, 2206-2209.

166. Najafi, M.; Yousefi, Y.; Rafati, A.A. Synthesis, characterization and adsorption studies of several heavy metal ions on amino-functionalized silica nano hollow sphere and silica gel. Sep. Purif. Technol. 2012, 85, 193-205.

167. Pavan, F.A.; Costa, T.M.H.; Benvenutti, E.V. Adsorption of $\mathrm{CoCl}_{2}, \mathrm{ZnCl}_{2}$ and $\mathrm{CdCl}_{2}$ on aniline/silica hybrid material obtained by sol-gel method. Colloids Surf. A 2003, 226, 95-100.

168. Parvulescu, V.; Mureseanu, M.; Reiss, A.; Ene, R.; Suh, S.-H. Metal-organic hybrids obtained by functionalization of mesoporous silica. Rev. Roum. Chim. 2010, 55, 1001-1008.

169. Yoshitake, H.; Yokoi, T.; Tatsumi, T. Adsorption of chromate and arsenate by amino-functionalized MCM-41 and SBA-1. Chem. Mater. 2002, 14, 4603-4610.

170. Aguado, J.; Arsuaga, J.M.; Arencibia, A.; Lindo, M.; Gascón, V. Aqueous heavy metals removal by adsorption on amine-functionalized mesoporous silica. J. Hazard. Mater. 2009, 163, 213-221.

171. Chen, D.; Huang, C.; He, M.; Hu, B. Separation and preconcentration of inorganic arsenic species in natural water samples with 3-(2-aminoethylamino) propyltrimethoxysilane modified ordered mesoporous silica micro-column and their determination by inductively coupled plasma optical emission spectrometry. J. Hazard. Mater. 2009, 164, 1146-1151.

172. Showkat, A.M.; Zhang, Y.-P.; Kim, M.S.; Gopalan, A.I.; Reddy, K.R.; Lee, K.-P. Analysis of heavy metal toxic ions by adsorption onto amino-functionalized ordered mesoporous silica. Bull. Korean Chem. Soc. 2007, 28, 1985-1992. 
173. Zhang, D.; Li, J.H. Ordered SBA-15 mesoporous silica with high amino-functionalization for adsorption of heavy metal ions. Chin. Sci. Bull. 2013, 58, 879-883.

174. Kang, T.; Park, Y.; Choi, K.; Sang Leec, J.; Yi, J. Ordered mesoporous silica (SBA-15) derivatized with imidazole-containing functionalities as a selective adsorbent of precious metal ions. J. Mater. Chem. 2004, 14, 1043-1049.

175. Mureseanu, M.; Reiss, A.; Stefanescu, I.; David, E.; Parvulescu, V.; Renard, G.; Hulea, V. Modified SBA-15 mesoporous silica for heavy metal ions remediation. Chemosphere 2008, 73, 1499-1504.

176. Hao, S.; Hou, J. Adsorption of $\mathrm{Ni}^{2+}$ on aminofunctionalized mesoporous silica templated by an anionic surfactant route. J. Mater. Res. 2013, 28, 2325-2331.

177. Pérez-Quintanilla, D.; del Hierro, I.; Fajardo, M.; Sierra, I. Adsorption of cadmium(II) from aqueous media onto a mesoporous silica chemically modified with 2-mercaptopyrimidine. J. Mater. Chem. 2006, 16, 1757-1764.

178. Lam, K.F.; Yeung, K.L.; McKay, G. An investigation of gold adsorption from a binary mixture with selective mesoporous silica adsorbents. J. Phys. Chem. B 2006, 110, 2187-2194.

179. Puanngam, M.; Unob, F. Preparation and use of chemically modified MCM-41 and silica gel as selective adsorbents for $\mathrm{Hg}(\mathrm{II})$ ions. J. Hazard. Mater. 2008, 154, 578-587.

180. Lam, K.F.; Yeung, K.L.; McKay, G. A rational approach in the design of selective mesoporous adsorbents. Langmuir 2006, 22, 9632-9641.

181. Xue, X.; Li, F. Removal of $\mathrm{Cu}(\mathrm{II})$ from aqueous solution by adsorption onto functionalized SBA-16 mesoporous silica. Microporous Mesoporous Mater. 2008, 116, 116-122.

182. Lombardo, M.V.; Videla, M.; Calvo, A.; Requejo, F.G.; Soler-Illia, G.J.A.A. Aminopropyl-modified mesoporous silica SBA-15 as recovery agents of $\mathrm{Cu}(\mathrm{II})$-sulfate solutions: Adsorption efficiency, functional stability and reusability aspects. J. Hazard. Mater. 2012, 223-224, 53-62.

183. Lee, B.; Bao, L.-L.; Im, H.-J.; Dai, S.; Hagaman, E.W.; Lin, J.S. Synthesis and characterization of organic-inorganic hybrid mesoporous anion-exchange resins for perrhenate $\left(\mathrm{ReO}_{4}{ }^{-}\right)$anion adsorption. Langmuir 2003, 19, 4246-4252.

184. Lee, B.; Kim, Y.; Lee, H.; Yi, J. Synthesis of functionalized porous silicas via templating method as heavy metal ion adsorbents: The introduction of surface hydrophilicity onto the surface of adsorbents. Microporous Mesoporous Mater. 2001, 50, 77-90.

185. Liu, Y.-C.; Liu, S.-T. A recyclable thiol-functionalized mesoporous silica for detection and removal of $\mathrm{Cu}(\mathrm{II})$ ions. JCCS 2010, 57, 946-949.

186. Aguado, J.; Arsuaga, J.M.; Arencibia, A. Adsorption of aqueous mercury(II) on propylthiol-functionalized mesoporous silica obtained by co-condensation. Ind. Eng. Chem. Res. 2005, 44, 3665-3671.

187. Olkhovyk, O.; Jarioniec, M. Ordered mesoporous silicas with 2,5-dimercapto-1,3,4-thiadiazole ligand: High capacity adsorbents for mercury ions. Adsorption 2005, 11, 205-214.

188. Antochshuck, V.; Olkhovyk, O.; Jaroniec, M.; Park, I.-S.; Ryoo, R. Benzoylthiourea-modified mesoporous silica for mercury(II) removal. Langmuir 2003, 19, 3031-3034.

189. Hao, N.; Han, L.; Yang, Y.; Wang, H.; Webley, P.A.; Zhao, D. A metal-ion-assisted assembly approach to synthesize disulfide-bridged periodical mesoporous organosilicas with high sulfide contents and efficient adsorption. Appl. Surf. Sci. 2010, 256, 5334-5342. 
190. Teng, M.; Wang, H.; Li, F.; Zhang, B. Thioether-functionalized mesoporous fiber membranes: Sol-gel combined electrospun fabrication and their applications for $\mathrm{Hg}^{2+}$ removal. J. Colloid Interface Sci. 2011, 355, 23-28.

191. Chiu, P.-J.; Vetrivel, S.; Chiang, A.S.T.; Kao, H.-M. Synthesis and characterization of cubic periodic mesoporous organosilicas with a high loading of disulfide groups. New J. Chem. 2011, 35, 489-494.

192. Awual, M.R.; Yaita, T.; El-Safty, S.A.; Shiwaku, H.; Okamoto, Y.; Suzuki, S. Investigation of palladium(II) detection and recovery using ligand modified conjugate adsorbent. Chem. Eng. J. 2013, 222, 172-179.

193. Awual, M.R.; Yaita, T.; El-Safty, S.A.; Shiwaku, H.; Suzuki, S.; Okamoto, Y. Copper(II) ions capturing from water using ligand modified a new type mesoporous adsorbent. Chem. Eng. J. 2013, 221, 322-330.

194. Lee, H.; Yi, J. Removal of copper ions using functionalizaed mesoporous silica in aqueous solution. Sep. Sci. Technol. 2001, 36, 2433-2444.

195. Lam, K.F.; Yeung, K.; McKay, G. Efficient approach for $\mathrm{Cd}^{2+}$ and $\mathrm{Ni}^{2+}$ removal and recovery using mesoporous mdsorbent with tunable selectivity. Environ. Sci. Technol. 2007, 41, 3329-3334.

196. Yoshitake, H.; Yokoi, T.; Tatsumi, T. Adsorption behavior of arsenate at transition metal cations captured by amino-functionalized mesoporous silicas, Chem. Mater. 2003, 15, 1713-1721.

197. Huang, J.; Ye, M.; Qu, Y.; Chu, L.; Chen, R.; He, Q.; Xu, D. Pb (II) removal from aqueous media by EDTA-modified mesoporous silica SBA-15. J. Colloid Interface Sci. 2012, 385, 137-146.

198. Ge, P.; Li, F. Kinetics and thermodynamics of heavy metal $\mathrm{Cu}(\mathrm{II})$ adsorption on mesoporous silicates. Pol. J. Environ. Stud. 2011, 20, 339-344.

199. Pandey, S.; Mishra, S.B. Organic-inorganic hybrid of chitosan/organoclay bionanocomposites for hexavalent chromium uptake. J. Colloid Interface Sci. 2011, 361, 509-520.

200. Futalan, C.M.; Tsai, W.-C.; Lin, S.-S.; Hsien, K.-J.; Dalida, M.L.; Wan, M.-W. Copper, nickel and lead adsorption from aqueous solution using chitosan-immobilized on bentonite in a ternary system. Sustain. Environ. Res. 2012, 22, 345-355.

201. Hasan, S.; Krishnaiah, A.; Ghosh, T.K.; Viswanath, D.S.; Boddu, V.M.; Smith, E.D. Adsorption of chromium (VI) on chitosan-coated perlite. Sep. Sci. Technol. 2003, 38, 3775-3793.

202. Kalyani, S.; Priya, J.A.; Rao, P.S.; Abburi, K. Removal of copper and nickel from aqueous solutions using chitosan coated on perlite as biosorbent. Sep. Sci. Technol. 2005, 40, 1483-1495.

203. Hasan, S.; Krishnaiah, A.; Ghosh, T.K.; Viswanath, D.S.; Boddu, V.M.; Smith, E.D. Adsorption of divalent cadmium (Cd(II)) from aqueous solutions onto chitosan-coated perlite beads. Ind. Eng. Chem. Res. 2006, 45, 5066-5077.

204. Hasan, S.; Ghosh, T.K.; Viswanath, D.S.; Boddu, V.M. Dispersion of chitosan on perlite for enhancement of copper(II) adsorption capacity. J. Hazard. Mater. 2008, 152, 826-837.

205. Dinu, M.V.; Dragan, E.S. Evaluation of $\mathrm{Cu}^{2+}, \mathrm{Co}^{2+}$ and $\mathrm{Ni}^{2+}$ ions removal from aqueous solution using anovel chitosan/clinoptilolite composite: Kinetics and isotherms. Chem. Eng. J. 2010, 160, 157-163.

206. Gandhi, M.R.; Viswanathanb, N.; Meenakshi, S. Preparation and application of alumina/chitosan biocomposite. Int. J. Biol. Macromol. 2010, 47, 146-154. 
207. Boddu, V.M.; Abburi, K.; Talbott, J.L.; Smith, E.D. Removal of hexavalent chromium from wastewater using a new composite chitosan biosorbent. Environ. Sci. Technol. 2003, 37, 4449-4456.

208. Fan, D.; Zhu, X.; Xu, M.; Yan, J. Adsorption properties of chromium (VI) by chitosan coated montmorillonite. J. Biol. Sci. 2006, 6, 941-945.

209. Bleiman, N.; Mishael, Y.G. Selenium removal from drinking water by adsorption to chitosan-clay composites and oxides: Batch and columns tests. J. Hazard. Mater. 2010, 183, 590-595.

210. Vijaya, Y.; Popuri, S.R.; Boddu, V.M.; Krishnaiah, A. Modified chitosan and calcium alginate biopolymer sorbents for removal of nickel (II) through adsorption. Carbohydr. Polym. 2008, 72, 261-271.

211. Choi, S.; Jeong, Y. The removal of heavy metals in aqueous solution by hydroxyapatite/cellulose composite. Fibers Polym. 2008, 9, 267-270.

212. Grisdanurak, N.; Akewaranugulsiri, S.; Futalan, C.M.; Tsai, W.C.; Kan, C.C.; Hsu, C.W.; Wan, M.W. The study of copper adsorption from aqueous solution using crosslinked chitosan immobilized on bentonite. J. Appl. Polym. Sci. 2012, 125, 132-142.

213. Zhang, J.; Jin, Y.; Wang, A. Rapid removal of $\mathrm{Pb}$ (II) from aqueous solution by chitosan-g-poly(acrylic acid)/attapulgite/sodium humate composite hydrogels. Environ. Technol. 2011, 32, 523-531.

214. Wang, X.; Zheng, Y.; Wang, A. Fast removal of copper ions from aqueous solution by chitosan-g-poly(acrylic acid)/attapulgite composites. J. Hazard. Mater. 2009, 168, 970-977.

215. Wang, X.; Wang, A. Adsorption characteristics of chitosan-g-poly(acrylic acid)/attapulgite hydrogel composite for $\mathrm{Hg}(\mathrm{II})$ ions from aqueous solution. Sep. Sci. Technol. 2010, 45, 2086-2094.

216. Anirudhan, T.S.; Rijith, S. Synthesis and characterization of carboxyl terminated poly(methacrylic acid) grafted chitosan/bentonite composite and its application for the recovery of uranium(VI) from aqueous media. J. Environ. Radioact. 2012, 106, 8-19.

217. Abdel Khalek, M.A.; Mahmoud, G.A.; El-Kelesh, N.A. Synthesis and caracterization of poly-methacrylic acid grafted chitosan-bentonite composite and its application for heavy metals recovery. Chem. Mater. Res. 2012, 2, 1-12.

218. Wang, X.; Wang, A. Equilibrium isotherm and mechanism studies of $\mathrm{Pb}(\mathrm{II})$ and $\mathrm{Cd}(\mathrm{II})$ ions onto hydrogel composite based on vermiculite. Desalin. Water Treat. 2012, 48, 38-49.

219. Anirudhan, T.S.; Suchithra, P.S. Heavy metals uptake from aqueous solutions and industrial wastewaters by humic acid-immobilized polymer/bentonite composite: Kinetics and equilibrium modeling. Chem. Eng. J. 2010, 156, 146-156.

220. Larraza, I.; López-Gónzalez, M.; Corrales, T.; Marcelo, G. Hybrid materials: Magnetite-polyethylenimine-montmorillonite, as magnetic adsorbents for $\mathrm{Cr}(\mathrm{VI})$ water treatment. J. Colloid Interface Sci. 2012, 385, 24-33.

221. Bulut, Y.; Akçay, G.; Elma, D.; Serhatli, I.E. Synthesis of clay-based superabsorbent composite and its sorption capability. J. Hazard. Mater. 2009, 171, 717-723.

222. Urbano, B.F.; Rivas, B.L.; Martinez, F.; Alexandratos, S.D. Equilibrium and kinetic study of arsenic sorption by water-insoluble nanocomposite resin of poly[N-(4-vinylbenzyl)-N-methyl-Dglucamine]-montmorillonite. Chem. Eng. J. 2012, 193-194, 21-30. 
223. Zhao, G.; Zhang, H.; Fan, Q.; Ren, X.; Li, J.; Chen, Y.; Wang, X. Sorption of copper(II) onto super-adsorbent of bentonite-polyacrylamide composites. J. Hazard. Mater. 2010, 173, 661-668.

224. Ulusoy, U.; Şimşek, S. Lead removal by polyacrylamide-bentonite and zeolite composites: Effect of phytic acid immobilization. J. Hazard. Mater. 2005, 127, 163-171.

225. Cui, H.; Qian, Y.; Li, Q.; Zhang, Q.; Zhai, J. Adsorption of aqueous $\operatorname{Hg}(\mathrm{II})$ by a polyaniline/attapulgite composite. Chem. Eng. J. 2012, 211-212, 216-223.

226. Zhao, Y.; Chen, Y.; Li, M.; Zhou, S.; Xue, A.; Xing, W. Adsorption of $\mathrm{Hg}^{2+}$ from aqueous solution onto polyacrylamide/attapulgite. J. Hazard. Mater. 2009, 171, 640-646.

227. Yang, L.; Li, Y.; Hu, H.; Jin, X.; Yeb, Z.; Ma, Y.; Zhang, S. Preparation of novel spherical PVA/ATP composites with macroreticular structure and their adsorption behavior for methylene blue and lead in aqueous solution. Chem. Eng. J. 2011, 173, 446-455.

228. Kaşgöz, H.; Durmus, A.; Kaşgöz, A. Enhanced swelling and adsorption properties of AAm-AMPSNa/clay hydrogel nanocomposites for heavy metal ion removal. Polym. Adv. Technol. 2008, 19, 213-220.

229. Şölener, M.; Tunali, S.; Özcan, A.S.; Özcan, A.; Gedikbey, T. Adsorption characteristics of lead(II) ions onto the clay/poly(methoxyethyl)acrylamide (PMEA) composite from aqueous solutions. Desalination 2008, 223, 308-322.

230. Demirbaş, O.; Alkan, M.; Doğan, M.; Turhan, Y.; Namli, H.; Turan, P. Electrokinetic and adsorption properties of sepiolite modified by 3 -aminopropyltriethoxysilane. J. Hazard. Mater. 2007, 149, 650-656.

231. Turhan, Y.; Turan, P.; Doğan, M.; Alkan, M.; Namli, H.; Demirbas, Ö. Characterization and adsorption properties of chemically modified sepiolite. Ind. Eng. Chem. Res. 2008, 47, 1883-1895.

232. Zhang, A.-C.; Sun, L.-S.; Xiang, J.; Hu, S.; Fu, P.; Su, S.; Zhou, Y.-S. Removal of elemental mercury from coal combustion flue gas by bentonite-chitosan and their modifier. J. Fuel Chem. Technol. 2009, 37, 489-495.

233. Xu, Q.; Yin, P.; Zhao, G.; Yin, G.; Qu, R. Synthesis and characterization of silica gel microspheres encapsulated by salicyclic acid functionalized polystyrene and its adsorption of transition metal ions from aqueous solutions. Cent. Eur. J. Chem. 2010, 8, 214-222.

234. Xu, Q.; Yin, P.; Zhao, G.; Sun, Y.; Qu, R. Adsorption selectivity and dynamic adsorption behaviors of $\mathrm{Cu}(\mathrm{II}), \mathrm{Ag}(\mathrm{I})$, and $\mathrm{Au}(\mathrm{III})$ on silica gel encapsulated by amino functionalized polystyrene. J. Appl. Polym. Sci. 2010, 117, 3645-3650.

235. Yin, P.; Xu, Q.; Qu, R.; Zhao, G.; Sun, Y. Adsorption of transition metal ions from aqueous solutions onto a novel silica gel matrix inorganic-organic composite material. J. Hazard. Mater. 2010, 173, 710-716.

236. Kumar, G.P.; Kumar, P.A.; Chakraborty, S.; Ray, M. Uptake and desorption of copper ion using functionalized polymer coated silica gel in aqueous environment. Sep. Purif. Technol. 2007, 57, 47-56.

237. Zhang, K.; Wang, Q.; Meng, H.; Wang, M.; Wu, W.; Chen, J. Preparation of polyacrylamide/silica composite capsules by inverse pickering emulsion polymerization. Particuology 2013, in press. 
238. Buhani; Suharso; Sembiring, Z. Immobilization of Chetoceros sp microalgae with silica gel through encapsulation technique as adsorbent of $\mathrm{Pb}$ metal from solution. OJC 2012, 28, $271-278$.

239. Li, F.; Du, P.; Chen, W.; Zhang, S. Preparation of silica-supported porous sorbent for heavy metal ions removal in wastewater treatment by organic-inorganic hybridization combined with sucrose and polyethylene glycol imprinting. Anal. Chim. Acta 2007, 585, 211-218.

240. Li, F.; Jiang, H.; Zhang, S. An ion-imprinted silica-supported organic-inorganic hybrid sorbent prepared by a surface imprinting technique combined with a polysaccharide incorporated sol-gel process for selective separation of cadmium(II) from aqueous solution. Talanta 2007, 71, 1487-1493.

241. Zheng, L.; Jiang, F.-H.; Dong, P.-J.; Zhuang, Q.-F.; Li, F. Preparation of spherical silica-supported biosorbent for copper ions removal in wastewater based on sol-gel reaction and simple treatment with sodium hydroxide. Chem. Res. Chin. Univ. 2010, 26, 355-359.

242. Singhon, R.; Husson, J.; Knorr, M.; Lakard, B.; Euvrard, M. Adsorption of Ni(II) ions on colloidal hybrid organic-inorganic silica composites. Colloids Surf. B 2012, 93, 1-7.

243. Shin, S.; Jang, J. Thiol containing polymer encapsulated magnetic nanoparticles as reusable and efficiently separable adsorbent for heavy metal ions. Chem. Commun. 2007, 2007, 4230-4232.

244. Song, J.; Kong, H.; Jang, J. Adsorption of heavy metal ions from aqueous solution by polyrhodanine-encapsulated magnetic nanoparticles. J. Colloid Interface Sci. 2011, 359, 505-511.

245. Chang, Y.-C.; Chen, D.-H. Preparation and adsorption properties of monodisperse chitosan-bound $\mathrm{Fe}_{3} \mathrm{O}_{4}$ magnetic nanoparticles for removal of $\mathrm{Cu}(\mathrm{II})$ ions. J. Colloid Interface Sci. 2005, 283, 446-451.

246. Chang, Y.-C.; Chen, D.-H. Recovery of gold(III) ions by a chitosan-coated magnetic nano-adsorbent. Gold Bull. 2006, 39, 98-102.

247. Tao, S.; Wang, C.; Ma, W.; Wu, S.; Meng, C. Designed multifunctionalized magnetic mesoporous microsphere for sequential sorption of organic and inorganic pollutants. Microporous Mesoporous Mater. 2012, 147, 295-301.

248. Gupta, A.; Yunus, M.; Sankararamakrishnan, N. Zerovalent iron encapsulated chitosan nanospheres-A novel adsorbent for the removal of total inorganic Arsenic from aqueous systems. Chemosphere 2012, 86, 150-155.

249. Jiang, W.; Chen, X.B.; Niu, Y.J.; Pan, B.C. Spherical polystyrene-supported nano- $\mathrm{Fe}_{3} \mathrm{O}_{4}$ of high capacity and low-field separation for arsenate removal from water. J. Hazard. Mater. 2012, 243, 319-325.

250. Wan, S.L.; Zhao, X.; Lv, L.; Su, Q.; Gu, H.N.; Pan, B.C.; Zhang, W.M.; Lin, Z.W.; Luan, J.F. Selective adsorption of $\mathrm{Cd}(\mathrm{II})$ and $\mathrm{Zn}(\mathrm{II})$ ions by nano-hydrous manganese dioxide (HMO)-encapsulated cation exchanger. Ind. Eng. Chem. Res. 2010, 49, 7574-7579.

251. Zhang, F.; Lan, J.; Zhao, Z.; Yang, Y.; Tan, R.; Song, W. Removal of heavy metal ions from aqueous solution using $\mathrm{Fe}_{3} \mathrm{O}_{4}-\mathrm{SiO}_{2}$-poly(1,2-diaminobenzene) core-shell sub-micron particles. J. Colloid Interface Sci. 2012, 387, 205-212.

252. Zhang, M.; Zhang, Z.; Liu, Y.; Yang, X.; Luo, L.; Chen, J.; Yao, S. Preparation of core-shell magnetic ion-imprinted polymer for selective extraction of $\mathrm{Pb}(\mathrm{II})$ from environmental samples. Chem. Eng. J. 2011, 178, 443-450. 
253. Zhang, S.; Zeng, M.; Xu, W.; Li, J.; Li, J.; Xu, J.; Wang, X. Polyaniline nanorods dotted on graphene oxide nanosheets as a novel super adsorbent for $\mathrm{Cr}(\mathrm{VI})$. Dalton Trans. 2013, 42, 7854-7858.

254. Wu, Y.-N.; Zhang, B.; Li, F.; Zhu, W.; Xu, D.; Hannam, P.; Li, G. Electrospun fibrous mats as a skeleton for fabricating hierarchically structured materials as sorbents for $\mathrm{Cu}^{2+}$. J. Mater. Chem. 2012, 22, 5089-5097.

255. Ma, X.; Li, L.; Yang, L.; Su, C.; Wang, K.; Jiang, K. Preparation of hybrid $\mathrm{CaCO}_{3}-$ pepsin hemisphere with ordered hierarchical structure and the application for removal of heavy metal ions. J. Cryst. Growth 2012, 338, 272-279.

256. Ma, X.; Li, L.; Yang, L.; Su, C.; Wang, K.; Yuan, S.; Zhou, J. Adsorption of heavy metal ions using hierarchical $\mathrm{CaCO}_{3}-$ maltose meso/macroporous hybrid materials: Adsorption isotherms and kinetic studies. J. Hazard. Mater. 2012, 209-210, 467-477.

(C) 2014 by the authors; licensee MDPI, Basel, Switzerland. This article is an open access article distributed under the terms and conditions of the Creative Commons Attribution license (http://creativecommons.org/licenses/by/3.0/). 